\title{
Proteinaceous determinants of surface colonization in bacteria: bacterial adhesion and biofilm formation from a protein secretion perspective
}

\author{
Caroline Chagnot ${ }^{1,2+}$, Mohamed A. Zorgani ${ }^{1+}$, Thierry Astruc ${ }^{2}$ and Mickaël Desvaux ${ }^{1 *}$ \\ ${ }^{1}$ UR454 Microbiologie, INRA, Saint-Genès Champanelle, France \\ 2 UR370 Qualité des Produits Animaux, INRA, Saint-Genès Champanelle, France
}

Edited by:

Biswarup Mukhopadhyay, Virginia

Bioinformatics Institute, USA

Reviewed by:

Dirk Linke, Max Planck Society,

Germany

Karl G. Wooldridge, University of

Nottingham, UK

*Correspondence:

Mickaël Desvaux, UR454

Microbiology, INRA

Clermont-Ferrand Research Centre,

Site of Theix, F-63122 Saint-Genès

Champanelle, France

e-mail:mickael.desvaux@

clermont.inra.fr

${ }^{t}$ These authors have contributed

equally to this work and share first authorship.

\begin{abstract}
Bacterial colonization of biotic or abiotic surfaces results from two quite distinct physiological processes, namely bacterial adhesion and biofilm formation. Broadly speaking, a biofilm is defined as the sessile development of microbial cells. Biofilm formation arises following bacterial adhesion but not all single bacterial cells adhering reversibly or irreversibly engage inexorably into a sessile mode of growth. Among molecular determinants promoting bacterial colonization, surface proteins are the most functionally diverse active components. To be present on the bacterial cell surface, though, a protein must be secreted in the first place. Considering the close association of secreted proteins with their cognate secretion systems, the secretome (which refers both to the secretion systems and their protein substrates) is a key concept to apprehend the protein secretion and related physiological functions. The protein secretion systems are here considered in light of the differences in the cell-envelope architecture between diderm-LPS (archetypal Gram-negative), monoderm (archetypal Gram-positive) and diderm-mycolate (archetypal acid-fast) bacteria. Besides, their cognate secreted proteins engaged in the bacterial colonization process are regarded from single protein to supramolecular protein structure as well as the non-classical protein secretion. This state-of-the-art on the complement of the secretome (the secretion systems and their cognate effectors) involved in the surface colonization process in diderm-LPS and monoderm bacteria paves the way for future research directions in the field.
\end{abstract}

Keywords: secretome, adhesin, pili/fimbriae/curli, cell surface, aggregation, secreted protein, MSCRAMM, protein secretion system

\section{INTRODUCTION}

Relative to the bacterial cell, three major classes of interactions can be distinguished: (i) the symbiotic relationships with others biological entities from eukaryotic cells, bacterial cells to viruses (bacteriophages), e.g., mutualism, amensalism, competition, etc..., (ii) the sensing of products or stimuli (cell-cell communication, mechano-physico-chemico sensitivity), and (iii) the direct contacts with surfaces or interfaces. Bacterial colonization corresponds to the presence of microorganisms in a particular environment. Colonization of biotic or abiotic surfaces results from two quite distinct microbiological processes, namely bacterial adhesion or biofilm formation. Initial bacterial adhesion can either be reversible or irreversible. Broadly speaking, a biofilm is defined as the sessile development of microbial cells. The engagement into a sessile mode of growth arises following irreversible bacterial adhesion (Zhao et al., 2013); though, not all single adhered bacterial cells necessarily engage into sessile development. Considering the differences in the molecular physiology of the bacterial cells, the distinction between single adhered and biofilm cells is of importance (Buncic et al., 2013). While initial attachment depends on the physiological state of the cell prior to adhesion, significant changes in gene/protein expression occur upon irreversible adhesion and further sessile cell division to colonize the site of adhesion. In all cases, the bacterial cell envelope plays a critical role in the primary interactions between the bacterial cell and its environment.

Numerous factors promote bacterial cell adhesion to surface and interfaces (An and Friedman, 1998; Shirtliff et al., 2002). They can be categorized into (i) general physico-chemical surface properties, (ii) the exopolymeric matrix, and (iii) the cell surface biochemical components. The physico-chemistry of the interactions (such as van der Waals attraction, gravitational force, electrostatic charge, or hydrophobic interaction) (Gottenbos et al., 2000) have been theorized into models by the thermodynamic (Morra and Cassinelli, 1996) and the DLVO (Derjaguin-LandauVerwey-Overbeek) theories, as well as its extended version (Jucker et al., 1998; Hermansson, 1999). While those models can help explaining some experimental observations, neither of them can fully describe bacterial adhesion as they fail in taking into account a fundamental properties of a biological system that is its adaptability and variability (Katsikogianni and Missirlis, 2004). Indeed, in the course of adhesion and/or biofilm formation, bacterial 
cells change their physiology at different regulatory levels, e.g., gene/protein expression. This can induce modifications of cell morphology, general surface properties and/or express specific determinants for adhesion. Among those, the exopolymers can be prominent components synthetized in the course of bacterial adhesion and biofilm formation where they play the role of molecular glue (Flemming and Wingender, 2010). A large variety of exopolymers can be involved in bacterial colonization process namely various exopolysaccharides (EPS), e.g., alginate, cellulose, or poly- $N$-acetylglucosamine (PNAG) (Ryder et al., 2007; Vu et al., 2009; Bazaka et al., 2011), extracellular DNA (eDNA) and polyglutamate (Candela and Fouet, 2006). In some cases, those exoplymers are closely associated with the bacterial cell envelope, such as some polyglutamate covalently linked to peptidoglycan (Candela et al., 2012). Some other components of the cell envelope can participate in biofilm formation such as lipopolysaccharides (LPS) (Nakao et al., 2012), (lipo)teichoic acids (Gross et al., 2001; Fabretti et al., 2006), or mycolic acids (Ojha et al., 2005; Zambrano and Kolter, 2005). Among cell envelope components, proteins are undoubtedly the most functionally diverse active components. To be present on the bacterial cell surface, though, a protein must be secreted in the first place (or released by non-active translocation process, e.g., cell lysis or membrane budding).

Protein secretion is a key event for the presence of effectors at the interface between the bacterial cell and its immediate environment (Henderson et al., 2004). Those effectors can be displayed on the bacterial cell surface following anchoring to the cell envelope, released into the extracellular milieu or even beyond, i.e., within a host cell. Secreted proteins feature the lifestyle of a bacterium, its interaction within the ecosystems, microbiota, and ecological niches; for instance, virulence factors in pathogenic bacteria or degradative enzymes in saprophytic bacteria. As such, protein secretion is a key player in bacterial cell physiology and interactions with their environment. To understand protein secretion systems in bacteria, it is crucial to consider the cell envelope architecture. In recent years, it clearly appeared the grouping of bacteria into Gram-positive and Gram-negative bacteria was not satisfactory but ambiguous to describe and categorize accurately the protein secretion systems. Considering the inherent ambiguities of the Gram-negative and Gram-positive terminology, which can refer to three different and sometimes completely unrelated aspects (i.e., Gram staining, cell envelope architecture, and taxonomic grouping) (Desvaux et al., 2009b), the description of monoderm and diderm bacteria is much more appropriate in the field of protein secretion, at least. Indeed, monoderm bacteria (monodermata) refers specifically to species exhibiting only one biological membrane, i.e., the cytoplasmic membrane (CM), whereas diderm bacteria (didermata) refers specifically to species exhibiting two biological membranes, i.e., a CM, then also called inner membrane (IM) and an outer membrane (OM). Diderm bacteria can be further discriminated into (i) diderm-LPS bacterial cells, which possess an archetypal and assymetrical OM containing lipopolysaccharide (LPS) on the external side, (ii) simple-diderm bacterial cells, which possess an OM lacking LPS, and (iii) diderm-mycolate bacterial cells, where an outer lipid layer resembling an OM is composed of mycolic acid molecules arranged in a highly ordered form (Brennan and Nikaido, 1995; Sutcliffe, 2010; Gupta, 2011).

Considering the close association of secreted proteins with their cognate secretion systems, the secretome is a key concept to apprehend the protein secretion and related physiological functions. The secretome refers both to the secretion/translocation systems and the protein substrates of these transport systems (Tjalsma et al., 2000; Antelmann et al., 2001, 2006; Van Dijl et al., 2001; Economou, 2002; Sarvas et al., 2004; Buist et al., 2006; Desvaux et al., 2009b). The secretome concept provides an integrated and global view of protein secretion by considering protein routing, transport mechanisms, post-translational modifications, and protein subcellular location. Confusion between the secretome and the secreted/extracellular proteins is a common misunderstanding promulgated in part of the scientific literature but it must be stressed again the secretome is neither the exoproteome (extracellular proteome) nor an "omics" approach per se (Desvaux et al., 2009b). The exoproteome refers specifically to the subset of proteins present in the supernatant (which are not necessarily secreted). Secreted proteins are not necessarily free soluble extracellular proteins (exoproteins) since they can have different final subcellular locations (membranes, cell wall, extracellular milieu) or be subunits of supramolecular protein complexes (e.g., flagellum, pilus, cellulosome). Secreted proteins can even have multiple final subcellular locations, which are described following the gene ontology (GO) for "Cellular component” (Figure 1). All extracytoplasmic proteins are not systematically secreted since some exoproteins can be released upon molecular events that are not active translocation process and thus not secretion per se, e.g., cell lysis (autolysis, allolysis, bacteriophage lysis), GTA (gene transfer agent) or membrane budding (vesicles). The translocation corresponds to the active transport across a biological membrane (Desvaux et al., 2009b); the secretion refers to active transport from the interior to the exterior of the cell and the export to active transport across the CM (Economou et al., 2006). While in monoderm bacteria secretion and export are synonymous, in diderm bacteria the secretion is completed only upon translocation across the OM. For the sake of clarity, these key definitions in the field of protein secretion are reminded in Table 1.

With these different concepts in hand, it becomes clear a comprehensive understanding of protein determinants involved in bacterial adhesion and/or biofilm formation necessitates a consideration of the cell envelope architecture, i.e., respective to the diderm-LPS, monoderm and diderm-mycolate bacteria trichotomy, as well as their respective protein secretion systems.

\section{THE PROTEIN SECRETION SYSTEMS IN DIDERM-LPS, MONODERM AND DIDERM-MYCOLATE BACTERIA}

In diderm-LPS bacteria, nine protein secretion systems have been unravelled so far. For better or worse, these systems have been numerically classified from the Type I (T1SS) to Type IX secretion systems (T9SS) (Desvaux et al., 2009b; McBride and Zhu, 2013) (Figure 2). The T1SS refers to a three-component complex, i.e., a pore-forming OM protein (OMP) of the TolC family, a membrane fusion protein (MFP), and an IM ATP-binding cassette (ABC) exporter (Delepelaire, 2004; Holland et al., 2005; 

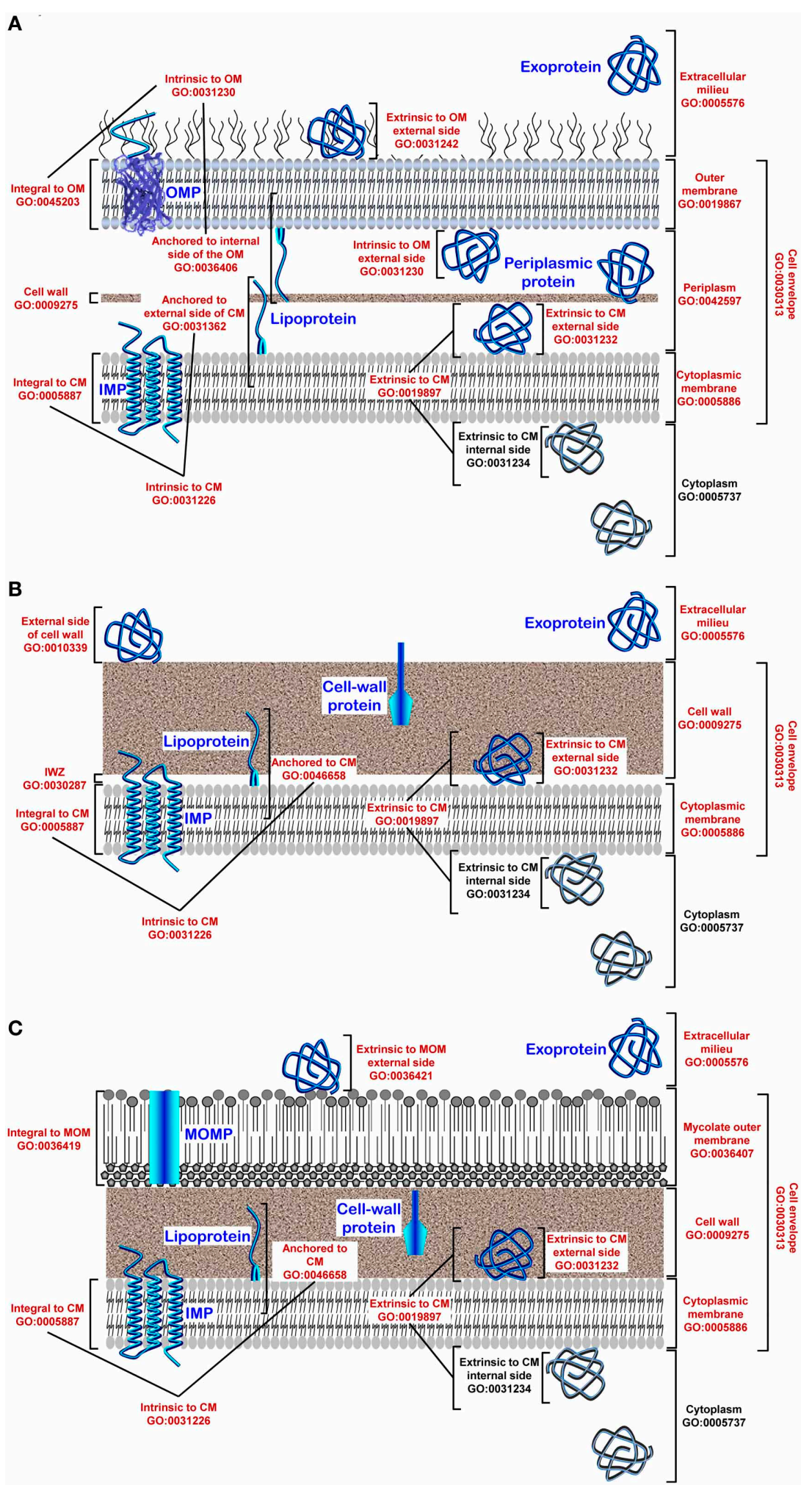

FIGURE 1 | Gene Ontology (GO) for cellular components and protein subcellular location in bacteria. (A) In diderm-LPS bacteria, five clearly defined compartments are considered (i) the cytoplasm (CP; GO:0005737), (ii) the cytoplasmic membrane (CM; GO:0005886), (iii) the periplasm (PP; GO:0042597), (iv) the outer membrane (OM; GO:0019867), and (v) the extracellular milieu (EM; GO:0005576). The cell envelope (GO:0010339) is constituted of the $\mathrm{OM}$ and $\mathrm{CM}$, also called inner membrane (IM), as well as a thin cell wall (CW) located in-between. The situation at the CM can be discriminated even further between locations either intrinsic (GO:0031226) or extrinsic (GO:0019897) to the CM. The former refers to gene products with covalently attached moieties embedded in the $\mathrm{CM}$, which splits into

(Continued) 


\section{FIGURE 1 | Continued}

locations (i) integral to CM (GO:0005887) where some part of the peptide sequence spans all or part of the $\mathrm{CM}$, i.e., the integral membrane proteins (IMPs), and (ii) anchored to the external side of CM (GO: 0031362) corresponding to proteins tethered to the $\mathrm{CM}$ by non-polypeptidic covalently attached anchor, i.e., the lipoproteins. The latter refers to proteins extrinsic to the $\mathrm{CM}$, i.e., neither anchored by covalent bonds to any moiety nor directly embedded in the CM. Peripheral proteins are loosely bound to the surface components of the $\mathrm{CM}$ on the internal (GO:0031234) or external side (GO:0031232). Some proteins localized at the OM can also be subunits of supramolecular protein complexes (GO:0043234). The situation at the OM can be discriminated even further between locations intrinsic (GO:003230) or extrinsic (GO:0031242) to the OM. The former refers to gene products with a covalently attached moiety embedded in the OM, which splits into locations (i) integral to OM (GO:00045203) where some part of the peptide sequence spans all or part of the OM, i.e., the outer membrane proteins (OMPs), and (ii) anchored to internal side of OM (GO:0036406) corresponding to proteins tethered to the OM by non-polypeptidic covalently attached anchor, i.e., some lipoproteins. (B) In monoderm bacteria, four clearly defined compartments are considered (i) the cytoplasm (CP; GO:0005737), (ii) the cytoplasmic membrane (CM; GO:0005886), (iii) the cell wall (CW; GO:0009275), and (iv) the extracellular milieu (EM; GO:0005576). An inner wall zone (IWZ) (Matias and Beveridge, 2005) has been identified (GO:0030287); importantly, it should not be considered sensu stricto as a periplasm since the CW is porous and therefore it is not bordered (bounded) contrary to the situation in diderm-LPS bacteria where the periplasmic space is strictly delimited by two biological membranes. The CM and CW constitute the cell envelope (GO:0010339). The situation at the CM is similar to what is described for diderm-LPS bacteria. Some proteins localized at the $\mathrm{CM}$ or $\mathrm{CW}$ can also be subunits of protein complex (GO:0043234) or be extrinsic to the CW (GO:0010339). (C) In diderm-mycolate bacteria, five clearly defined compartments are considered (i) the cytoplasm (CP; GO:0005737), (ii) the cytoplasmic membrane (CM; GO:0005886), (iii) the cell wall (CW; GO:0009275), (iv) the mycolate outer membrane (MOM) or mycomembrane (GO:0036407), and (v) the extracellular milieu (EM; GO:0005576). The cell envelope (GO:0010339) is constituted of the MOM, CW, and CM; a pseudo-periplasm might exist but remains to be evidenced. The situation at the CM is similar to what is described for diderm-LPS or diderm bacteria. The situation at the MOM (GO:0036407) can be discriminated further between location integral to the mycomembrane (GO:0036419), i.e., the MOM proteins (MOMPs), or extrinsic to the MOM (GO:0036420). Location at the cell surface (GO:0009986) refers (i) in diderm-LPS, to the OM and/or external side of the OM and is intended to proteins exposed externally (GO:0031242) or intrinsic to the OM (GO:0031230) (similar rermarks apply to diderm-mycolate bacteria and the MOM), and (ii) in monoderm bacteria, to the CW and/or external side of the $\mathrm{CM}$ and is intended to proteins exposed externally or attached to the $\mathrm{CW}$ (GO:0009275) or the CM, i.e., integrated (GO:0005887), anchored (GO:0046658) or loosely bound (GO:0031232). As the CW is not a permeability barrier in monoderm bacteria but porous, the surface proteins do not necessarily have domains protruding from the confine of the cell envelope to interact with the external environment. Altogether with the subset of proteins localized extracellularly (GO:0005576), i.e., the exoproteome, these gene products (GO numbers in red) correspond to the extracytoplasmic proteins, i.e., the extracytoproteome (proteins depicted in blue).
Lee et al., 2012); a common misunderstanding is to make the T1SS synonymous to an ABC transporter (Desvaux et al., 2009b). The T2SS, also called the secreton-depend pathway (SDP) is a protein complex composed of around a dozen of proteins bridging the IM and OM to allow secretion of proteins translocated in the first place by the Sec or Tat export system (Sandkvist, 2001; Voulhoux et al., 2001; Cianciotto, 2005; Douzi et al., 2012; McLaughlin et al., 2012). It can be stressed again that referring to the general secretory pathway (GSP) or to the main terminal branch (MTB) for this system is nowadays obsolete and misleading (Desvaux et al., 2004b); as referred to in Pfam (Bateman et al., 2004), the naming of the different T2SS subunits as T2SE for instance is much more preferable than GspE (Peabody et al., 2003; Desvaux et al., 2004b). The T3SS is a highly complex molecular machine composed of at least 20 proteins and also one of the most extensively investigated protein secretion system (Ghosh, 2004; Cornelis, 2006, 2010; Minamino et al., 2008; Büttner, 2012). The T4SS is composed of around a dozen of proteins subunits forming a protein-conducting channel spanning the entire bacterial cell envelope (Christie et al., 2005; Waksman and Fronzes, 2010; Zechner et al., 2012); there is still much misunderstanding and confusion in part of the scientific literature about the T4SS and T2SS, as well as Type 4 pili (T4P), but it must be stressed again they can be clearly phylogenetically differentiated (Nunn, 1999; Planet et al., 2001; Mattick, 2002; Peabody et al., 2003; Hazes and Frost, 2008). T5SS refers to proteins depending on the Sec machinery for IM transit and then transported across the OM via a translocation unit formed by a $\beta$-barrel to complete secretion (Henderson et al., 2004; Leo et al., 2012); the BAM ( $\beta$-barrel assembly machinery) complex as well as several periplasmic chaperones (namely SurA, Skp, DegP, and FkpA) are taking part to the secretion process across the OM (Desvaux et al., 2004a; Knowles et al., 2009; Ruiz-Perez et al., 2010; Rossiter et al., 2011b; Leyton et al., 2012). The T6SS is a composite system of at least 13 protein subunits from various hypothetical phylogenetic origins, with essentially two subassemblies, i.e., one dynamic structure related the contractile bacteriophage tail-like structure and one cell-envelope-spanning membrane-associated complex (Cascales and Cambillau, 2012; Silverman et al., 2012). The T7SS corresponds to the chaperone-usher pathway (CUP) used for pilus assembly (Desvaux et al., 2009b; Waksman and Hultgren, 2009; Busch and Waksman, 2012); as further explained below, this system for diderm-LPS bacteria must not be mistaken with the diderm-mycolate bacterial "Type VII secretion system," which is in fact the ESX (ESAT-6 system). The T8SS corresponds to the extracellular nucleation-precipitation pathway (ENP) (Barnhart and Chapman, 2006; Desvaux et al., 2009b; Blanco et al., 2012; Dueholm et al., 2012). The T9SS corresponds to the Por (porphyrin accumulation on the cell surface) secretion system (Sato et al., 2010, 2013; Shoji et al., 2011; McBride and Zhu, 2013). In diderm-LPS bacteria, the complement of the secretome potentially involved in bacterial colonization process gathers some secreted proteins and their associated secretion systems, which can be either the T1SS, T2SS, T3SS, T4SS, T5SS, T7SS, T8SS, or T9SS (Figure 2). In general, the secreted proteins involved in bacterial colonization are either cell-surface exposed single proteins or subunits of cell-surface supramolecular complexes, such as pili or flagella. In the rest of the manuscript, pili will be used as a generic term synonymous with fimbriae or curli (which are just some particular types of pili).

There are no counterparts to the molecular machineries required for transport across the OM of diderm bacteria in monoderm bacteria as this membrane is not present in the latter organisms. Consequently, the use of the numerical classification 
Table 1 | Some key definitions in the field of bacterial protein secretion.

\begin{tabular}{lll}
\hline Terminology & Definition & Note $^{\text {a }}$ \\
\hline Monoderm bacteria & $\begin{array}{l}\text { Bacterial species exhibiting only one } \\
\text { biological membrane, i.e. the CM. }\end{array}$ & $\begin{array}{l}\text { Corresponds to the archetypal Gram-positive bacteria } \\
\text { (i.e., with a CW) but also includes the Mycoplasma } \\
\text { (devoided of a CW) since they also possess only one } \\
\end{array}$ \\
& $\begin{array}{l}\text { biological membrane. Monoderm bacteria are also } \\
\text { called monodermata. }\end{array}$ \\
\hline
\end{tabular}

\begin{tabular}{|c|c|c|c|}
\hline Diderm-LPS bacteria & $\begin{array}{l}\text { Bacterial species exhibiting two } \\
\text { biological membranes and where the } \\
\text { assymetrical OM contains } \\
\text { lipopolysaccharide (LPS) on the } \\
\text { external side. }\end{array}$ & $\begin{array}{l}\text { Corresponds to the archetypal Gram-negative } \\
\text { bacteria. Some diderm bacteria lack LPS in their OM } \\
\text { and are called simple-diderm bacteria. Diderm } \\
\text { bacteria are also called didermata. }\end{array}$ & $\begin{array}{l}\text { Shatalkin, 2004; } \\
\text { Desvaux et al., } \\
\text { 2009b; Sutcliffe, } \\
\text { 2010; Gupta, } 2011\end{array}$ \\
\hline
\end{tabular}

\begin{tabular}{ll}
\hline Diderm-mycolate bacteria & Bacterial species exhibiting two \\
& biological membranes and where an \\
& outer lipid layer called MOM is \\
& composed of mycolic acid molecules \\
& arranged in a highly ordered form.
\end{tabular}

Corresponds to the archetypal acid-fast bacteria, e.g., Mycobacterium and Corynebacterium.
References

Shatalkin, 2004;

Desvaux et al., 2009b; Sutcliffe, 2010; Gupta, 2011

Shatalkin, 2004; Desvaux et al., 2009b; Sutcliffe, 2010; Gupta, 2011
Secretome
Concept for an integrated and global view of the protein secretion by considering protein routing, transport mechanisms, post-translational modifications, and protein subcellular location.
Secretion
Active transport from the interior to the exterior of the cell.
The secretome considers both secreted proteins and proteins constituting the secretion machinery (and associated maturation pathways). This original definition of the secretome has been somehow usurped, misused, and misunderstood by some authors in the literature. The secretome can be investigated by different "omics" approaches (i.e., proteogenomics, transcriptomics, proteomics, and meta-omics counterparts) but is not a proteome per se. The secretome is not the exoproteome, which is the most commonly investigated but only one of the complement of the secretome. Other complements of the secretome can be (i) the protein secretion systems, (ii) the cell-surface proteins (including single and supramolecular protein structure), or (iii) the lipoproteome, etc... Since it is not secretion per se, the secretome do not cover protein release upon molecular events that are not active translocation process, e.g., cell lysis (autolysis, allolysis, bacteriophage lysis), or membrane budding (vesicles).

Applies to protein entirely outside of the outer-most lipid bilayer, including exoproteins, surface proteins, and cell-surface appendages (e.g., pili and flagella, cellulosomes). In diderm bacteria, secretion is mediated by specific translocon for transport across the OM (or MOM in diderm-mycolate bacteria) and cannot be defined by the translocons located at IM (CM). Sensu stricto, it does not cover molecular events that are not active translocation process and thus not secretion per se, e.g., cell lysis (autolysis, allolysis, bacteriophage lysis) or membrane budding (vesicles).

In monoderm bacteria, export and secretion are
synonymous but not in diderm bacteria. In diderm bacteria, the Sec and Tat translocon directs proteins to the CM (IM) or periplasm but cannot ensure their secretion sensu stricto.
Tjalsma et al., 2000; Antelmann et al., 2001, 2006; Van Dijl et al., 2001;

Economou, 2002;

Sarvas et al., 2004; Buist et al., 2006; Desvaux et al., $2009 b$

Desvaux et al., 2004b, 2009b; Economou et al., 2006

Desvaux et al., 2004b, 2009b; Economou et al., 2006 
Table 1 | Continued

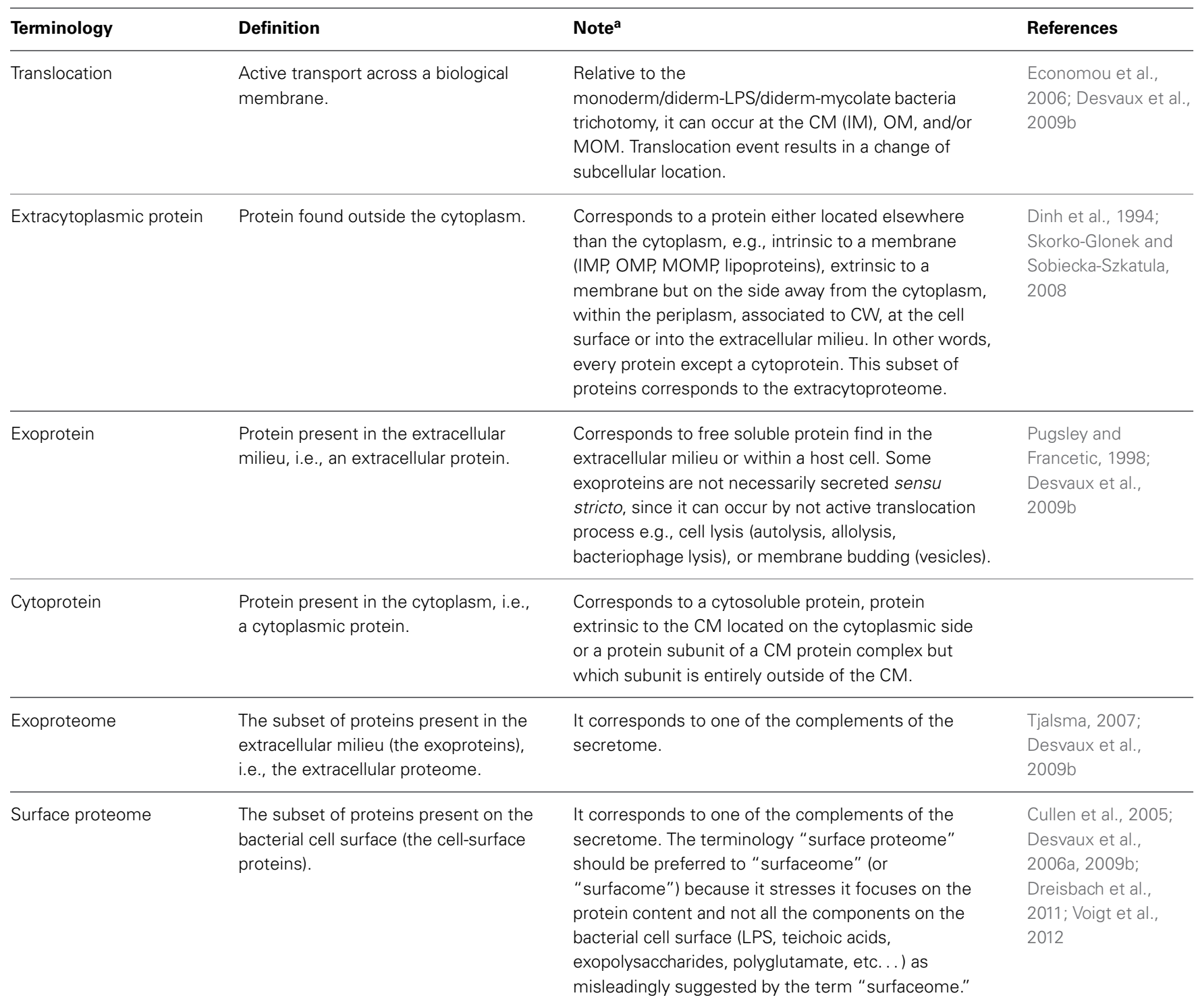

a IM, inner membrane; CM, cytoplasmic membrane; CW, cell wall; OM, outer membrane; MOM: mycolate outer membrane; IMP, integral membrane protein; OMP, outer membrane protein; MOMP, mycolate outer membrane protein.

for systems dedicated to protein secretion in diderm-LPS bacteria (i.e., protein transport from inside to outside the cell across the IM and OM) does not make any sense and cannot be applied to monoderm bacteria. However, this does not prohibit phylogenetic relationships between the protein translocation systems in monoderm and diderm-LPS bacteria. Indeed, they both possess a cytoplasmic membrane (also called IM in didermata) with some common protein transport systems allowing secretion in monoderm bacteria and export in diderm-LPS bacteria, respectively. The protein secretion system present in monoderm bacteria are (i) the Sec (secretion), (ii) the Tat (twin-arginine translocation), (iii) $\mathrm{ABC}$ protein exporter, (iv) the FPE (fimbrilin-protein exporter), (v) the holin (hole forming), (vi) the Tra (transfer), misleadingly called the "Type IV-like secretion system" in monoderm bacteria), (vii) the FEA (flagella export apparatus), and (viii) the Wss (WXG100 secretion system) (Desvaux et al., 2009b; Desvaux, 2012) (Figure 3). From the current knowledge in the field, the complement of the secretome potentially involved in the colonization process in monoderm bacteria gathers the Sec, FPE and FEA as well as some of their respective substrates (Figure 3). These systems secrete either cell-surface exposed single proteins or subunits of cell-surface supramolecular complexes, such as pili, cellulosome, or flagella (Renier et al., 2012).

In diderm-mycolate (archetypal acid-fast) bacteria, the term "Type VII secretion system" has also been coined to describe a Wss-like machinery (Economou et al., 2006; Abdallah et al., 2007; Schneewind and Missiakas, 2012). It must be stressed, this "Type VII secretion system" is restricted to diderm-mycolate bacteria 


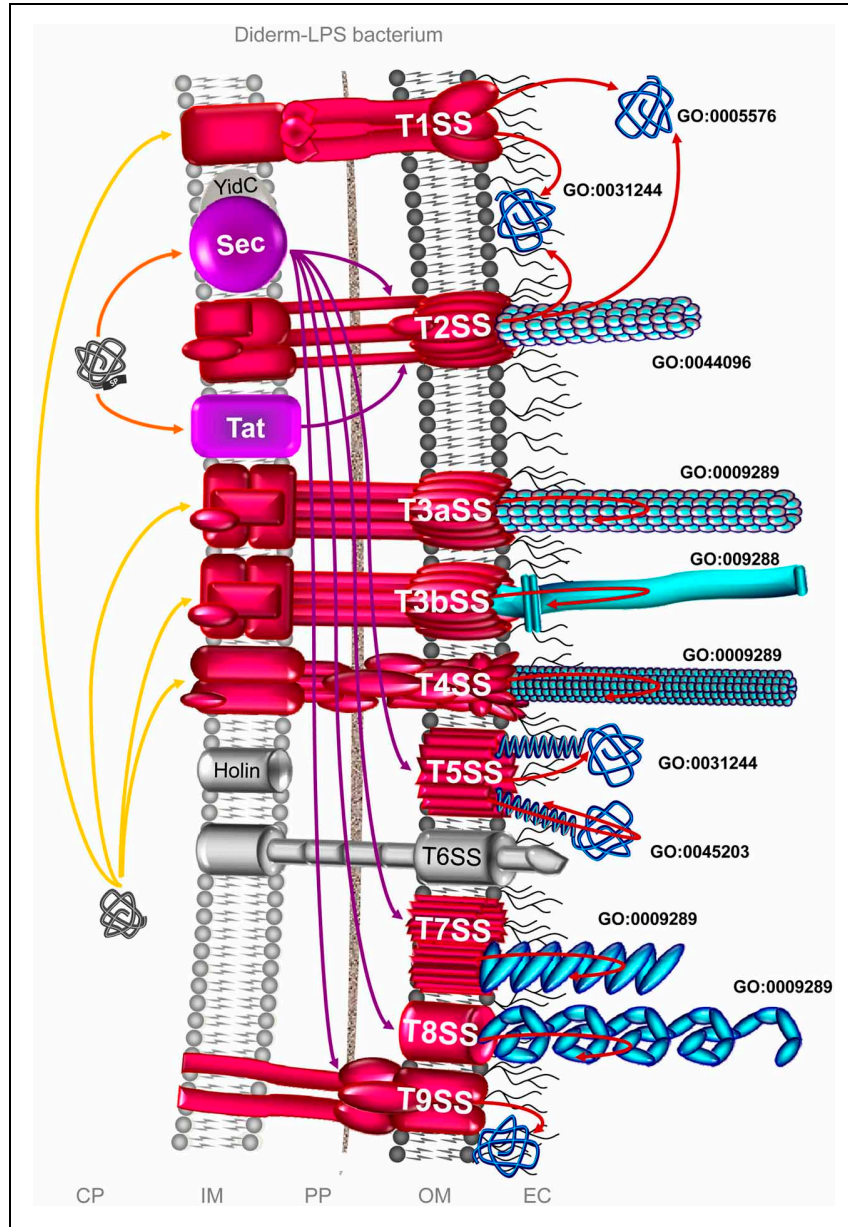

FIGURE 2 | The complement of the secretome involved in colonization process in diderm-LPS bacteria. Among the 9 distinct secretion systems through which a secreted protein can be translocated across the OM in diderm-LPS bacteria, the T1SS, T2SS, T3SS, T4SS, T5SS, T7SS, T8SS, and T9SS can be involved in colonization process (depicted in red). Translocation machineries depicted in violet are protein export pathway participating to the protein transport of effectors involved in colonization process. The T1SS can secrete adhesins, which the release into the extracellular milieu (GO:0005576) and/or the association to the external side of the OM (GO:0031244) remain to be clarified. Besides the secretion of adhesion factors, the T2SS is involved in the formation of Type 4 pilus (GO:0044096), i.e., the T2SS subfamily c (T2cSS). The subfamily a of the T3SS (T3aSS) can be involved in the formation of pilus structure (GO:0009289), i.e., either the injectisome or the Hrp (hypersensitive response and pathogenicity) pilus, whereas the subfamily $b$ of the T3SS (T3bSS) is involved in flagellum assembly (GO:009288). The T4SS is involved in the formation of pili (GO:0009289), either pilus T (T4aSS) or pilus $F(T 4 b S S)$. The T5SS is involved in the secretion of adhesion either integral (GO:0045203) or extrinsic (GO:0031244) to the OM. The T7SS (CUP; chaperone-usher pathway) is involved in the formation of Type 1 pilus, and the T8SS (ENP; extracellular nucleation-precipitation pathway) in the formation of pilus of the type curli. The T9SS (Por secretion system) can secrete adhesins involved in gliding motility. In addition, some surface proteins could use systems as yet uncovered, the so-called non-classical (NC) secretion. Only branches corresponding to the complement of the secretome involved in bacterial colonization are colored. Extracytoplasmic proteins, i.e., single proteins and supramolecular protein structures, potentially involved in surface colonization are depicted in blue. Orange and yellow arrows indicate the routes for proteins targeted to the $\mathrm{CM}$ possessing or lacking an $\mathrm{N}$-terminal $\mathrm{SP}$, respectively. Violet arrows indicate the routes for exported proteins and red arrows for secreted proteins. $\mathrm{CP}$, cytoplasm; IM, inner membrane; $\mathrm{PP}$, periplasm; OM, outer membrane; EC, extracellular milieu; SP, signal peptide.

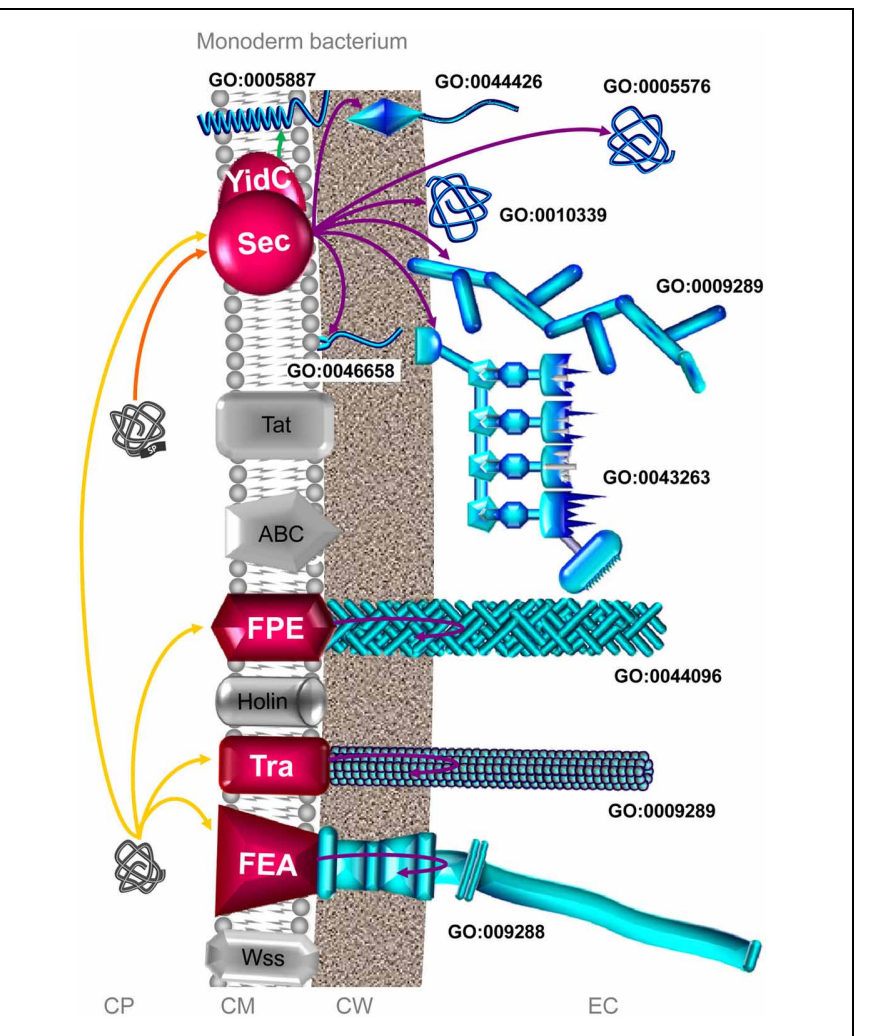

FIGURE 3 | The complement of the secretome involved in colonization process in monoderm bacteria. Among the 8 distinct secretion systems through which a secreted protein can be translocated across the CM, the Sec, FPE, Tra, and FEA pathways can potentially be involved in colonization process in monoderm bacteria (depicted in red). The Sec pathway covers (i) integration of membrane protein (GO:0005887) via YidC, (ii) the anchoring to $\mathrm{CM}$ (GO:0046658) via the lipoprotein maturation pathway, (iii) the anchoring to the CW (GO:0044426) in a covalent or non-covalent manner, (iv) the association on the external side of the CW (GO:0010339), (v) the formation of cell surface supramolecular structure, namely pilus (GO:0009289) and cellulosome (GO:0043263), and (vi) protein secretion in the extracellular milieu (GO:0005576). It is worth noting that some proteins with no N-terminal SP can be translocated via Sec in a SecA2-dependent manner in monodermata (Rigel and Braunstein, 2008; Renier et al., 2013). The FPE is involved the formation of Type 4 pilus (GO:0044096). The Tra system (misleadingly called "Type IV-like secretion system" in monoderm bacteria) is involved in the formation of conjugative pili (GO:0009289). The FEA is involved in the secretion and assembly of the flagellum protein subunits (GO:009288). In addition, some surface proteins could use systems as yet uncovered, the so-called non-classical (NC) secretion. Extracytoplasmic proteins, i.e., single proteins and supramolecular protein structures, potentially involved in surface colonization are depicted in blue. Only branches corresponding to the complement of the secretome involved in bacterial colonization are colored. Orange and yellow arrows indicate the routes for proteins targeted to the $\mathrm{CM}$ possessing or lacking an $\mathrm{N}$-terminal SP. Violet arrows indicate the routes for exported/secreted proteins (export and secretion are synonymous in monoderm bacteria). Green arrow indicates proteins integrated into the CM. CP: cytoplasm; CM: cytoplasmic membrane; CW: cell wall; EC, extracellular milieu; SP: signal peptide.

only since this system is absolutely not found in any archetypal diderm-LPS bacteria and, consequently, does not fit with standard numerical classification of protein secretion systems specifically designated for diderm-LPS (archetypal Gram-negative) bacteria (Salmond and Reeves, 1993; Sutcliffe, 2010). This "Type VII secretion system" further stands alone in diderm-mycolate 
bacteria since there are neither T1SS, T2SS, T3SS, T4SS, T5SS, nor T6SS but only Sec and Tat systems (which are not included in the standard numerical classification) (Digiuseppe Champion and Cox, 2007) (Figure 4). The molecular machinery described for this diderm-mycolate bacterial "Type VII secretion system" is an export pathway (protein transport across the cytoplasmic membrane) just as the Sec and Tat systems are (Economou et al., 2006; Desvaux et al., 2009a; Houben et al., 2012). In fact, no translocon in the mycolate outer membrane (MOM), which would truly enable protein secretion and thus form a complete secretion pathway, has been uncovered as yet in diderm-mycolate bacteria [the secretion of proteins exported in the first instance by the Wss, Sec, and Tat could then be completed by the very same MOM translocon, or different MOM translocons specific to each of these export systems (Desvaux et al., 2009a)] (Niederweis, 2003; Converse and Cox, 2005; Ize and Palmer, 2006; Digiuseppe Champion and Cox, 2007; Song et al., 2008; Desvaux et al., 2009a; Niederweis et al., 2010; Stoop et al., 2012; Freudl, 2013; Van Der Woude et al., 2013). This “Type VII secretion system" nomenclature in diderm-mycolate bacteria is clearly not compatible with the numerical classification basically designed to describe OM translocation systems in diderm-LPS bacteria (Salmond and Reeves, 1993; Economou et al., 2006; Desvaux et al., 2009a). All-in-all, using the "Type VII secretion system" denomination for the phylogenetically related secretion systems in monoderm bacteria (i.e., the Wss) is very much confusing since it does not align with the other secretion systems present such as Sec and Tat (which do not withstand the numerical classification terminology) (Desvaux et al., 2004b, 2009a). When designating this "Type VII secretion system" it is then highly advisable to clearly specify it relates to diderm-mycolate bacteria only to prevent any confusion with the unrelated T7SS in diderm-LPS bacteria. Ultimately, its use should be refrained in favor of the "ESX (ESAT-6 system)" designation in diderm-mycolate bacteria (archetypal acid-fast bacteria) and/or the generic "WXG100 secretion system (Wss)" designation especially relevant to monodermata (archetypal Gram-positive bacteria). At the moment only protein export systems have been reported in didermmycolate bacteria (Digiuseppe Champion and Cox, 2007; Feltcher et al., 2010; Ligon et al., 2012) but sensu stricto no protein secretion system has been identified (Figure 4). As for the T1SS to T9SS in diderm-LPS bacteria, only the identification of translocon components at the MOM would truly permit to define a protein secretion system (Desvaux et al., 2009a), which at worse could be the unique terminal branch for all the three export systems (Sec, Tat, and ESX) in diderm-mycolate bacteria (Figure 4).

For effectors involved in bacterial colonization, this review will especially focus on protein secretion systems in diderm-LPS (archetypal Gram-negative) and monoderm (archetypal Grampositive) bacteria since none has been characterized as yet in diderm-mycolate (archetypal acid-fast) bacteria.

\section{SECRETED PROTEINS INVOLVED IN SURFACE COLONIZATION IN DIDERM-LPS BACTERIA}

Out of the 9 distinct protein secretion systems through which a secreted protein can be translocated across the OM, only the T6SS

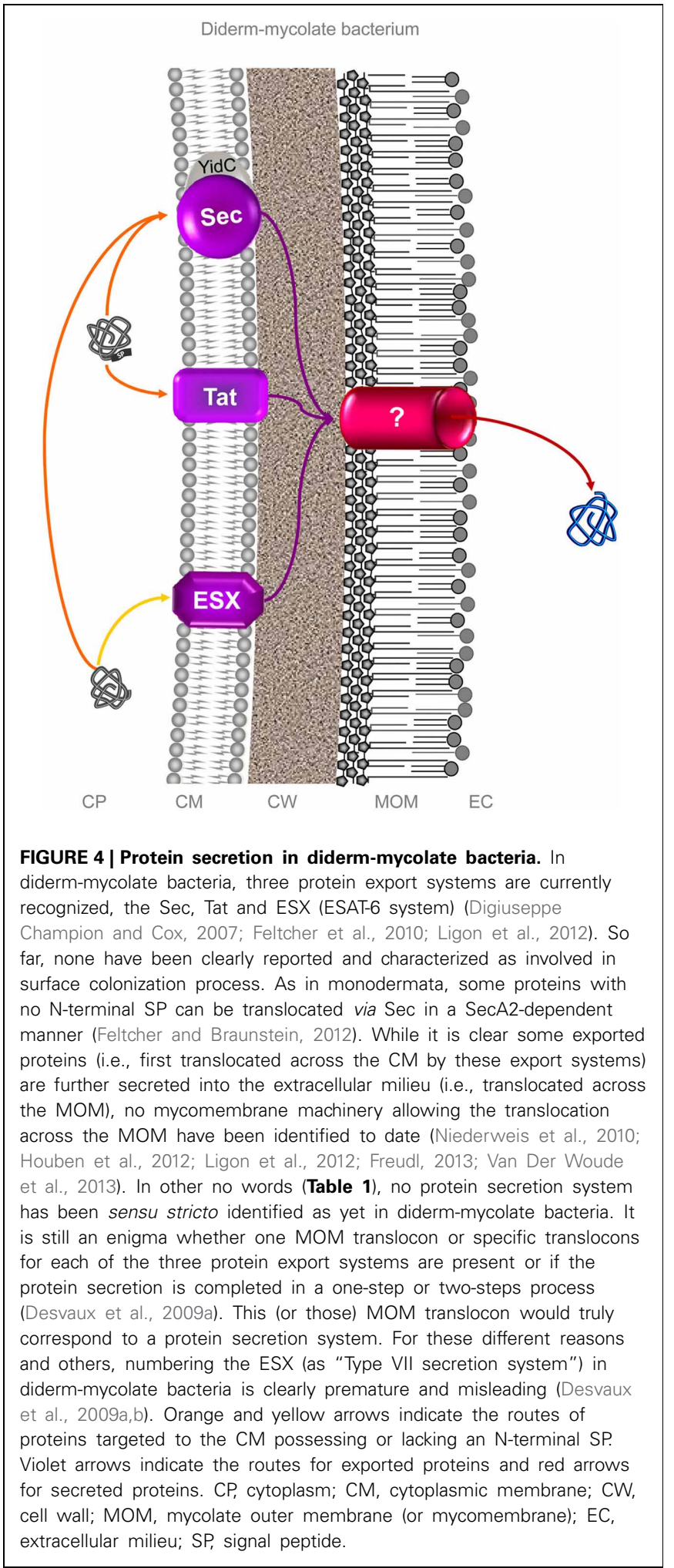

has never been reported so far to be involved in bacterial adhesion and/or biofilm formation in diderm-LPS bacteria (Figure 2). The T2SS, T3SS, T4SS, and T5SS are further divided into different subtypes. 


\section{ADHESINS SECRETED VIA THE T1SS}

The T1SS has been demonstrated to allow the secretion of large bacterial adhesins belonging to the Bap family (Delepelaire, 2004; Lasa and Penadés, 2006; Latasa et al., 2006). In Salmonella enterica, SiiE (Salmonella intestinal infection E) and BapA (Biofilmassociated protein A) have been characterized. SiiE is a very large adhesin of $600 \mathrm{kDa}$ of Salmonella enteric required for adhesion to epithelial cells. SiiE would essentially exist as an exoprotein that may only be loosely associated the OM but upon host cell contact it is retained on the bacterial cell surface (Wong et al., 1998; Morgan et al., 2004; Gerlach et al., 2007). The ability of SiiE to bind $\mathrm{Ca}^{2+}$ ions would confer a rigid rod-like habitus that is required for reach out beyond the LPS and initiates bacterial adhesion to polarized host cells (Wagner et al., 2011; Griessl et al., 2013). BapA is a $386 \mathrm{kDa}$ protein allowing homotypic adhesion during Salmonella biofilm formation and is involved in pathogenesis, especially internalization and invasion of intestinal epithelium (Latasa et al., 2005; Jonas et al., 2007; Biswas et al., 2011; Suez et al., 2013). BapA is secreted extracellularly where it remains in loose association with the bacterial cell surface. In Pseudomonas fluorescens, LapA (large adhesion protein A) is the largest T1SS-dependent adhesin uncovered so far, with a molecular weight estimated at $888 \mathrm{kDa}$ (Hinsa et al., 2003; Hinsa and O'toole, 2006). LapA enables irreversible adhesion and biofilm formation on abiotic surfaces but also adhesion to corn seeds in Pseudomonas putida (Mus20 or Mus24; mutant unattached to seeds) (Espinosa-Urgel et al., 2000; Huber et al., 2002; Hinsa et al., 2003; Ivanov et al., 2012; Zhang et al., 2013). LapA is found both in the extracellular milieu and in a loose association with the bacterial cell surface but not in the OM (Hinsa et al., 2003). In Burkholderia cepacia, the loss of Bap resulted in decreased surface hydrophobicity and in colony conversion to a rough morphotype (Huber et al., 2002). Additional adhesins of the Bap family, presumably secreted via a T1SS as supported by the genomic context, have been characterized in diderm-LPS bacteria, namely VPA1445 (Vibrio parahaemolyticus locus 1445) (Enos-Berlage et al., 2005) and YeeJ (systematic nomenclature) in Escherichia coli (Roux et al., 2005). In all cases, the mediation of adhesion via an extracellular protein is difficult to conceptualize and still demands experimental investigations for validation (Gerlach and Hensel, 2007).

\section{TYPE 4 PILUS (T4P) AND COLONIZATION FACTOR VIA THE T2SS}

Based on phylogenetic analysis, T2SSs were further subdivided into the subfamilies T2aSS and T2bSS, corresponding, respectively, to Xcp (Xanthomonas campestris general secretion pathway) and Hxc (homolog to Xcp) systems (Filloux, 2004; Michel and Voulhoux, 2009; Durand et al., 2011). At the same period, it was proposed to include the Type 4 piliation (T4P) system (Desvaux et al., 2009b) within the T2SS since the T4P is homologous to the Xcp and falls into discrete phylogenetic cluster (Planet et al., 2001; Peabody et al., 2003; Tomich et al., 2007; Ayers et al., 2010). To make the nomenclature coherent, we propose to classify those systems as T2aSS for the classical SDP extensively investigated in Pseudomonas aeruginosa, i.e., Xcp type system (Voulhoux et al., 2001), T2bSS for the Hxc type system (Durand et al., 2011), and T2cSS for the T4P system (Mattick, 2002). The Type 4 pili promote initial bacterial attachment and are of importance for the early stages of biofilm development, i.e., microcolony formation (Hahn, 1997; Giltner et al., 2006; Burrows, 2012). The Type 4 pili are subdivided into two main classes assembled by the T2cSS (Strom and Lory, 1993; Kachlany et al., 2001; Pelicic, 2008), i.e., (i) the T4a pilins, and (ii) the T4b pilins (Strom and Lory, 1993; Skerker and Shapiro, 2000; Craig et al., 2004; Craig and Li, 2008; Giltner et al., 2012). Besides adherence, the T4aP are responsible for a number of related processes associated with bacterial motility, including twitching, swarming, crawling, walking, and slingshoting, which participate to biofilm development (Desvaux et al., 2005a; Burrows, 2012; Conrad, 2012).

The colonization factor GbpA ( $\mathrm{N}$-acetylglucosamine-binding protein A) from Vibrio cholerae is secreted in a T2SS-dependent manner in the extracellular milieu (Kirn et al., 2005). This protein is required for efficient environmental colonization by organisms such as zooplankton, and also intestinal colonization, especially of human epithelial cells, by binding to a sugar present on both surfaces (Stauder et al., 2012). GbpA has a modular architecture with chitin-binding and mucin-binding domains enabling attachment to different host surfaces and other domains binding to the bacterial cell surface (Wong et al., 2012). Despite its secretion into the extracellular milieu, GbpA thus has a bridging function between $V$. cholerae and its host allowing efficient colonization of chitinous exoskeletons of arthropods or the intestinal epithelium.

\section{T3SS: INJECTISOME, HRP (HYPERSENSITIVE RESPONSE AND PATHOGENICITY) PILUS AND FLAGELLUM}

The T3SSs can be subdivided into (i) the non-flagellar T3SS, i.e., the T3aSS, involved in the assembly of the injectisome or Hrp (hypersensitive response and pathogenicity) pilus, and (ii) the flagellar T3SS, i.e., T3bSS, responsible for assembly of the flagellum (Tampakaki et al., 2004; Journet et al., 2005; Pallen et al., 2005; Desvaux et al., 2006b).

While acting primarily as a molecular syringe for injecting protein effectors directly into the cytosol of a host cell (Cornelis, 2006, 2010), the injectisome (T3aSS) mediates intimate bacterial adhesion and colonization of cells such as gut epithelial cells (Garmendia et al., 2005). In enterohemorrhagic Escherichia coli (EHEC), it was further demonstrated to play a role in the adhesion to lettuce leaves with a marked tropism for the stomata, and thus to contribute to the transmission of this food-borne pathogen to humans (Shaw et al., 2008; Berger et al., 2010). While the injectisome is found in animal-pathogenic bacteria, the Hrp pilus (T3aSS) is found in plant-pathogenic bacteria (Tang et al., 2006; Tampakaki et al., 2010). By injecting T3SS effectors into the host cell, the Hrp pilus allows the phytopathogens to subdue the vegetable-cell response (Zhou and Chai, 2008) but also participate to plant colonization through initial bacterial adhesion (Darsonval et al., 2008; Correa et al., 2012).

The flagella (T3bSS) are involved in cell motility through swimming and/or swarming, where it can contribute to bacterial colonization by bringing the cell in contact with biotic or abiotic surfaces by chemiotaxis for instance, or by translocating the bacterial cells over a surface, respectively (Pratt and Kolter, 1998; Harshey, 2003; Verstraeten et al., 2008). Besides, the flagella mediate bacterial adhesion directly to biotic and abiotic surfaces, e.g., 
to plasticware, human mucus and mucin, epithelial cells, enterocytes, vegetables (Grant et al., 1993; Ramphal et al., 1996; Lillehoj et al., 2002; Kirov et al., 2004; Berger et al., 2009b; Mahajan et al., 2009; Shaw et al., 2011; Tran et al., 2011; Bucior et al., 2012; Troge et al., 2012). Interestingly in Salmonella enterica, adhesion to salad leaves mediated by the flagella was shown to be strainspecific (Berger et al., 2009a). Salmonella enterica can further internalize into vegetable leaves through flagella-chemotaxis via open stomata (Kroupitski et al., 2009a). Although the internalization is variable in leafy vegetables and fresh herbs (Golberg et al., 2011; Kroupitski et al., 2011), the flagella is clearly an important determinant for colonization of some vegetables and can thus contribute to the transmission of this food-borne pathogen to humans even after washing (Berger et al., 2009a; Kroupitski et al., 2009a,b).

\section{PILI ASSEMBLED BY THE T4SS}

The T4SSs are broadly subdivided into (i) T4aSs corresponding to the prototypical VirB/D4 complex extensively investigated in Agrobacterium tumefaciens, and (ii) T4bSS corresponding to the prototypical F-conjugal transfer system of the self-transmissible IncI plasmid composed of the widely conserved Tra (transfer) proteins also present in monoderm bacteria (Christie and Vogel, 2000; Sexton and Vogel, 2002; Lawley et al., 2003; Harris and Silverman, 2004; Christie et al., 2005; Hazes and Frost, 2008; Voth et al., 2012). The T4SS allows transport of proteins into prokaryotic or eukaryotic cells. This system is also involved and ancestrally related to bacterial conjugation with the transport of DNA as nucleo-protein complex (Lawley et al., 2003). Rather than focusing on protein secretion system only, the nomenclature is quite confusing at the moment since it mixes up homologic (phylogenetic) and analogic (functional) based-classifications on aspects related to DNA transport as well as the systems present in monoderm and diderm-LPS bacteria (Alvarez-Martinez and Christie, 2009; Wallden et al., 2010); in addition, some phylogenetic relatedness between the T2SS assembling Type 4 pili (T4P) and T4SS assembling conjugative pili of Type 2 (Ottow, 1975) accentuates the complexity of the situation (Hazes and Frost, 2008). As it has been done previously for other protein secretion systems (Henderson et al., 2000; Desvaux et al., 2004b, 2006b, 2009b), this stresses the need to clarify the classification within the T4SS respective to the current terminology and ontology issues in the field of bacterial protein secretion, which should be rather based on homology and phylogeny rather than analogy (Desvaux et al., 2006b, 2009b). Regarding bacterial colonization, the F episome (natural conjugative plasmid) was demonstrated to induce the formation of a thick biofilm in E. coli and that conjugative pilus synthesis from the tra operon of the F plasmid was required for biofilm formation (Ghigo, 2001). In fact, the bacterial cells harboring the $\mathrm{F}$ episome had increased adhesion ability thanks to the expression of conjugative pili. It appeared these plasmids can be further transferred by conjugation from these donor cells to recipient cells. Then, the increasing proportion of transconjugant cells within the biofilm further improved the colonization ability of the bacterial population. While the positive influence of conjugative plasmid on biofilm formation was reported in other species (Bahl et al., 2007; Burmolle et al., 2008), it can also have adverse effects in complex multi-species biofilms and would depend on the composition of the bacterial community (Roder et al., 2013).

Phylogenetic analyses revealed the tight-adherence (Tad) system originally uncovered in Aggregatibacter (formerly Actinobacillus) actinomycetemcomitans was actually related to the T4SS and would constitute a major subfamily (Tomich et al., 2007). The Tad system is involved in the piliation of the Flp (fimbrial low-molecular-weight protein). Those pili are composed of Type 4 pilin of the subfamily b (Giltner et al., 2012). Flp pili are highly adhesive and essential for biofilm formation (Kachlany et al., 2001). Rather than binding to specific receptor(s), the bacterial-bacterial and bacterial-host interactions lead to strong attachment. Bacterial aggregation is mediated by the association of pilus fibers, which leads to pilus bundling. This system is widespread among diderm-LPS bacterial species, including the genera Haemophilus, Pasteurella, Pseudomonas, Yersinia, or Caulobacter (Kachlany et al., 2000, 2001; Bernard et al., 2009).

\section{CELL-SURFACE ADHESINS OF THE T5SS}

T5SSs are subdivided into five subtypes (Henderson et al., 2000, 2004; Desvaux et al., 2003, 2004a; Henderson and Desvaux, 2004; Salacha et al., 2010; Leo et al., 2012), (i) the T5aSS corresponding to the classical autotransporter or autotransporter of Type 1 (AT-1), (ii) the T5bSS corresponding to the two-partner secretion (TPS), (iii) the T5cSS corresponding to the trimeric autotransporter or autotransporter of Type 2 (AT-2), (iv) the T5dSS corresponding to hybrid autotransporter between AT-1 and TPS, or autotransporter of Type 3 (AT-3), and (v) the T5eSS corresponding to invasin/intimin family of inverted autotransporter or autotransporter of Type 4 (AT-4). No function in bacterial colonization has been reported as yet for the hybrid autotransporters (T5dSS) (Salacha et al., 2010).

\section{Adhesins of the classical autotransporter pathway (T5aSS)}

Among the classical autotransporters (T5aSS), the SAATs (Selfassociating autotransporters) actively participate in biofilm development and encompasse the Ag43 (antigen 43), AIDA (adhesin involved in diffuse adherence,) and TibA (enterotoxigenic invasion locus b protein A) (Klemm et al., 2006; Van Der Woude and Henderson, 2008). The SAATs promote bacterial autoaggregation and interaction with other SAAT partners, for instance between AIDA and Ag43, leading to the formation of mixed bacterial cell aggregates (Sherlock et al., 2004). Selfrecognition is sensitive to environmental conditions, such as $\mathrm{pH}$ or the presence of bile salt (Klemm et al., 2004; Sherlock et al., 2004, 2005; Girard et al., 2010) and intercellular aggregation can be abolished by pili or exopolymers, which compromise SAATs interaction (Klemm et al., 2006). SAATs further mediate and enhance biofilm formation (Klemm et al., 2006). Ag43, however, would not contribute significantly to intestinal colonization (Parham et al., 2005; De Luna et al., 2008). Besides SAATs, several other AT-1s act as adhesins (Henderson et al., 2004; Girard and Mourez, 2006). YfaL, YpjA, and YcgV (E. coli systematic nomenclature) are involved in initial bacterial adhesion and biofilm formation (Roux et al., 2005). BrkA (Bordetella resistance to killing protein A) (Ewanowich et al., 1989; Fernandez 
and Weiss, 1994) and Pertactin (Leininger et al., 1991) promote adhesion to different mammalian cells. Aae (A. actinomycetemcomitans epithelial cell binding) (Rose et al., 2003; Fine et al., 2005), App (adhesion and penetration protein) (Serruto et al., 2003), CapA (Campylobacter adhesion protein A) (Ashgar et al., 2007), EspP (extracellular serine protease P) (Dziva et al., 2007; Puttamreddy et al., 2010), McaP (Moraxella catarrhalis adherence protein) (Timpe et al., 2003; Lipski et al., 2007), PmpD (Polymorphic membrane protein D) (Wehrl et al., 2004), rOmpB (Rickettsia outer membrane protein B) (Uchiyama et al., 2006), and Sab (STEC autotransporter mediating biofilm formation) (Herold et al., 2009), enable adherence to epithelial cells; for some of them it was further demonstrated they participated to intestinal colonization and/or biofilm formation, namely CapA, EspP and Sab. Hap (Haemophilus autotransporter protein) further mediates microcolony formation as well as binding to fibronectin, laminin, and collagen (Fink et al., 2003), whereas MisL (membrane insertion and secretion protein L) and ShdA (shedding protein A) bind to collagen and fibronectin (Kingsley et al., 2000, 2002, 2004; Dorsey et al., 2005). EhaA (EHEC autotransporter A) (Wells et al., 2008), EhaB (Wells et al., 2009), and EhaJ (Easton et al., 2011) are MSCRAMM (microbial surface components recognizing adhesive matrix molecules) proteins binding differentially to various extracellular matrix (ECM) proteins and contributing to biofilm formation (Chagnot et al., 2012, 2013). Tsh (temperature-sensitive haemagglutinin) also binds to ECM proteins and further adheres to red blood cells and hemoglobin (Kostakioti and Stathopoulos, 2004). AlpA (adherence-associated lipoprotein A) (Odenbreit et al., 1999), BabA (blood group antigen-binding adhesin) (Ilver et al., 1998), and SabA (sialic acid-binding adhesin) (Mahdavi et al., 2002) are involved in adhesion to human gastric epithelia by the fucosylated Lewis b histo-blood group antigen for BabA and by sialyl-dimericLewis $\times$ glycosphingolipid for SabA.

Of major importance in the colonization process, the expression of many autotransporters (such as Ag43) is subjected to phase variation (Henderson et al., 1999; Van Der Woude and Henderson, 2008; Rossiter et al., 2011a). In addition, proteolytic processing of the passenger domain of the autotransporter on the bacterial cell surface can have a regulatory function on bacterial adhesion (Leyton et al., 2012). In fact, the passenger domain of AT-1s can either remain attached or cleaved off the translocation unit upon OM translocation. This proteolytic cleavage can arise following different scenarios (Leyton et al., 2012) but basically the cleavage can either be intramolecular and autocatalytic or intermolecular resulting in the release of passenger domain into the extracellular milieu, for example the SPATEs (serine protease autotransporters of Enterobacteriaceae). Some processed AT-1s, though, remain strongly associated with their cognate translocation unit, e.g., the adhesins Hap, pertactin, AIDA, or Ag43. It also appeared, the protein function is not modified when the cleavage is abolished (Charbonneau et al., 2009), which questions the purpose or benefit of this processing. For Hap, however, it was demonstrated the cleavage influenced the adherence to epithelial cells as well as adhesion to ECM proteins (Fink et al., 2002, 2003). Interestingly, NalP (Neisseria autotransporter lipoprotein), which is subjected to phase-variable expression by slipped-strand mispairing (Saunders et al., 2000) and modifies the cleavage patterns of other surface-associated proteins (including some other autotransporters and surface-exposed lipoproteins) (Van Ulsen et al., 2003, 2006; Roussel-Jazede et al., 2010; Serruto et al., 2010), affects in turn adhesion and biofilm formation (Arenas et al., 2013). Similar proteins are found in other bacterial pathogens.

\section{Adhesins of the TPS pathway (T5bSS)}

In the TPS (T5bSS), the passenger domain or exoprotein (TpsA) is translated separately from its cognate translocation unit (TpsB) (Jacob-Dubuisson et al., 2004). The exoprotein FHA (filamentous haemagglutinin) is a multifaceted adhesin and major attachment factor of Bordetella spp required for colonization of the lower respiratory tract (Locht et al., 1993). While part of the exoprotein is found to be surface-associated, another part is released into the extracellular milieu. Contrary to our previous understanding, it appeared that the C-terminus of FHA is oriented away from the bacterial cell surface and is required for adherence to epithelial cells (Mazar and Cotter, 2006). The exoproteins HMW1 (high-molecular-weight protein 1) and HMW2 of Haemophilus influenza are crucial colonization factors involved in bacterial adherence to a variety of respiratory epithelial cell types (St Geme et al., 1993; St Geme and Yeo, 2009). HrpA (hemagglutinin/hemolysin-related protein A) from Neisseria meningitidis and MhaB1 (M. catarrhalis FhaB-like protein 1) from Moraxella catarrhalis mediate binding to human epithelial cells (Schmitt et al., 2007). In the phytopathogen Xanthomonas axonopodis, $\mathrm{XacFhaB} \mathrm{(} X$. axonopodis pv. citri filamentous haemagglutinin-like protein $B$ ) is required for leaf tissue colonization, especially adhesion and biofilm formation (Gottig et al., 2009). In Pseudomonas putida, HlpA (haemolysinlike protein A) would play a direct role in the bacterial cell-root surface interaction (Molina et al., 2006). HecA (hemolysin-like E. chrysanthemi protein A) from Erwinia chrysanthemi contributes to the attachment and cell aggregation on leaves (Rojas et al., 2002). Interestingly, the exoprotein EtpA (ETEC two-partner secretion protein A) mediates bacterial adhesion by bridging the flagella with the host cells (Roy et al., 2009).

\section{Adhesins of the trimeric autotransporter pathway (T5cSS)}

A cardinal feature of the T5SS is a functional OM translocation unit, e.g., located at the C-terminus in monomeric classical autotransporter (T5aSS) or the TspB for the T5bSS. In the T5cSS, the C-terminal translocation unit is formed upon trimerization and serves as an $\mathrm{OM}$ anchor for cell-surface exposure of the passenger domains (Cotter et al., 2005; Lyskowski et al., 2011). YadA (Yersinia adhesin A) is the prototypical member of this T5SS subfamily (Hoiczyk et al., 2000; El Tahir and Skurnik, 2001; Eitel and Dersch, 2002; Nummelin et al., 2004; Leo et al., 2010). The high-molecular weight trimer formed by the passenger domains protrudes from the OM and consists of three domains, the stalk, necks and head (Linke et al., 2006; Hartmann et al., 2012). Differences in the size of the protruding AT-2s result from the length of their stalks (Linke et al., 2006). The head is involved in binding to some ECM proteins, including collagen, and makes YadA a major adhesion factor. All trimeric 
autotransporters $(\mathrm{T} 5 \mathrm{cSS})$ characterized to date are involved in bacterial adhesion (Linke et al., 2006). Besides YadA, several other AT-2s have been characterized to date in this expanding protein family (Cotter et al., 2005), e.g., Hia (Haemophilus influenzae adhesin) (Hoiczyk et al., 2000; St Geme and Cutter, 2000), UspA (ubiquitous surface protein A) of Moraxella catharralis (Conners et al., 2008), Hag (hemagglutinin) (Pearson et al., 2002; Bullard et al., 2007), NadA (Neisseria adhesin A) (Comanducci et al., 2002), BadA (Bartonella henselae adhesin) (Riess et al., 2004), NcaA (necessary for collagen adhesion A) (Fulcher et al., 2006), NhhA (Neisseriahia Hsf homologue protein A) (Scarselli et al., 2006), DsrA (ducreyi serum resistance A) (Leduc et al., 2008), EhaG (EHEC adhesin G) (Valle et al., 2008), SadA (Salmonella adhesin A) (Raghunathan et al., 2011), or UpaG (UPEC adhesin G) (Totsika et al., 2012). Each of these trimeric autotransporters are quite multifunctional and in terms of bacterial colonization they can be involved in autoagglutination, hemagglutination, ECM-binding, and/or adhesion to epithelial cells (El Tahir and Skurnik, 2001; Linke et al., 2006).

\section{Intimins/invasins of the inverted autotransporter pathway (T5eSS)}

Intimins/invasins (T5eSS) belong to a large and novel subfamily of the T5SS (Tsai et al., 2010; Leo et al., 2012; Oberhettinger et al., 2012). Compared to the classical autotransporter, the secretion mechanism is inverted in the sense, the translocation unit is located at the N-terminal instead of the C-terminal end of the monomeric autotransporter. The intimin/invasin family regroups adhesins that mediate bacterial adhesion and/or invasion of their host cells. In Yersinia spp., invasin binds to mammalian cell receptors of the integrin family (Isberg et al., 2000; Palumbo and Wang, 2006). In enteropathogenic E. coli, intimin mediates intimate adherence between the bacteria and the host cells by interacting with Tir (translocated intimin receptor) (Frankel and Phillips, 2008). Tir is a T3aSS-secreted protein, which integrates into the plasma membrane of the host cell (Devinney et al., 1999); upon binding to intestinal epithelial cells, the intiminTir interaction leads to the formation of actin pedestals beneath bound bacteria (Campellone and Leong, 2003; Brady et al., 2011). Interestingly, intimin can further promote intestinal colonization in a Tir-independent way (Mallick et al., 2012).

\section{PILI ASSEMBLED BY THE T7SS}

In diderm-LPS bacteria, the T7SS corresponds to the chaperoneusher pathway (CUP) (Desvaux et al., 2009b); as explained above it has nothing to do with the "Type VII secretion system" of diderm-mycolate (archetypal acid-fast) bacteria, i.e., the ESX. The T7SS is involved in the OM secretion and assembly of pili, which have been named very differently from one bacterial species to another (Sauer et al., 2004; Zav'yalov et al., 2010; Busch and Waksman, 2012; Thanassi et al., 2012), e.g., Afa/Dr (diffuse adherence fibrillar adhesin/Dr blood group antigen), AF/R1 (adhesive fimbriae on RDEC-1), AafD (aggregative adherence fimbriae), $\mathrm{P}$ pili, Type 3 fimbriae, Lpf (long polar fimbriae) or CS (coli surface) pili. More rationally, those pili can be categorized into (i) monoadhesive pili (represent the majority of cases), which display either thick rigid or thin flexible morphology and present a single adhesive domain at the tip, and (ii) polyadhesive pili, which display non-pilar, amorphous or capsule-like morphology and present two independent binding sites specific to different host-cell receptors for each of the subunits composing the organelle (Zav'yalov et al., 2010). Monoadhesive pili are also named FGS (F1-G1 short loop short) chaperone-assembled monoadhesin (e.g., Lpf) (Hung et al., 1996), and polyadhesive pili can either be FGL (F1-G1 long loop) chaperone-assembled polyadhesin (e.g., Afa/Dr) or FGS chaperone-assembled polyadhesin (e.g., AF/R1) (Zavialov et al., 2007). Of note, the socalled "alternate chaperone-usher pathway" (Soto and Hultgren, 1999 ) is obsolete and now included within the T7SS (Nuccio and Baumler, 2007; Poole et al., 2007; Zav'yalov et al., 2010; Thanassi et al., 2012). Pili secreted and assembled by the T7SS are involved bacterial adhesion, interbacterial interactions, aggregation, thereby promoting biofilm formation (Zav'yalov et al., 2010; Thanassi et al., 2012). Those pili can also initiate contact with host-cell receptors and mediate colonization of host cell surfaces. Interestingly, the adhesion of FimH pili (subfamily 2.5 FGS chaperone-assembled monoadhesins-5-1) is modulated by the shear force (Nilsson et al., 2006; Yakovenko et al., 2008; Le Trong et al., 2010).

\section{PILI ASSEMBLED BY THE T8SS}

The T8SS corresponds to the extracellular nucleationprecipitation (ENP) pathway (Desvaux et al., 2009b) involved in the OM secretion and assembly of thin and aggregative pili called curli (Hammar et al., 1996; Barnhart and Chapman, 2006; Dueholm et al., 2012; Hammer et al., 2012). Curli are functional amyloid fibers (Epstein and Chapman, 2008). They are involved in cell aggregation, bacterial adhesion and the formation of mature biofilms (Fronzes et al., 2008). They can actually change bacterial surface properties thereby enhancing adherence and attachment to surfaces. In the course of sessile development they constitute a significant part of the proteinaceous component of the biofilm matrix (Blanco et al., 2012). Curli also mediate host cell-bacteria interactions during infection (Wurpel et al., 2013).

\section{ADHESINS SECRETED VIA THE T9SS}

The T9SS corresponds to the Por (porphyrin accumulation on the cell surface) secretion system (Sato et al., 2010, 2013; Shoji et al., 2011; McBride and Zhu, 2013). This secretion system has been essentially investigated in Porphyromonas gingivalis and Flavobacterium johnsoniae and seems restricted to members of the phylum Bacteroidetes (McBride and Zhu, 2013). Respective to surface colonization process, the T9SS is required for the secretion of cell-surface motility adhesins, namely SprB (colonyspreadingprotein B) and RemA (redundant motility protein A), but also some hemin-binding proteins (Nelson et al., 2007; Shoji et al., 2011; Shrivastava et al., 2012; Sato et al., 2013). The cellsurface adhesin SprB allows attachment to the substratum but is also required for efficient gliding as it is propelled along a closed helical loop track, generating rotation and translation of the bacterial cell (Nelson et al., 2007; Nakane et al., 2013a,b). While SprB is involved in movement over agar, RemA is involved in movement over surfaces coated with F. johnsoniae polysaccharide (Shrivastava et al., 2012). Gliding involves the rapid movement of the semiredundant motility adhesins SprB and RemA along 
the cell surface (Shrivastava et al., 2013). T9SS-secreted proteins exhibit C-terminal domains (CTDs) considered essential for attachment to the bacterial cell surface by an A-LPS anchor containing anionic polysaccharide repeating units (Kondo et al., 2010; Shoji et al., 2011; Slakeski et al., 2011; Shrivastava et al., 2013). CTD region function as a recognition signal for the T9SS and glycosylation occurs after removal of the CTD region (Shoji et al., 2011; Glew et al., 2012).

\section{SECRETED PROTEINS INVOLVED IN SURFACE COLONIZATION IN MONODERM BACTERIA}

In monoderm bacteria, no protein secreted via the Tat, $\mathrm{ABC}$ exporter, holin, or Wss pathways has been reported as yet to be involved in bacterial adhesion and/or biofilm formation (Figure 3) but some proteins secreted by Sec, FPE, Tra and FEA have.

\section{SEC-SECRETED PROTEINS INVOLVED IN BACTERIAL COLONIZATION}

Once translocated by $\mathrm{Sec}$, secreted proteins can have radically different locations in monoderm bacteria as they can either be (i) integrated or anchored to the CM, i.e., IMPs (inner membrane proteins) and lipoproteins, respectively, (ii) associated with the $\mathrm{CW}$, i.e., parietal proteins (CW-proteins), (iii) subunits of pili, or (iv) released into the extracellular milieu and beyond (e.g., into a host cell) (Desvaux et al., 2006a, 2009b; Renier et al., 2012) (Figures 1, 3). Sec-secreted CW-proteins can either be anchored (i) covalently to the CW by a sortase if they exhibit an LPXTG domain (Ton-That et al., 2004; Schneewind and Missiakas, 2012), or (ii) non-covalently if they exhibit a CWBD (cell-wall binding domain), i.e., SLHD (S-layer homology domain), CWBD1 (CWBD of Type 1), CWBD2, LysM (lysin motif), WXL or GW motifs (Desvaux et al., 2006a). While no protein located at the $\mathrm{CM}$ has been reported to be involved in bacterial colonization in monodermata, several proteins located at the CW or forming cellsurface supramolecular complexes were reported to participate to this process.

\section{Colonization factors located at the cell wall}

In monoderm bacteria, proteins of the Bap family exhibit a Cterminal LPXTG domain enabling their covalent anchoring to the CW by sortases (Lasa and Penadés, 2006; Latasa et al., 2006). While Bap is involved in biofilm formation in S. aureus (Cucarella et al., 2001), the bap gene has never been found in S. aureus human isolates but only in isolates associated with ruminant mastitis (Lasa and Penadés, 2006). Strains encoding bap show lower adherence to some ECM proteins (fibrinogen and fibronectin) but also epithelial cell cultures, suggesting Bap might act as an anti-attachment factor preventing initial attachment to host tissues (Cucarella et al., 2002). At the same time, Bap facilitates the colonization of host tissues and the establishment of persistent infections by S. aureus (Cucarella et al., 2004; Valle et al., 2012). The interaction of Bap with Gp96/GRP94/Hsp90 provokes a significant reduction of epithelial cell invasion by interfering with the fibronectin binding protein invasion pathway. While Bap is often considered as a key determinant for biofilm formation (Lasa, 2006), a recent investigation revealed that there is no direct correlation with biofilm formation and that a single gene or subset of genes cannot be utilized as a biofilm indicator for morphology in S. aureus (Tang et al., 2013). Interestingly, Bap is subjected to phase variation and the switch between Bap ON/Bap OFF states might regulate sessile development (Henderson et al., 1999; Tormo et al., 2007). In Enterococcus faecalis, Esp (enterococcal surface protein) also leads to a significant increase in biofilm formation (Tendolkar et al., 2004) and contributes to persistence in the host (Sava et al., 2010). In S. epidermidis and Listeria monocytogenes, however, Bhp (Bap homologue protein) and BapL, respectively, are not clearly involved in biofilm formation (Tormo et al., 2005; Lasa and Penadés, 2006; Jordan et al., 2008; Renier et al., 2011).

As recently reviewed (Chagnot et al., 2012), different MSCRAMM surface proteins have been investigated in monoderm bacteria (Vengadesan and Narayana, 2011). Among the main ECM fibrillar proteins, namely collagen, fibronectin, laminin and elastin, eight fibronectin-binding domains (FBD1 to FBD8) and only one collagen-binding domain (CBD) have been characterized to date and much remains to be learned about specific binding to other ECM components (Chagnot et al., 2012). Very interestingly, domains involved in binding to ECM proteins such as fibronectin and collagen could also bind polystyrene as demonstrated with RspA (Rhusiopathiae surface protein A) (Shimoji et al., 2003).

In B. subtilis, the S-layer protein BslA (Bacillus S-layer protein A; formerly YuaB) is important for pellicle biofilms (Ostrowski et al., 2011; Vlamakis et al., 2013). BslA has amphiphilic properties and forms a hydrophobic layer on the surface of the biofilm which can contribute to colonization of the air-surface interface (Kovacs and Kuipers, 2011; Kobayashi and Iwano, 2012).

\section{Pili: Type 3 (T3P) and amyloid fibers}

A little bit more than a decade ago, pili were considered to be absent from monoderm bacteria. The first pathway recognized in pilus biogenesis in monodermata involves polymerization of LPXTG-pilins by different types of transpeptidase sortases, (Shimoji et al., 2003; Ton-That and Schneewind, 2003; Ton-That et al., 2004; Telford et al., 2006; Kang and Baker, 2012). Those pili of Type 3 (T3P) are involved in adhesion, biofilm formation and host colonization (Swierczynski and Ton-That, 2006; Danne and Dramsi, 2012). LipA (light-inducible pilin A) from Arthrobacter photogonimos was proposed as the major pilin of an alternative pilus formation pathway in monoderm bacteria (Yang and Hoober, 1998, 1999; Ton-That and Schneewind, 2004; Swierczynski and Ton-That, 2006).

In $B$. subtilis, pili formation of the amyloid-fiber type has been recently demonstrated to be essential in colony and pellicle biofilms but not for surface-adhered biofilms (Romero et al., 2010; Vlamakis et al., 2013). The CW-protein TapA (TasA anchoring and assembly protein A; formerly YqxM) allows the CW anchoring and assembly of TasA (translocationdependent antimicrobial spore component A) into long amyloid fibers (Stover and Driks, 1999; Romero et al., 2011), these proteins are not required in biofilms. In Peptostreptococcus micros, auto-aggregative pili are formed at least from a CWBD1 protein called FibA (fibril-like structure subunit A) (Kremer et al., 1999). 


\section{Cellulosome}

Cellulosomes are supramolecular protein complexes found on the cell surface of some cellulolytic anaerobic monoderm bacteria, such as the thermophilic Clostridium thermocellum or mesophilic C. cellulolyticum, and dedicated to specific adhesion, colonization and degradation of insoluble lignocellulosic substrates (Bayer et al., 2004, 2008; Gilbert, 2007; Fontes and Gilbert, 2010). It is also responsible for regulating the entering carbon metabolic flux in the bacterial cell, which in turn can influence the bacterial colonization of the insoluble lignocellulosic substratum (Guedon et al., 1999, 2000; Payot et al., 1999; Desvaux et al., 2001; Desvaux and Petitdemange, 2001, 2002; Desvaux, 2004). The cellulosome is composed of a non-catalytic protein called scaffoldin, which exhibits domains called cohesin of Type I (Coh I) domains allowing the specific binding of a dockerin domain of Type I (Doc) borne by cellulosomal enzymes. Actually, a single Doc I can simultaneously bind two Coh I and thus allow the linking of two scaffoldins resulting in the formation of polycellulosomes (Carvalho et al., 2003). In C. thermocellum, a cellulosome has a size ranging from 2.0 to $6.5 \mathrm{MDa}$ depending on the bacterial strain (Béguin and Lemaire, 1996) and forms polycellulosomal protuberances of up to $100 \mathrm{MDa}$ (Shoham et al., 1999). The cellulosomal enzymes and/or the scaffoldin contain carbohydratebinding modules (CBMs) involved in the tight binding to a carbohydrate-polymer such as cellulose (Shoseyov et al., 2006; Guillen et al., 2010). The scaffoldin can also exhibit a Doc II domain that can interact with Coh II present in SLHD cell-wall proteins, thus permitting cell-surface display of the cellulosome. In C. cellulolyticum for instance, the molecular mechanisms for attachment of the cellulosome to the bacterial cell surface remains unknown (Desvaux, 2005a,b). The architecture of the cellulosome can be even more complex with the assembly of scaffoldins on other scaffoldins like in Acetivibrio cellulolyticus where one supramolecular complex can potentially bind 84 different cellulosomal enzymes (Rincon et al., 2003; Xu et al., 2003, 2004). However, the molecular mechanisms permitting the coordinated assembly of the different protein subunits on the bacterial cellsurface remain unclear (Desvaux, 2005b, 2006).

\section{TYPE 4 PILUS (T4P) ASSEMBLED BY THE FPE}

The Com (Competence development) pathway involves both the bacterial competence-related DNA transformation transporter and the FPE system (Dubnau, 1997, 1999; Dubnau and Provvedi, 2000; Chen and Dubnau, 2004). In B. subtilis, the FPE system is involved in the formation of a pseudopilus from Type 4 prepilins (Chen and Dubnau, 2004; Chen et al., 2006) but do not form a complete Type 4 pilus (T4P). While this was considered as a paradigm for monoderm bacteria, it was recently demonstrated the FPE could form complete Type 4 pilus in Streptococcus pneumonia (Laurenceau et al., 2013). While this T4P was only considered in the context of DNA transformation, its implication in bacterial colonization as reported for T4P in diderm-LPS bacteria is an intriguing possibility that would require further investigations in other species such as L. monocytogenes (Rabinovich et al., 2012). GP25 (glycoprotein of 25kDa) from Ruminococcus albus was characterized as the major protein subunit of T4P present at the bacterial cell surface (Pegden et al., 1998; Mosoni and Gaillard-Martinie, 2001; Rakotoarivonina et al., 2002, 2005). Those pili could be involved in cellulose colonization and cellulose degradation. T4P involved in biofilm formation and gliding motility was also uncovered in Clostridium perfringens (Varga et al., 2006; Mendez et al., 2008; Varga et al., 2008).

Protein components of the FPE machinery are homologous to some proteins found in T2SS, T4SS, and T4P assembly apparatus in diderm-LPS bacteria and have been collectively called PSTC (Pilus/Secretion/Twitching motility/Competence) (Fussenegger et al., 1997; Dubnau, 1999; Peabody et al., 2003). In Bifidobacterium breve, a functional Tad system involved in the formation of T4bP has recently been uncovered ( $\mathrm{O}^{\prime}$ connell Motherway et al., 2011). These pili are essential for intestinal colonization of the host. Besides the genus Actinobacteria, a Tad system was also identified in Clostridia, namely Cl. acetobutylicum (Desvaux et al., 2005b). Again, there is much confusion between the pili assembly by FPE, Tad and the misleading called "Type IV-like secretion system" in monoderm bacteria corresponding more adequately to the Tra system. This would necessitate indepth phylogenetic and functional-genetic analyses to clarify the situation.

\section{FLAGELLUM ASSEMBLED BY THE FEA}

In monoderm bacteria, the flagellar subunits are secreted and assembled by the FEA but the involvement and exact contribution of flagella in biofilm formation remain difficult to establish. Taking L. monocytogenes as a case study, it is clear that the regulation of flagella expression is quite complex with the intervention of several transcription regulators but basically that flagella are not expressed at temperatures higher than $30^{\circ} \mathrm{C}$ and bacterial cells are then non-motile (Renier et al., 2011). Regarding listerial colonization, it was shown flagella were not essential for biofilm development but facilitated initial attachment to surfaces (Vatanyoopaisarn et al., 2000) and were even crucial for initial adhesion (Tresse et al., 2006). During infection, though, the flagella would act as mediators of motility rather than adhesins to enhance the adhesion of $L$. monocytogenes to targeted host cells (O'neil and Marquis, 2006). By contrast with early findings, it was further shown the role of the flagella as mediators of motility rather than adhesins was critical for initial surface attachment and subsequent biofilm formation (Lemon et al., 2007). In dynamic culture conditions for sessile development (i.e., using flow cells), the loss of the flagella resulted in the formation of a very dense biofilm (hyperbiofilm) (Todhanakasem and Young, 2008). These conflicting findings could arise from the use of different L. monocytogenes strains as some of them can be more or less laboratoryadapted (domesticated) and have different regulations of flagella expression (Grundling et al., 2004). It could also result from the use of different culture conditions, such as the growth media (e.g., complex undefined or chemically defined), temperature (e.g., related to infection or environmental conditions), support (e.g., plasticware, stainless steel or glass) and/or culture systems (e.g., static or dynamic conditions) (Renier et al., 2011).

In Bacillus cereus, flagella motility (i) is necessary for biofilm formation at air-liquid interface as it allows bacteria to reach it, (ii) promotes recruitment of planktonic cells within the biofilm by allowing motile bacteria to invade the whole biofilm, and (iii) 
allows spreading of the biofilm on surfaces (Houry et al., 2010). In B. subtilis, however, motility and biofilm formation are quite clearly coordinately and oppositely controlled (Kearns et al., 2005; Newman et al., 2013; Vlamakis et al., 2013). It was further demonstrated a protein clutch arrested flagellar motilily by disengaging motor force-generating elements in cells engaged in sessile development (Blair et al., 2008). Nonetheless, and while the number of motile cells decreases in the course of sessile development, a subpopulation of motile cells remains in mature biofilms (Vlamakis et al., 2008) and a biofilm exclusively composed of unflagellated cells is delayed in forming pellicle biofilms (Kobayashi, 2007) and defective in the formation of surface-adhered biofilms (Chagneau and Saier, 2004). Interestingly, motile Bacillus thuringiensis can tunnel deep within a biofilm structure (Houry et al., 2012). Those swimming cells create transient pores that increase irrigation within the biofilm. This can either improve biofilm bacterial fitness by increasing nutrient flow in the matrix or facilitating the penetration of toxic substances detrimental for biofilm formation.

\section{NON-CLASSICAL PROTEIN SECRETION AND BACTERIAL COLONIZATION}

Analysis of the protein content of the extracellular milieu and/or the cell surface, revealed the presence of unexpected proteins primarily predicted or known to be localized in the cytoplasm, with no N-terminal signal peptide (SP), and no dedicated protein secretion system. While early investigations suggested it could result from bacterial cell lysis, it later appeared some of those proteins were actually secreted by previously unrecognized pathways, e.g., some SecA2-dependent secreted proteins (Desvaux and Hébraud, 2006, 2009; Rigel and Braunstein, 2008; Renier et al., 2013). Non-classical (NC) protein secretion refers to the uncharacterized mechanisms responsible for secretion of those proteins (prior to characterization such apparent secretion could be the result of phenomenon unrelated to secretion per se, such as membrane budding, allolysis, phage-mediated lysis, GTA, etc. . . ) (Bendtsen et al., 2005; Bendtsen and Wooldridge, 2009). Another unexpected finding was the involvement of some of those proteins in an additional function completely different form the primary one. Indeed, the glyceraldehyde-3-phosphate dehydrogenase (GAPDH) is a well-known and key glycolytic enzyme but when present on the bacterial cell surface it exhibits very significant binding activity against plasmin(ogen), fibrinogen, and human cells ( $\mathrm{C} 1 \mathrm{q}$ component of the classical component pathway) (Bergmann et al., 2004; Jin et al., 2005; Egea et al., 2007; Matta et al., 2010; Tunio et al., 2010; Terrasse et al., 2012). Several of those so-called moonlighting proteins have been identified in bacteria and play a significant role in bacterial colonization, especially in an infection context (Jeffery, 2003, 2009; Huberts and Van Der Klei, 2010; Copley, 2012; Henderson and Martin, 2013). Most enzymes of the EMP (Embden-Meyerhof-Parnas) pathway can moonlight and a role as an adhesin is quite common, e.g., for enolase, aldolase, or phosphoglucomutase (PGM) (Henderson and Martin, 2011, 2013). However, the molecular mechanisms responsible for their bacterial cell-surface localization remain unknown.

\section{CONCLUSIONS AND PERSPECTIVES}

While extremely useful, the secretome concept has not been fully exploited and is still in its infancy. In the context of bacterial colonization, it allows a rational approach for comprehending the secreted proteins directly involved in bacterial adhesion and/or biofilm formation. Considering the protein routing and secretion mechanisms embrace the idea that some of those adhesins and/or adhesion supramolecular complexes share common posttranslational and post-translocational maturation mechanisms that may lead to the identification of novel targets for therapeutic strategies. While the majority of investigations are focused on colonization factors in the context of infection, their involvement in the interactions of commensal bacterial, as well as bacteria in an environmental context, are also important areas and should not be overlooked. Bacterial colonization is not the prerogative of pathogens and there is much to gain from the study of colonization of host species by commensal bacteria, as well as environmentally orientated studies. Clearly, there are numerous proteins and supramolecular structures involved in bacterial adhesion and biofilm formation but their functional characterization still demands extensive investigations, e.g., alternative pili in monoderm bacteria or collagen-/laminin-/elastin-binding domains. The understanding of the global and coordinated regulation of the secretome in the course of colonization at the single cell, homogenous population, and multi-species microbial community levels is a major challenge in different ecological niches. Phase variation for instance is a well-known phenomenon especially for factors involved in colonization process but is rarely considered and is poorly understood at a global scale. In the last couple of years, new secretion system such as the T6SS or T9SS have been unexpectedly uncovered and there is much to bet that other protein secretion system(s) are yet to be discovered. Besides, the exact contribution of NC secretion and other protein trafficking mechanisms in bacterial colonization (e.g., allolysis, phage-mediated lysis, membrane budding or GTA) remains to be determined. Regarding the different secretion systems present in a single bacterial cell and numerous systems within microbiota as well as their associated secreted proteins involved in colonization, they promise to be the subject of a lot of research work ahead as well as exciting new developments in the field.

\section{ACKNOWLEDGMENTS}

This work was supported by INRA (French National Institute for Agronomical Research) with the MICEL project funded by the inter-department CEPIA/MICA (Science and Process Engineering of Agricultural Products/Microbiology and Food Chain) AIP ("Action Incitative Programmée") and COST (European Cooperation in Science and Technology) Action 1202 BacFoodNet (A European Network For Mitigating Bacterial Colonization and Persistence On Foods and Food Processing Environments). Mohamed Amine Zorgani is a $\mathrm{PhD}$ research fellow granted by the "Ministère de l'Enseignement Supérieur et de la Recherche." Caroline Chagnot is a PhD Research Fellow granted by the "Région Auvergne-FEDER (Fonds Européen de Développement Régional)." The authors are thankful to Reviewers for their very constructive comments. 


\section{REFERENCES}

Abdallah, A. M., Gey Van Pittius, N. C., Champion, P. A., Cox, J., Luirink, J., Vandenbroucke-Grauls, C. M., et al. (2007). Type VII secretionmycobacteria show the way. Nat. Rev. Microbiol. 5, 883-891. doi: 10.1038/nrmicro1773

Alvarez-Martinez, C. E., and Christie, P. J. (2009). Biological diversity of prokaryotic Type IV secretion systems. Microbiol. Mol. Biol. Rev. 73, 775-808. doi: 10.1128/MMBR.00023-09

An, Y. H., and Friedman, R. J. (1998). Concise review of mechanisms of bacterial adhesion to biomaterial surfaces. J. Biomed. Mater. Res. 43, 338-348.

Antelmann, H., Tjalsma, H., Voigt, B., Ohlmeier, S., Bron, S., Van Dijl, J. M., et al. (2001). A proteomic view on genome-based signal peptide predictions. Genome Res. 11, 1484-1502. doi: 10.1101/gr. 182801

Antelmann, H., Van Dijl, J. M., Bron, S., and Hecker, M. (2006). Proteomic survey through secretome of Bacillus subtilis. Methods Biochem. Anal. 49, 179-208.

Arenas, J., Nijland, R., Rodriguez, F. J., Bosma, T. N., and Tommassen, J. (2013). Involvement of three meningococcal surface-exposed proteins, the heparin-binding protein NhbA, the a-peptide of IgA protease and the autotransporter protease NalP, in initiation of biofilm formation. Mol. Microbiol. 87, 254-268. doi: 10.1111/mmi. 12097

Ashgar, S. S., Oldfield, N. J., Wooldridge, K. G., Jones, M. A., Irving, G. J., Turner, D. P., et al. (2007). CapA, an autotransporter protein of Campylobacter jejuni, mediates association with human epithelial cells and colonization of the chicken gut. J. Bacteriol. 189, 1856-1865. doi: 10.1128/JB.01427-06

Ayers, M., Howell, P. L., and Burrows, L. L. (2010). Architecture of the Type II secretion and Type 4 pilus machineries. Future Microbiol. 5, 1203-1218. doi: 10.2217/fmb.10.76

Bahl, M. I., Hansen, L. H., and Sorensen, S. J. (2007). Impact of conjugal transfer on the stability of IncP-1 plasmid pKJK5 in bacterial populations. FEMS Microbiol. Lett. 266, 250-256. doi: 10.1111/j.15746968.2006.00536.x

Barnhart, M. M., and Chapman, M. R. (2006). Curli biogenesis and function. Annu. Rev. Microbiol. 60, 131-147. doi: 10.1146/annurev. micro.60.080805.142106
Bateman, A., Coin, L., Durbin, R., Finn, R. D., Hollich, V., GriffithsJones, S., et al. (2004). The Pfam protein families database. Nucleic Acids Res. 32, D138-D141. doi: 10.1093/nar/gkh121

Bayer, E. A., Belaich, J. P., Shoham, Y., and Lamed, R. (2004). The cellulosomes: multienzyme machines for degradation of plant cell wall polysaccharides. Annu. Rev. Microbiol. 58, 521-554. doi: 10.1146/annurev.micro.57.030502. 091022

Bayer, E. A., Lamed, R., White, B. A., and Flint, H. J. (2008). From cellulosomes to cellulosomics. Chem. Rec. 8, 364-377. doi: 10.1002/tcr.20160

Bazaka, K., Crawford, R. J., Nazarenko, E. L., and Ivanova, E. P. (2011). Bacterial extracellular polysaccharides. Adv. Exp. Med. Biol. 715, 213-226. doi: 10.1007/978-94-0070940-9_13

Béguin, P., and Lemaire, M. (1996). The cellulosome: an exocellular, multiprotein complex specialized in cellulose degradation. Crit. Rev. Biochem. Mol. Biol. 31, 201-236. doi: 10.3109/10409239609106584

Bendtsen, J. D., Kiemer, L., Fausboll, A., and Brunak, S. (2005). Non-classical protein secretion in bacteria. $B M C$ Microbiol. 5:58. doi: 10.1186/14712180-5-58

Bendtsen, J. D., and Wooldridge, K. G. (2009). "Chapter 10: non-classical secretion," in Bacterial Secreted Proteins: Secretory Mechanisms and Role in Pathogenesis, ed K. Wooldridge (Norwich: Caister Academic Press), 226-235.

Berger, C. N., Shaw, R. K., Brown, D. J., Mather, H., Clare, S., Dougan, G., et al. (2009a). Interaction of Salmonella enterica with basil and other salad leaves. ISME J. 3, 261-265. doi: 10.1038/ismej.2008.95

Berger, C. N., Shaw, R. K., Ruiz-Perez, F., Nataro, J. P., Henderson, I. R., Pallen, M. J., et al. (2009b). Interaction of enteroaggregative Escherichia coli with salad leaves. Environ. Microbiol. Rep. 1, 234-239. doi: 10.1111/j.1758-2229.2009.00037.x

Berger, C. N., Sodha, S. V., Shaw, R. K., Griffin, P. M., Pink, D., Hand, P., et al. (2010). Fresh fruit and vegetables as vehicles for the transmission of human pathogens. Environ. Microbiol. 12, 2385-2397. doi: 10.1111/j.1462-2920.2010.02297.x

Bergmann, S., Rohde, M., and Hammerschmidt, S. (2004). Glyceraldehyde-3-phosphate dehydrogenase of Streptococcus pneumoniae is a surface-displayed plasminogen-binding protein. Infect. Immun.. 72, 2416-2419. doi: 10.1128/IAI.72.4.2416-2419.2004

Bernard, C. S., Bordi, C., Termine, E., Filloux, A., and De Bentzmann, S. (2009). Organization and PprB-dependent control of the Pseudomonas aeruginosa tad Locus, involved in Flp pilus biology. J. Bacteriol. 191, 1961-1973. doi: 10.1128/JB.01330-08

Biswas, R., Agarwal, R. K., Bhilegaonkar, K. N., Kumar, A., Nambiar, P., Rawat, S., et al. (2011). Cloning and sequencing of biofilm-associated protein (bapA) gene and its occurrence in different serotypes of Salmonella. Lett. Appl. Microbiol. 52, 138-143. doi: 10.1111/j.1472-765X.2010.02975.x

Blair, K. M., Turner, L., Winkelman, J. T., Berg, H. C., and Kearns, D. B. (2008). A molecular clutch disables flagella in the Bacillus subtilis biofilm. Science 320, 1636-1638. doi: 10.1126/science. 1157877

Blanco, L. P., Evans, M. L., Smith, D. R., Badtke, M. P., and Chapman, M. R. (2012). Diversity, biogenesis and function of microbial amyloids. Trends Microbiol. 20, 66-73. doi: 10.1016/j.tim.2011.11.005

Brady, M. J., Radhakrishnan, P., Liu, H., Magoun, L., Murphy, K. C., Mukherjee, J., et al. (2011). Enhanced actin pedestal formation by enterohemorrhagic Escherichia coli O157:H7 Adapted to the Mammalian Host. Front. Microbiol. 2:226. doi: 10.3389/fmicb.2011.00226

Brennan, P. J., and Nikaido, H. (1995). The envelope of mycobacteria. Annu. Rev. Biochem. 64, 29-63. doi: 10.1146/annurev.bi.64.070195. 000333

Bucior, I., Pielage, J. F., and Engel, J. N. (2012). Pseudomonas aeruginosa pili and flagella mediate distinct binding and signaling events at the apical and basolateral surface of airway epithelium. PLoS Pathog. 8:e1002616. doi: 10.1371/journal.ppat.1002616

Buist, G., Ridder, A. N. J. A., Kok, J., and Kuipers, O. P. (2006). Different subcellular locations of secretome components of Gram-positive bacteria. Microbiology 152, 2867-2874. doi: 10.1099/mic.0.29113-0

Bullard, B., Lipski, S., and Lafontaine, E. R. (2007). Regions important for the adhesin activity of Moraxella catarrhalis Hag. BMC Microbiol. 7:65. doi: 10.1186/1471-2180-7-65

Buncic, S., Nychas, G. J., Lee, M. R., Koutsoumanis, K., Hebraud, M., Desvaux, M., et al. (2013).
Microbial pathogen control in the beef chain: recent research advances. Meat Sci. doi: 10.1016/j.meatsci. 2013.04.040. [Epub ahead of print]

Burmolle, M., Bahl, M. I., Jensen, L. B., Sorensen, S. J., and Hansen, L. H. (2008). Type 3 fimbriae, encoded by the conjugative plasmid pOLA52, enhance biofilm formation and transfer frequencies in Enterobacteriaceae strains. Microbiology 154, 187-195. doi: 10.1099/mic.0.2007/010454-0

Burrows, L. L. (2012). Pseudomonas aeruginosa twitching motility:Type 4 pili in action. Annu. Rev. Microbiol. 66, 493-520. doi: 10.1146/annurev-micro092611-150055

Busch, A., and Waksman, G. (2012). Chaperone-usher pathways: diversity and pilus assembly mechanism. Philos. Trans. R. Soc. Lond. B Biol. Sci. 367, 1112-1122. doi: 10.1098/rstb.2011.0206

Büttner, D. (2012). Protein export according to schedule: architecture, assembly, and regulation of type iii secretion systems from plant- and animalpathogenic bacteria. Microbiol. Mol. Biol. Rev. 76, 262-310. doi: 10.1128/MMBR.05017-11

Campellone, K. G., and Leong, J. M. (2003). Tails of two Tirs: actin pedestal formation by enteropathogenic E. coli and enterohemorrhagic E. coli O157:H7. Curr. Opin. Microbiol. 6, 82-90. doi: 10.1016/S1369-5274(03)00005-5

Candela, T., Dumetz, F., Tosi-Couture, E., Mock, M., Goossens, P. L., and Fouet, A. (2012). Cell-wall preparation containing poly-gD-glutamate covalently linked to peptidoglycan, a straightforward extractable molecule, protects mice against experimental anthrax infection. Vaccine 31, 171-175. doi: 10.1016/j.vaccine.2012.10.071

Candela, T., and Fouet, A. (2006). Poly-gamma-glutamate in bacteria. Mol. Microbiol. 60, 1091-1098. doi: 10.1111/j.1365-2958.2006.05179.x

Carvalho, A. L., Dias, F. M. V., Prates, J. A. M., Nagy, T., Gilbert, H. J., Davies, G. J., et al. (2003). Cellulosome assembly revealed by the crystal structure of the cohesindockerin complex. Proc. Natl. Acad. Sci. U.S.A. 100, 13809-13814. doi: 10.1073/pnas. 1936124100

Cascales, E., and Cambillau, C. (2012). Structural biology of Type VI secretion systems. Philos. Trans. R. Soc. B Biol. Sci. 367, 1102-1111. doi: 10.1098/rstb.2011.0209

Chagneau, C., and Saier, M. H. Jr. (2004). Biofilm-defective 
mutants of Bacillus subtilis. J. Mol. Microbiol. Biotechnol. 8, 177-188. doi: $10.1159 / 000085790$

Chagnot, C., Agus, A., Renier, S., Peyrin, F., Talon, R., Astruc, T., et al. (2013). In vitro colonization of the muscle extracellular matrix components by Escherichia coli O157:H7: the influence of growth medium, temperature and $\mathrm{pH}$ on initial adhesion and induction of biofilm formation by collagens I and III. PLoS ONE 8:e59386. doi: 10.1371/journal.pone.0059386

Chagnot, C., Listrat, A., Astruc, T., and Desvaux, M. (2012). Bacterial adhesion to animal tissues: protein determinants for recognition of extracellular matrix components. Cell Microbiol.. 14, 1687-1696. doi: 10.1111/cmi. 12002

Charbonneau, M. E., Janvore, J., and Mourez, M. (2009). Autoprocessing of the Escherichia coli AIDA-I autotransporter: a new mechanism involving acidic residues in the junction region. J. Biol. Chem 284, 17340-17351. doi: 10.1074/jbc.M109.010108

Chen, I., and Dubnau, D. (2004). DNA uptake during bacterial transformation. Nat. Rev. Microbiol 2, 241-249. doi: $10.1038 /$ nrmicro 844

Chen, I., Provvedi, R., and Dubnau, D. (2006). A macromolecular complex formed by a pilin-like protein in competent Bacillus subtilis. J. Biol. Chem 281, 21720-21727. doi: 10.1074/jbc.M604071200

Christie, P. J., Atmakuri, K., Krishnamoorthy, V., Jakubowski, S., and Cascales, E. (2005). Biogenesis, architecture, and function of bacterial Type IV secretion systems. Ann. Rev. Microbiol. 59, 451-485. doi: 10.1146/annurev.micro.58.030603. 123630

Christie, P. J., and Vogel, J. P. (2000). Bacterial Type IV secretion: conjugation systems adapted to deliver effector molecules to host cells. Trends Microbiol. 8, 354-360. doi: 10.1016/S0966-842X(00)01792-3

Cianciotto, N. P. (2005). Type II secretion: a protein secretion system for all seasons. Trends Microbiol. 13, 581-588. doi: 10.1016/j.tim.2005.09.005

Comanducci, M., Bambini, S., Brunelli, B., Adu-Bobie, J., Arico, B., Capecchi, B., et al. (2002). NadA, a novel vaccine candidate of Neisseria meningitidis. J. Exp. Med. 195, 1445-1454. doi: 10.1084/jem.20020407

Conners, R., Hill, D. J., Borodina, E., Agnew, C., Daniell, S. J., Burton, N. M., et al. (2008). The Moraxella adhesin UspAl binds to its human CEACAM1 receptor by a deformable trimeric coiledcoil. EMBO J. 27, 1779-1789. doi: 10.1038/emboj.2008.101

Conrad, J. C. (2012). Physics of bacterial near-surface motility using flagella and Type 4 pili: implications for biofilm formation. Res. Microbiol. 163, 619-629. doi: 10.1016/j.resmic.2012.10.016

Converse, S. E., and Cox, J. S. (2005) A protein secretion pathway critical for Mycobacterium tuberculosis virulence is conserved and functional in Mycobacterium smegmatis. J. Bacteriol. 187, 1238-1245. doi: 10.1128/JB.187.4.1238-1245.2005

Copley, S. D. (2012). Moonlighting is mainstream: paradigm adjustment required. Bioessays 34, 578-588. doi: 10.1002/bies.201100191

Cornelis, G. R. (2006). The Type III secretion injectisome. Nat. Rev. Microbiol. 4, 811-825. doi: 10.1038 /nrmicro 1526

Cornelis, G. R. (2010). The Type III secretion injectisome, a complex nanomachine for intracellular 'toxin' delivery. Biol. Chem. 391, 745-751. doi: 10.1515/bc. 2010.079

Correa, V. R., Majerczak, D. R., Ammar El, D., Merighi, M., Pratt, R. C., Hogenhout, S. A., et al. (2012). The bacterium Pantoea stewarti uses two different Type III secretion systems to colonize its plant host and insect vector. Appl. Environ. Microbiol. 78, 6327-6336. doi: 10.1128/AEM.00892-12

Cotter, S. E., Surana, N. K., and St Geme, J. W. 3rd. (2005). Trimeric autotransporters: a distinct subfamily of autotransporter proteins. Trends Microbiol. 13, 199-205. doi: 10.1016/j.tim.2005.03.004

Craig, L., and Li, J. (2008). Type 4 pili: paradoxes in form and function. Curr. Opin. Struct. Biol. 18, 267-277. doi: 10.1016/j.sbi.2007.12.009

Craig, L., Pique, M. E., and Tainer, J. A. (2004). Type 4 pilus structure and bacterial pathogenicity. Nat. Rev. Microbiol. 2, 363-378. doi: 10.1038/nrmicro885

Cucarella, C., Solano, C., Valle, J., Amorena, B., Lasa, I., and Penades, J. R. (2001). Bap, a Staphylococcus aureus surface protein involved in biofilm formation. J. Bacteriol. 183, 2888-2896. doi: 10.1128/JB.183.9.2888-2896.2001

Cucarella, C., Tormo, M. A., Knecht, E., Amorena, B., Lasa, I., Foster, T. J., et al. (2002). Expression of the biofilm-associated protein interferes with host protein receptors of Staphylococcus aureus and alters the infective process.
Infect. Immun. 70, 3180-3186. doi: 10.1128/IAI.70.6.3180-3186.2002

Cucarella, C., Tormo, M. A., Ubeda, C., Trotonda, M. P., Monzon, M., Peris, C., et al. (2004). Role of biofilm-associated protein bap in the pathogenesis of bovine Staphylococcus aureus. Infect. Immun. 72, 2177-2185. doi: 10.1128/IAI.72.4.2177-2185.2004

Cullen, P. A., Xu, X., Matsunaga, J., Sanchez, Y., Ko, A. I., Haake, D. A., et al. (2005). Surfaceome of Leptospira spp Infect. Immun. 73, 4853-4863. doi 10.1128/IAI.73.8.4853-4863.2005

Danne, C., and Dramsi, S. (2012) Pili of Gram-positive bacteria: roles in host colonization. Res. Microbiol. 163, 645-658. doi: 10.1016/j.resmic.2012.10.012

Darsonval, A., Darrasse, A., Meyer, D. Demarty, M., Durand, K., Bureau, C., et al. (2008). The Type III secretion system of Xanthomonas fuscans subsp. fuscans is involved in the phyllosphere colonization process and in transmission to seeds of susceptible beans. Appl. Environ. Microbiol. 74, 2669-2678. doi: 10.1128/AEM.02906-07

De Luna, M. G., Scott-Tucker, A., Desvaux, M., Ferguson, P., Morin, N. P., Dudley, E. G. et al. (2008). The Escherichia coli biofilm-promoting protein Antigen 43 does not contribute to intestinal colonization. FEMS Microbiol. Lett. 284, 237-246. doi: 10.1111/j.1574-6968.2008.01207.x

Delepelaire, P. (2004). Type I secretion in Gram-negative bacteria. Biochim. Biophys. Acta Mol. Cell Res. 1694, 149-161. doi: 10.1016/j.bbamcr.2004.05.001

Desvaux, M. (2004). Mapping of carbon flow distribution in the central metabolic pathways of Clostridium cellulolyticum: direct comparison of bacterial metabolism with a soluble versus an insoluble carbon source. J. Microbiol. Biotechnol. 14, 1200-1210.

Desvaux, M. (2005a). The cellulosome of Clostridium cellulolyticum. Enz. Microb. Technol. 37, 373-385. doi: 10.1016/j.enzmictec.2004.04.025

Desvaux, M. (2005b). Clostridium cellulolyticum: model organism of mesophilic cellulolytic clostridia. FEMS Microbiol. Rev. 29, 741-764. doi: 10.1016/j.femsre.2004.11.003

Desvaux, M. (2006). Unravelling carbon metabolism in anaerobic cellulolytic bacteria. Biotechnol. Prog. 22, 1229-1238. doi: 10.1002/bp060016e

Desvaux, M. (2012). Contribution of holins to protein trafficking: secretion, leakage or lysis?
Trends Microbiol. 20, 259-261. doi: 10.1016/j.tim.2012.03.008

Desvaux, M., Dumas, E., Chafsey, I., and Hébraud, M. (2006a). Protein cell surface display in Gram-positive bacteria: from single protein to macromolecular protein structure. FEMS Microbiol. Lett. 256, 1-15. doi: 10.1111/j.1574-6968.2006.00122.x

Desvaux, M., Hebraud, M., Henderson, I. R., and Pallen, M. J. (2006b). Type III secretion: what's in a name? Trends Microbiol. 14, 157-160. doi: 10.1016/j.tim.2006.02.009

Desvaux, M., Guedon, E., and Petitdemange, H. (2001). Kinetics and metabolism of cellulose degradation at high substrate concentrations in steady-state continuous cultures of Clostridium cellulolyticum on a chemically defined medium. Appl. Environ. Microbiol. 67, 3837-3845. doi: 10.1128/AEM.67.9.3837-3845.2001

Desvaux, M., and Hébraud, M. (2006). The protein secretion systems in Listeria: inside out bacterial virulence. FEMS Microbiol. Rev. 30, 774-805. doi: 10.1111/j.1574-6976.2006.00035.x

Desvaux, M., and Hébraud, M. (2009). "Chapter 14: listeria monocytogenes," in Bacterial Secreted Proteins: Secretory Mechanisms and Role in Pathogenesis, ed K. Wooldridge (Norwich: Caister Academic Press), 313-345.

Desvaux, M., Hébraud, M., Talon, R., and Henderson, I. R. (2009a). Outer membrane translocation: numerical protein secretion nomenclature in question in mycobacteria. Trends Microbiol. 17, 338-340. doi: 10.1016/j.tim.2009.05.008

Desvaux, M., Hébraud, M., Talon, R., and Henderson, I. R. (2009b). Secretion and subcellular localizations of bacterial proteins: a semantic awareness issue. Trends Microbiol. 17, 139-145. doi: 10.1016/j.tim.2009.01.004

Desvaux, M., Khan, A., Beatson, S., Scott-Tucker, A., and Henderson, I. R. (2005a). Protein secretion systems in Fusobacterium nucleatum: genomic identification of Type 4 piliation and complete Type $\mathrm{V}$ pathways brings new insight in mechanisms of pathogenesis. Biochim. Biophys. Acta Biomembr. 1713, 92-112. doi: 10.1016/j.bbamem.2005.05.002

Desvaux, M., Khan, A., Scott-Tucker, A., Chaudhuri, R. R., Pallen, M. J., and Henderson, I. R. (2005b). Genomic analysis of the protein secretion systems in Clostridium acetobutylicum 
ATCC824. Biochim. Biophys. Acta Mol. Cell Res. 1745, 223-253. doi: 10.1016/j.bbamcr.2005.04.006

Desvaux, M., Parham, N. J., and Henderson, I. R. (2003). Type V secretion system in Gram-negative bacteria Biofutur 237, 34-37.

Desvaux, M., Parham, N. J., and Henderson, I. R. (2004a). Type V protein secretion: simplicity gone awry? Curr. Issues Mol. Biol. 6, 111-124.

Desvaux, M., Parham, N. J., ScottTucker, A., and Henderson, I. R. (2004b). The general secretory pathway: a general misnomer? Trends Microbiol. 12, 306-309. doi: 10.1016/j.tim.2004.05.002

Desvaux, M., and Petitdemange, H. (2001). Flux analysis of the metabolism of Clostridium cellulolyticum grown in cellulosefed continuous culture on a chemically defined medium under ammonium-limited conditions. Appl. Environ. Microbiol. 67, 3846-3851. doi: 10.1128/AEM.67.9.3846-3851.2001

Desvaux, M., and Petitdemange, $\mathrm{H}$. (2002). Sporulation of Clostridium cellulolyticum while grown in cellulose-batch and cellulosefed continuous cultures on a mineral-salt based medium. Microb. Ecol. 43, 271-279. doi: 10.1007/s00248-001-0043-7

Devinney, R., Gauthier, A., Abe, A., and Finlay, B. B. (1999). Enteropathogenic Escherichia coli: a pathogen that inserts its own receptor into host cells. Cell Mol. Life Sci. 55, 961-976. doi: 10.1007/PL00013202

Digiuseppe Champion, P. A., and Cox, J. S. (2007). Protein secretion systems in Mycobacteria. Cell Microbiol.. 9, 1376-1384. doi: 10.1111/j.1462-5822.2007.00943.x

Dinh, T., Paulsen, I. T., and Saier, M. H. Jr. (1994). A family of extracytoplasmic proteins that allow transport of large molecules across the outer membranes of Gram-negative bacteria. J. Bacteriol. 176, 3825-3831.

Dorsey, C. W., Laarakker, M. C., Humphries, A. D., Weening, E. H., and Baumler, A. J. (2005). Salmonella enterica serotype Typhimurium MisL is an intestinal colonization factor that binds fibronectin. Mol. Microbiol. 57, 196-211. doi: 10.1111/j.1365-2958.2005.04666.x

Douzi, B., Filloux, A., and Voulhoux, R. (2012). On the path to uncover the bacterial Type II secretion system. Philos. Trans. R. Soc. B Biol. Sci. 367, 1059-1072. doi: 10.1098/rstb.2011.0204
Dreisbach, A., Van Dijl, J. M., and Buist, G. (2011). The cell surface proteome of Staphylococcus aureus. Proteomics 11, 3154-3168. doi: 10.1002/pmic.201000823

Dubnau, D. (1997). Binding and transport of transforming DNA by Bacillus subtilis: the role of type-IV pilin-like proteins-a review. Gene 192, 191-198. doi: 10.1016/S03781119(96)00804-9

Dubnau, D. (1999). DNA uptake in bacteria. Annu. Rev. Microbiol. 53, 217-244. doi: 10.1146/annurev. micro.53.1.217

Dubnau, D., and Provvedi, R. (2000). Internalizing DNA. Res. Microbiol. 151, 475-480. doi: 10.1016/S09232508(00)00166-2

Dueholm, M. S., Albertsen, M., Otzen, D., and Nielsen, P. H. (2012). Curli functional amyloid systems are phylogenetically widespread and display large diversity in operon and protein structure. PLOS ONE 7:e51274. doi: 10.1371/journal.pone.0051274

Durand, E., Alphonse, S., BrochierArmanet, C., Ball, G., Douzi, B., Filloux, A., et al. (2011). The assembly mode of the pseudopilus: a hallmark to distinguish a novel secretion system subtype. J. Biol. Chem. 286, 24407-24416. doi: 10.1074/jbc.M111.234278

Dziva, F., Mahajan, A., Cameron, P., Currie, C., McKendrick, I. J., Wallis, T. S., et al. (2007). EspP, a Type V-secreted serine protease of enterohaemorrhagic Escherichia coli O157:H7, influences intestinal colonization of calves and adherence to bovine primary intestinal epithelial cells. FEMS Microbiol. Lett. 271, 258-264. doi: 10.1111/j.1574-6968.2007.00724.X

Easton, D. M., Totsika, M., Allsopp, L. P., Phan, M. D., Idris, A., Wurpel, D. J., et al. (2011). Characterization of EhaJ, a new autotransporter protein from enterohemorrhagic and enteropathogenic Escherichia coli. Front. Microbiol. 2:120. doi: 10.3389/fmicb.2011.00120

Economou, A. (2002). Bacterial secretome: the assembly manual and operating instructions. Mol. Membr. Biol. 19, 159-169. doi: 10.1080/09687680210152609

Economou, A., Christie, P. J., Fernandez, R. C., Palmer, T., Plano, G. V., and Pugsley, A. P. (2006). Secretion by numbers: protein traffic in prokaryotes. Mol. Microbiol. 62, 308-319. doi: 10.1111/j.1365-2958.2006.05377.x

Egea, L., Aguilera, L., Gimenez, R., Sorolla, M. A., Aguilar, J., Badia, J., et al. (2007). Role of secreted glyceraldehyde-3-phosphate dehydrogenase in the infection mechanism of enterohemorrhagic and enteropathogenic Escherichia coli: interaction of the extracellular enzyme with human plasminogen and fibrinogen. Int. J. Biochem. Cell Biol. 39, 1190-1203. doi: 10.1016/j. biocel.2007.03.008

Eitel, J., and Dersch, P. (2002). The YadA protein of Yersinia pseudotuberculosis mediates high-efficiency uptake into human cells under environmental conditions in which invasin is repressed. Infect. Immun.. 70, 4880-4891. doi: 10.1128/IAI.70.9.4880-4891.2002

El Tahir, Y., and Skurnik, M. (2001). YadA, the multifaceted Yersinia adhesin. Int. J. Med. Microbiol. 291, 209-218. doi: 10.1078/1438-4221-00119

Enos-Berlage, J. L., Guvener, Z. T., Keenan, C. E., and McCarter, L. L. (2005). Genetic determinants of biofilm development of opaque and translucent Vibrio parahaemolyticus. Mol. Microbiol. 55, 1160-1182. doi: 10.1111/j.1365-2958.2004.04453.x

Epstein, E. A., and Chapman, M. R. (2008). Polymerizing the fibre between bacteria and host cells: the biogenesis of functional amyloid fibres. Cell Microbiol.. 10, 1413-1420. doi: 10.1111/j.1462-5822.2008.01148.x

Espinosa-Urgel, M., Salido, A., and Ramos, J. L. (2000). Genetic analysis of functions involved in adhesion of Pseudomonas putida to seeds. J. Bacteriol. 182, 2363-2369. doi 10.1128/JB.182.9.2363-2369.2000

Ewanowich, C. A., Melton, A. R., Weiss, A. A., Sherburne, R. K., and Peppler, M. S. (1989). Invasion of HeLa 229 cells by virulent Bordetella pertussis. Infect. Immun. 57, 2698-2704.

Fabretti, F., Theilacker, C., Baldassarri, L., Kaczynski, Z., Kropec, A., Holst, O., et al. (2006). Alanine esters of enterococcal lipoteichoic acid play a role in biofilm formation and resistance to antimicrobial peptides. Infect. Immun. 74, 4164-4171. doi 10.1128/IAI.00111-06

Feltcher, M. E., and Braunstein, M. (2012). Emerging themes in SecA2mediated protein export. Nat. Rev. Microbiol. 10, 779-789. doi: 10.1038/nrmicro2874

Feltcher, M. E., Sullivan, J. T., and Braunstein, M. (2010). Protein export systems of Mycobacterium tuberculosis: novel targets for drug development? Future Microbiol. 5, 1581-1597. doi: 10.2217/fmb.10.112

Fernandez, R. C., and Weiss, A. A. (1994). Cloning and sequencing of a
Bordetella pertussis serum resistance locus. Infect. Immun. 62, 4727-4738.

Filloux, A. (2004). The underlying mechanisms of Type II protein secretion. Biochim. Biophys. Acta Mol. Cell. Res. 1694, 163-179. doi: 10.1016/j.bbamcr.2004.05.003

Fine, D. H., Velliyagounder, K., Furgang, D., and Kaplan, J. B. (2005). The Actinobacillus actinomycetemcomitans autotransporter adhesin Aae exhibits specificity for buccal epithelial cells from humans and old world primates. Infect. Immun. 73, 1947-1953. doi: 10.1128/IAI.73.4.1947-1953.2005

Fink, D. L., Buscher, A. Z., Green, B., Fernsten, P., and St Geme, J. W. 3rd. (2003). The Haemophilus influenzae Hap autotransporter mediates microcolony formation and adherence to epithelial cells and extracellular matrix via binding regions in the C-terminal end of the passenger domain. Cell Microbiol. 5, 175-186. doi: 10.1046/j.1462-5822.2003.00266.x

Fink, D. L., Green, B. A., and St Geme, J. W. 3rd. (2002). The Haemophilus influenzae Hap autotransporter binds to fibronectin, laminin, and collagen IV. Infect. Immun. 70, 4902-4907. doi: 10.1128/IAI.70.9.4902-4907.2002

Flemming, H. C., and Wingender, J. (2010). The biofilm matrix. Nat Rev. Microbiol. 8, 623-633.

Fontes, C. M., and Gilbert, H. J. (2010). Cellulosomes: highly efficient nanomachines designed to deconstruct plant cell wall complex carbohydrates. Annu. Rev. Biochem. 79, 655-681. doi: 10.1146/annurevbiochem-091208-085603

Frankel, G., and Phillips, A. D. (2008). Attaching effacing Escherichia coli and paradigms of Tirtriggered actin polymerization: getting off the pedestal. Cell Microbiol. 10, 549-556. doi: 10.1111/j.1462-5822.2007.01103.x

Freudl, R. (2013). Leaving home ain't easy: protein export systems in Gram-positive bacteria. Res. Microbiol. 164, 664-674. doi: 10.1016/j.resmic.2013.03.014

Fronzes, R., Remaut, H., and Waksman, G. (2008). Architectures and biogenesis of non-flagellar protein appendages in Gram-negative bacteria. EMBO J. 27, 2271-2280. doi: 10.1038/emboj.2008.155

Fulcher, R. A., Cole, L. E., Janowicz, D. M., Toffer, K. L., Fortney, K. R., Katz, B. P., et al. (2006). Expression of Haemophilus ducreyi collagen binding outer membrane protein $\mathrm{NcaA}$ is required for virulence in swine and human 
challenge models of chancroid. Infect. Immun. 74, 2651-2658. doi: 10.1128/IAI.74.5.2651-2658.2006

Fussenegger, M., Rudel, T., Barten, R., Ryll, R., and Meyer, T. F. (1997). Transformation competence and type- 4 pilus biogenesis in Neisseria gonorrhoeae-a review. Gene 192, 125-134.

Garmendia, J., Frankel, G., and Crepin, V. F. (2005). Enteropathogenic and enterohemorrhagic Escherichia coli infections: translocation, translocation, translocation. Infect. Immun. 73, 2573-2585. doi: 10.1128/IAI.73. 5.2573-2585.2005

Gerlach, R. G., and Hensel, M. (2007). Protein secretion systems and adhesins: the molecular armory of Gram-negative pathogens. Int. J. Med. Microbiol. 297, 401-415. doi: 10.1016/j.ijmm.2007.03.017

Gerlach, R. G., Jackel, D., Stecher, B., Wagner, C., Lupas, A., Hardt, W. D., et al. (2007). Salmonella Pathogenicity Island 4 encodes a giant non-fimbrial adhesin and the cognate Type 1 secretion system. Cell Microbiol. 9, 1834-1850. doi: 10.1111/j.1462-5822.2007.00919.x

Ghigo, J. M. (2001). Natural conjugative plasmids induce bacterial biofilm development. Nature 412, 442-445. doi: 10.1038/35086581

Ghosh, P. (2004). Process of protein transport by the Type III secretion system. Microbiol.Mol. Biol. Rev. 68, 771-795. doi: 10.1128/MMBR.68.4. 771-795.2004

Gilbert, H. J. (2007). Cellulosomes: microbial nanomachines that display plasticity in quaternary structure. Mol. Microbiol. 63, 1568-1576. doi: 10.1111/j.13652958.2007.05640.x

Giltner, C. L., Nguyen, Y., and Burrows, L. L. (2012). Type 4 pilin proteins: versatile molecular modules. Microbiol. Mol. Biol. Rev. 76, 740-772. doi: 10.1128/MMBR.00035-12

Giltner, C. L., Van Schaik, E. J., Audette, G. F., Kao, D., Hodges, R. S., Hassett, D. J., et al. (2006). The Pseudomonas aeruginosa Type 4 pilin receptor binding domain functions as an adhesin for both biotic and abiotic surfaces. Mol. Microbiol. 59, 1083-1096. doi: 10.1111/j.13652958.2005.05002.x

Girard, V., Cote, J. P., Charbonneau, M. E., Campos, M., Berthiaume, F., Hancock, M. A., et al. (2010). Conformation change in a selfrecognizing autotransporter modulates bacterial cell-cell interaction. J. Biol. Chem. 285, 10616-10626. doi: 10.1074/jbc. M109.069070
Girard, V., and Mourez, M. (2006). Adhesion mediated by autotransporters of Gram-negative bacteria: structural and functional features. Res. Microbiol. 157, 407-416. doi: 10.1016/j.resmic. 2006.02.001

Glew, M. D., Veith, P. D., Peng, B., Chen, Y. Y., Gorasia, D. G., Yang, Q., et al. (2012). PG0026 is the C-terminal signal peptidase of a novel secretion system of Porphyromonas gingivalis. J. Biol. Chem. 287, 24605-24617. doi: 10.1074/jbc.M112.369223

Golberg, D., Kroupitski, Y., Belausov, E., Pinto, R., and Sela, S. (2011). Salmonella Typhimurium internalization is variable in leafy vegetables and fresh herbs. Int. J. Food Microbiol. 145, 250-257. doi: 10.1016/j.ijfoodmicro.2010.12.031

Gottenbos, B., Van Der Mei, H. C., and Busscher, H. J. (2000). Initial adhesion and surface growth of Staphylococcus epidermidis and Pseudomonas aeruginosa on biomedical polymers. J. Biomed. Mater. Res. 50, 208-214.

Gottig, N., Garavaglia, B. S., Garofalo, C. G., Orellano, E. G., and Ottado, J. (2009). A filamentous hemagglutinin-like protein of Xanthomonas axonopodis pv. citri, the phytopathogen responsible for citrus canker, is involved in bacterial virulence. PLoS ONE 4:e4358. doi: 10.1371/journal.pone.0004358

Grant, C. C., Konkel, M. E., Cieplak, W. Jr., and Tompkins, L. S. (1993). Role of flagella in adherence, internalization, and translocation of Campylobacter jejuni in nonpolarized and polarized epithelial cell cultures. Infect. Immun. 61, 1764-1771.

Griessl, M. H., Schmid, B., Kassler, K., Braunsmann, C., Ritter, R., Barlag, B., et al. (2013). Structural insight into the giant $\mathrm{Ca}^{2+}$ binding adhesin SiiE: implications for the adhesion of Salmonella enterica to polarized epithelial cells. Structure 21, 741-752. doi: 10.1016/j.str.2013.02.020

Gross, M., Cramton, S. E., Gotz, F., and Peschel, A. (2001). Key role of teichoic acid net charge in Staphylococcus aureus colonization of artificial surfaces. Infect. Immun. 69, 3423-3426. doi: 10.1128/IAI.69.5.3423-3426.2001

Grundling, A., Burrack, L. S., Bouwer, H. G., and Higgins, D. E. (2004). Listeria monocytogenes regulates flagellar motility gene expression through MogR, a transcriptional repressor required for virulence. Proc. Natl. Acad. Sci.
U.S.A. 101, 12318-12323. doi: 10.1073/pnas.0404924101

Guedon, E., Desvaux, M., Payot, S., and Petitdemange, H. (1999). Growth inhibition of Clostridium cellulolyticum by an inefficiently regulated carbon flow. Microbiology 145, 1831-1838. doi: 10.1099/13500872-145-8-1831

Guedon, E., Payot, S., Desvaux, M. and Petitdemange, H. (2000). Relationships between cellobiose catabolism, enzyme levels, and metabolic intermediates in Clostridium cellulolyticum grown in a synthetic medium. Biotechnol. Bioeng. 67, 327-335.

Guillen, D., Sanchez, S., and Rodriguez-Sanoja, R. (2010). Carbohydrate-binding domains: multiplicity of biological roles. Appl. Microbiol. Biotechnol. 85, 1241-1249. doi: 10.1007/s00253009-2331-y

Gupta, R. S. (2011). Origin of diderm (Gram-negative) bacteria: antibiotic selection pressure rather than endosymbiosis likely led to the evolution of bacterial cells with two membranes. Antonie Van Leeuwenhoek 100, 171-182. doi: 10.1007/s10482-011-9616-8

Hahn, H. P. (1997). The Type 4 pilus is the major virulence-associated adhesin of Pseudomonas aeruginosa. Gene 192, 99-108. doi: 10.1016/S0378-1119(97)00116-9

Hammar, M., Bian, Z., and Normark, S. (1996). Nucleator-dependent intercellular assembly of adhesive curli organelles in Escherichia coli. Proc. Natl. Acad. Sci. U.S.A. 93, 6562-6566. doi: 10.1073/pnas.93.13.6562

Hammer, N. D., McGuffie, B. A., Zhou, Y., Badtke, M. P., Reinke, A. A., Brannstrom, K., Gestwicki, J. E., Olofsson, A., Almqvist, F., and Chapman, M. R. (2012). The Cterminal repeating units of $\mathrm{CsgB}$ direct bacterial functional amyloid nucleation. J. Mol. Biol. 422, 376-389. doi: 10.1016/j.jmb.2012. 05.043

Harris, R. L., and Silverman, P. M. (2004). Tra proteins characteristic of F-like Type IV secretion systems constitute an interaction group by yeast two-hybrid analysis. J. Bacteriol. 186, 5480-5485. doi: 10.1128/JB.186.16.5480-5485.2004

Harshey, R. M. (2003). Bacterial motility on a surface: many ways to a common goal. Annu. Rev. Microbiol. 57, 249-273. doi: 10.1146/annurev. micro.57.030502.091014

Hartmann, M. D., Grin, I., DuninHorkawicz, S., Deiss, S., Linke, D., Lupas, A. N., et al. (2012). Complete fiber structures of complex trimeric autotransporter adhesins conserved in enterobacteria. Proc. Natl. Acad. Sci. U.S.A. 109, 20907-20912. doi: $10.1073 /$ pnas. 1211872110

Hazes, B., and Frost, L. (2008). Towards a systems biology approach to study Type II/IV secretion systems. Biochim. Biophys. Acta Biomembr. 1778, 1839-1850. doi: 10.1016/j.bbamem.2008.03.011

Henderson, B., and Martin, A. (2011). Bacterial virulence in the moonlight: multitasking bacterial moonlighting proteins are virulence determinants in infectious disease. Infect. Immun. 79, 3476-3491. doi: 10.1128/IAI.00179-11

Henderson, B., and Martin, A. (2013). Bacterial moonlighting proteins and bacterial virulence. Curr. Top. Microbiol. Immunol. 358, 155-213. doi: 10.1007/82_2011_188

Henderson, I. R., and Desvaux, M. (2004). Type V secretion pathway: a premium source source of virulence factors? Drug Discov. Today 9, 241.

Henderson, I. R., Nataro, J. P., Kaper, J. B., Meyer, T. F., Farrand, S. K., Burns, D. L., et al. (2000). Renaming protein secretion in the Gram-negative bacteria. Trends Microbiol 8, 352. doi: 10.1016/S0966-842X(00)01814-X

Henderson, I. R., Navarro-Garcia, F., Desvaux, M., Fernandez, R. C., and Ala'aldeen, D. (2004). Type V protein secretion pathway: the autotransporter story. Microbiol. Mol. Biol. Rev. 68, 692-744.

Henderson, I. R., Owen, P., and Nataro, J. P. (1999). Molecular switches: the $\mathrm{ON}$ and $\mathrm{OFF}$ of bacterial phase variation. Mol. Microbiol. 33, 919-932. doi: 10.1046/j.13652958.1999.01555.x

Hermansson, M. (1999). The DLVO theory in microbial adhesion. Colloids Surf. B. Biointerfaces 14, 105-119. doi: 10.1016/S0927-7765(99)00029-6

Herold, S., Paton, J. C., and Paton, A. W. (2009). Sab, a novel autotransporter of locus of enterocyte effacement-negative shiga-toxigenic Escherichia coli O113:H21, contributes to adherence and biofilm formation. Infect. Immun. 77, 3234-3243. doi: 10.1128/IAI.00031-09

Hinsa, S. M., Espinosa-Urgel, M., Ramos, J. L., and O'toole, G. A. (2003). Transition from reversible to irreversible attachment during biofilm formation by Pseudomonas fluorescens WCS365 requires an $\mathrm{ABC}$ transporter and a large secreted protein. Mol. Microbiol. 49, 905-918. 
Hinsa, S. M., and O'toole, G. A. (2006). Biofilm formation by Pseudomonas fluorescens WCS365: a role for LapD. Microbiology 152, 1375-1383.

Hoiczyk, E., Roggenkamp, A., Reichenbecher, M., Lupas, A., and Heesemann, J. (2000). Structure and sequence analysis of Yersinia YadA and Moraxella UspAs reveal a novel class of adhesins. EMBO J. 19, 5989-5999. doi: 10.1093/emboj/19.22.5989

Holland, I. B., Schmitt, L., and Young, J. (2005). Type I protein secretion in bacteria, the ABCtransporter dependent pathway. Mol. Membr. Biol. 22, 29-39. doi: $10.1080 / 09687860500042013$

Houben, E. N., Bestebroer, J., Ummels, R., Wilson, L., Piersma, S. R., Jimenez, C. R., et al. (2012). Composition of the Type VII secretion system membrane complex. Mol. Microbiol. 86, 472-484. doi: 10.1111/j.1365-2958.2012.08206.x

Houry, A., Briandet, R., Aymerich, S., and Gohar, M. (2010). Involvement of motility and flagella in Bacillus cereus biofilm formation. Microbiology 156, 1009-1018. doi: 10.1099/mic.0.034827-0

Houry, A., Gohar, M., Deschamps, J., Tischenko, E., Aymerich, S., Gruss, A., et al. (2012). Bacterial swimmers that infiltrate and take over the biofilm matrix. Proc. Natl. Acad. Sci. U.S.A. 109, 13088-13093. doi: 10.1073/pnas.1200791109

Huber, B., Riedel, K., Kothe, M., Givskov, M., Molin, S., and Eberl, L. (2002). Genetic analysis of functions involved in the late stages of biofilm development in Burkholderia cepacia H111. Mol. Microbiol. 46, 411-426. doi: 10.1046/j.1365-2958.2002.03182.x

Huberts, D. H., and Van Der Klei, I. J. (2010). Moonlighting proteins: an intriguing mode of multitasking. Biochim. Biophys. Acta Mol. Cell. Res. 1803, 520-525. doi: 10.1016/j.bbamcr.2010.01.022

Hung, D. L., Knight, S. D., Woods, R. M., Pinkner, J. S., and Hultgren, S. J. (1996). Molecular basis of two subfamilies of immunoglobulinlike chaperones. $E M B O$ J. 15, 3792-3805.

Ilver, D., Arnqvist, A., Ogren, J., Frick, I. M., Kersulyte, D., Incecik, E. T., et al. (1998). Helicobacter pylori adhesin binding fucosylated histoblood group antigens revealed by retagging. Science 279, 373-377. doi: 10.1126/science.279.5349.373

Isberg, R. R., Hamburger, Z., and Dersch, P. (2000). Signaling and invasin-promoted uptake via integrin receptors. Microbes
Infect. 2, 793-801. doi: 10.1016/S1286-4579(00)90364-2

Ivanov, I. E., Boyd, C. D., Newell, P. D., Schwartz, M. E., Turnbull, L., Johnson, M. S., et al. (2012). Atomic force and super-resolution microscopy support a role for LapA as a cell-surface biofilm adhesin of Pseudomonas fluorescens. Res. Microbiol. 163, 685-691. doi: 10.1016/j.resmic.2012.10.001

Ize, B., and Palmer, T. (2006). Microbiology. Mycobacteria's export strategy. Science 313, 1583-1584. doi: 10.1126/science. 1132537

Jacob-Dubuisson, F., Fernandez, R., and Coutte, L. (2004). Protein secretion through autotransporter and two-partner pathways. Biochim. Biophys. Acta Mol. Cell. Res. 1694, 235-257. doi: 10.1016/j.bbamcr.2004.03.008

Jeffery, C. J. (2003). Moonlighting proteins: old proteins learning new tricks. Trends Genet. 19, 415-417. doi: $\quad 10.1016 / S 0168-9525(03)$ 00167-7

Jeffery, C. J. (2009). Moonlighting proteins-an update. Mol. Biosyst. 5, 345-350. doi: 10.1039/ b900658n

Jin, H., Song, Y. P., Boel, G., Kochar, J., and Pancholi, V. (2005). Group A streptococcal surface GAPDH, $\mathrm{SDH}$, recognizes uPAR/CD87 as its receptor on the human pharyngeal cell and mediates bacterial adherence to host cells. J. Mol. Biol. 350, 27-41. doi: 10.1016/j.jmb.2005.04.063

Jonas, K., Tomenius, H., Kader, A., Normark, S., Romling, U., Belova, L. M., et al. (2007). Roles of curli, cellulose and BapA in Salmonella biofilm morphology studied by atomic force microscopy. BMC Microbiol. 7:70. doi: 10.1186/1471-2180-7-70

Jordan, S. J., Perni, S., Glenn, S., Fernandes, I., Barbosa, M., Sol, M., et al. (2008). Listeria monocytogenes biofilm-associated protein (BapL) may contribute to surface attachment of L. monocytogenes but is absent from many field isolates. Appl. Environ. Microbiol. 74, 5451-5456. doi: 10.1128/AEM.02419-07

Journet, L., Hughes, K. T., and Cornelis, G. R. (2005). Type III secretion: a secretory pathway serving both motility and virulence. Mol. Membr. Biol. 22, 41-50. doi: 10.1080/09687860500041858

Jucker, B. A., Zehnder, A. J. B., and Harms, H. (1998). Quantification of polymer interactions in bacterial adhesion. Envir. Science \&
Technology 32, 2909-2915. doi: $10.1021 / \mathrm{es} 980211 \mathrm{~s}$

Kachlany, S. C., Planet, P. J., Bhattacharjee, M. K., Kollia, E., Desalle, R., Fine, D. H. et al. (2000). Nonspecific adherence by Actinobacillus actinomycetemcomitans requires genes widespread in Bacteria and Archaea. J. Bacteriol. 182, 6169-6176. doi 10.1128/JB.182.21.6169-6176.2000

Kachlany, S. C., Planet, P. J., Desalle, R., Fine, D. H., and Figurski, D. H. (2001). Genes for tight adherence of Actinobacillus actinomycetemcomitans: from plaque to plague to pond scum. Trends Microbiol. 9, 429-437. doi: 10.1016/S0966-842X(01)02161-8

Kang, H. J., and Baker, E. N. (2012). Structure and assembly of Grampositive bacterial pili: unique covalent polymers. Curr. Opin. Struct. Biol. 22, 200-207. doi 10.1016/j.sbi.2012.01.009

Katsikogianni, M., and Missirlis, Y. F. (2004). Concise review of mechanisms of bacterial adhesion to biomaterials and of techniques used in estimating bacteria-material interactions. Eur. Cell. Mater. 8, 37-57.

Kearns, D. B., Chu, F., Branda, S. S. Kolter, R., and Losick, R. (2005). A master regulator for biofilm formation by Bacillus subtilis. Mol. Microbiol. 55, 739-749. doi: 10.1111/j.1365-2958.2004.04440.x

Kingsley, R. A., Abi Ghanem, D., Puebla-Osorio, N., Keestra, A. M., Berghman, L., and Baumler, A. J. (2004). Fibronectin binding to the Salmonella enterica serotype Typhimurium ShdA autotransporter protein is inhibited by a monoclonal antibody recognizing the A3 repeat. J. Bacteriol. 186, 4931-4939. doi 10.1128/JB.186.15.4931-4939.2004

Kingsley, R. A., Santos, R. L., Keestra, A. M., Adams, L. G., and Baumler, A. J. (2002). Salmonella enterica serotype Typhimurium ShdA is an outer membrane fibronectin-binding protein that is expressed in the intestine. Mol. Microbiol. 43, 895-905. doi: 10.1046/j.1365-2958.2002.02805.x

Kingsley, R. A., Van Amsterdam, K., Kramer, N., and Baumler, A. J. (2000). The shdA gene is restricted to serotypes of Salmonella enterica subspecies I and contributes to efficient and prolonged fecal shedding. Infect. Immun. 68, 2720-2727. doi 10.1128/IAI.68.5.2720-2727.2000

Kirn, T. J., Jude, B. A., and Taylor, R. K. (2005). A colonization factor links Vibrio cholerae environmental survival and human infection. Nature 438, 863-866. doi: 10.1038/ nature 04249

Kirov, S. M., Castrisios, M., and Shaw, J. G. (2004). Aeromonas flagella (polar and lateral) are enterocyte adhesins that contribute to biofilm formation on surfaces. Infect. Immun. 72, 1939-1945. doi: 10.1128/IAI.72.4.1939-1945.2004

Klemm, P., Hjerrild, L., Gjermansen, M., and Schembri, M. A. (2004). Structure-function analysis of the self-recognizing Antigen 43 autotransporter protein from Escherichia coli. Mol. Microbiol. 51, 283-296. doi: 10.1046/j.1365-2958. 2003.03833.x

Klemm, P., Vejborg, R. M., and Sherlock, O. (2006). Self-associating autotransporters, SAATs: functional and structural similarities. Int. J. Med. Microbiol. 296, 187-195. doi: 10.1016/j.ijmm.2005.10.002

Knowles, T. J., Scott-Tucker, A., Overduin, M., and Henderson, I. R. (2009). Membrane protein architects: the role of the BAM complex in outer membrane protein assembly. Nat. Rev. Microbiol. 7, 206-214. doi: 10.1038/nrmicro2069

Kobayashi, K. (2007). Bacillus subtilis pellicle formation proceeds through genetically defined morphological changes. J. Bacteriol. 189, 4920-4931. doi: $10.1128 / \mathrm{JB}$. 00157-07

Kobayashi, K., and Iwano, M. (2012). BslA(YuaB) forms a hydrophobic layer on the surface of Bacillus subtilis biofilms. Mol. Microbiol. 85, 51-66. doi 10.1111/j.1365-2958.2012.08094.x

Kondo, Y., Ohara, N., Sato, K., Yoshimura, M., Yukitake, H., Naito, M., et al. (2010). Tetratricopeptide repeat protein-associated proteins contribute to the virulence of Porphyromonas gingivalis. Infect. Immun. 78, 2846-2856. doi: 10.1128/IAI.01448-09

Kostakioti, M., and Stathopoulos, C. (2004). Functional analysis of the Tsh autotransporter from an avian pathogenic Escherichia coli strain. Infect. Immun. 72, 5548-5554. doi: 10.1128/IAI.72.10. 5548-5554.2004

Kovacs, A. T., and Kuipers, O. P. (2011). Rok regulates $y u a B$ expression during architecturally complex colony development of Bacillus subtilis 168 . J. Bacteriol. 193, 998-1002. doi: 10.1128/JB.01170-10

Kremer, B. H., Bijlsma, J. J., Kusters, J. G., de Graaff, J., and van Steenbergen, T. J. (1999). Cloning of fibA, encoding an immunogenic subunit of the fibril-like surface 
structure of Peptostreptococcus micros. J. Bacteriol. 181, 2485-2491.

Kroupitski, Y., Golberg, D., Belausov, E., Pinto, R., Swartzberg, D., Granot, D., et al. (2009a). Internalization of Salmonella enterica in leaves is induced by light and involves chemotaxis and penetration through open stomata. Appl. Environ. Microbiol. 75, 6076-6086. doi: 10.1128/AEM.01084-09

Kroupitski, Y., Pinto, R., Brandl, M. T., Belausov, E., and Sela, S. (2009b). Interactions of Salmonella enterica with lettuce leaves. J. Appl. Microbiol. 106, 1876-1885. doi: 10.1111/j.1365-2672.2009.04152.x

Kroupitski, Y., Pinto, R., Belausov, E., and Sela, S. (2011). Distribution of Salmonella typhimurium in romaine lettuce leaves. Food Microbiol. 28, 990-997. doi: 10.1016/j.fm.2011. 01.007

Lasa, I. (2006). Towards the identification of the common features of bacterial biofilm development. Int. Microbiol. 9, 21-28.

Lasa, I., and Penadés, J. R. (2006). Bap: a family of surface proteins involved in biofilm formation. Res. Microbiol. 157, 99-107. doi: 10.1016/j.resmic.2005.11.003

Latasa, C., Roux, A., Toledo-Arana, A., Ghigo, J. M., Gamazo, C., Penades, J. R., et al. (2005). BapA, a large secreted protein required for biofilm formation and host colonization of Salmonella enterica serovar Enteritidis. Mol. Microbiol. 58, 1322-1339. doi: 10.1111/j.13652958.2005.04907.x

Latasa, C., Solano, C., Penades, J. R., and Lasa, I. (2006). Biofilmassociated proteins. C. R. Biol. 329, 849-857. doi: 10.1016/j.crvi.2006. 07.008

Laurenceau, R., Pehau-Arnaudet, G., Baconnais, S., Gault, J., Malosse, C., Dujeancourt, A., et al. (2013). A Type IV pilus mediates DNA binding during natural transformation in Streptococcus pneumoniae. PLoS Pathog. 9:e1003473. doi: 10.1371/journal.ppat.1003473

Lawley, T. D., Klimke, W. A., Gubbins, M. J., and Frost, L. S. (2003). F factor conjugation is a true Type IV secretion system. FEMS Microbiol. Lett. 224, 1-15. doi: 10.1016/S03781097(03)00430-0

Le Trong, I., Aprikian, P., Kidd, B. A., Forero-Shelton, M., Tchesnokova, V., Rajagopal, P., et al. (2010). Structural basis for mechanical force regulation of the adhesin FimH via finger traplike b sheet twisting. Cell 141, 645-655. doi: 10.1016/j.cell.2010. 03.038
Leduc, I., White, C. D., Nepluev, I., Throm, R. E., Spinola, S. M. and Elkins, C. (2008). Outer membrane protein DsrA is the major fibronectin-binding determinant of Haemophilus ducreyi. Infect. Immun. 76, 1608-1616. doi: 10.1128/IAI.00994-07

Lee, M., Jun, S. Y., Yoon, B. Y., Song, S., Lee, K., and Ha, N. C. (2012). Membrane fusion proteins of Type I secretion system and tripartite efflux pumps share a binding motif for TolC in gram-negative bacteria. PLOS ONE 7:e40460. doi: 10.1371/journal.pone.0040460

Leininger, E., Roberts, M., Kenimer, J. G., Charles, I. G., Fairweather, N., Novotny, P., et al. (1991). Pertactin, an Arg-Gly-Asp-containing Bordetella pertussis surface protein that promotes adherence of mammalian cells. Proc. Natl. Acad. Sci. U.S.A. 88, 345-349. doi: 10.1073/pnas.88.2.345

Lemon, K. P., Higgins, D. E., and Kolter, R. (2007). Flagellar motility is critical for Listeria monocytogenes biofilm formation. J. Bacteriol. 189, 4418-4424. doi: 10.1128/JB. 01967-06

Leo, J. C., Elovaara, H., Bihan, D., Pugh, N., Kilpinen, S. K., Raynal, N., et al. (2010). First analysis of a bacterial collagen-binding protein with collagen Toolkits: promiscuous binding of YadA to collagens may explain how YadA interferes with host processes. Infect. Immun. 78, 3226-3236. doi: 10.1128/IAI. 01057-09

Leo, J. C., Grin, I., and Linke, D. (2012). Type V secretion: mechanism(s) of autotransport through the bacterial outer membrane. Philos. Trans. R. Soc. B Biol. Sci. 367, 1088-1101. doi: 10.1098/rstb.2011.0208

Leyton, D. L., Rossiter, A. E., and Henderson, I. R. (2012). From self sufficiency to dependence: mechanisms and factors important for autotransporter biogenesis. Nat. Rev. Microbiol. 10, 213-225. doi: $10.1038 /$ nrmicro 2733

Ligon, L. S., Hayden, J. D., and Braunstein, M. (2012). The ins and outs of Mycobacterium tuberculosis protein export. Tuberculosis (Edinb.) 92, 121-132. doi: 10.1016/j.tube.2011.11.005

Lillehoj, E. P., Kim, B. T., and Kim, K. C. (2002). Identification of Pseudomonas aeruginosa flagellin as an adhesin for Mucl mucin. Am. J. Physiol. Lung Cell Mol. Physiol. 282, L751-L756.

Linke, D., Riess, T., Autenrieth, I. B., Lupas, A., and Kempf, V. A. (2006). Trimeric autotransporter adhesins: variable structure, common function. Trends Microbiol. 14, 264-270. doi: 10.1016/j.tim.2006.04.005

Lipski, S. L., Akimana, C., Timpe, J. M. Wooten, R. M., and Lafontaine, E. R. (2007). The Moraxella catarrhalis autotransporter McaP is a conserved surface protein that mediates adherence to human epithelial cells through its $\mathrm{N}$-terminal passenger domain. Infect. Immun. 75, 314-324. doi: 10.1128/IAI.01330-06

Locht, C., Bertin, P., Menozzi, F. D. and Renauld, G. (1993). The filamentous haemagglutinin, a multifaceted adhesion produced by virulent Bordetella spp. Mol. Microbiol. 9, 653-660. doi: 10.1111/j.13652958.1993.tb01725.x

Lyskowski, A., Leo, J. C., and Goldman, A. (2011). Structure and biology of trimeric autotransporter adhesins. Adv. Exp. Med. Biol. 715, 143-158. doi: 10.1007/978-94-007-0940-9_9

Mahajan, A., Currie, C. G., Mackie, S. Tree, J., McAteer, S., McKendrick, I., et al. (2009). An investigation of the expression and adhesin function of $\mathrm{H} 7$ flagella in the interaction of Escherichia coli O157 : H7 with bovine intestinal epithelium. Cell Microbiol. 11, 121-137. doi: 10.1111/j.1462-5822.2008.01244.x

Mahdavi, J., Sonden, B., Hurtig, M. Olfat, F. O., Forsberg, L., Roche, N., et al. (2002). Helicobacter pylori SabA adhesin in persistent infection and chronic inflammation. Science 297, 573-578. doi: 10.1126/science. 1069076

Mallick, E. M., Brady, M. J., Luperchio, S. A., Vanguri, V. K., Magoun, L., Liu, H., et al. (2012). Alleleand tir-independent functions of intimin in diverse animal infection models. Front. Microbiol. 3:11. doi 10.3389/fmicb.2012.00011

Matias, V. R., and Beveridge, T. J. (2005). Cryo-electron microscopy reveals native polymeric cell wall structure in Bacillus subtilis 168 and the existence of a periplasmic space. Mol. Microbiol. 56, 240-251. doi: 10.1111/j.1365-2958. 2005.04535.x

Matta, S. K., Agarwal, S., and Bhatnagar, R. (2010). Surface localized and extracellular Glyceraldehyde-3-phosphate dehydrogenase of Bacillus anthracis is a plasminogen binding protein. Biochim. Biophys. Acta Proteins Proteomics 1804, 2111-2120. doi: 10.1016/j.bbapap.2010.08.004

Mattick, J. S. (2002). Type 4 pili and twitching motility. Annu. Rev. Microbiol. 56, 289-314. doi: $10.1146 /$ annurev.micro.56. 012302.160938
Mazar, J., and Cotter, P. A. (2006). Topology and maturation of filamentous haemagglutinin suggest a new model for two-partner secretion. Mol. Microbiol. 62, 641-654. doi: $\quad 10.1111 /$ j.1365-2958.2006. 05392.x

McBride, M. J., and Zhu, Y. (2013). Gliding motility and Por secretion system genes are widespread among members of the phylum Bacteroidetes. J. Bacteriol. 195, 270-278. doi: 10.1128/JB.01962-12

McLaughlin, L. S., Haft, R. J. F., and Forest, K. T. (2012). Structural insights into the Type II secretion nanomachine. Curr. Opin. Struct. Biol. 22, 208-216. doi: 10.1016/j.sbi.2012.02.005

Mendez, M., Huang, I. H., Ohtani, K., Grau, R., Shimizu, T., and Sarker, M. R. (2008). Carbon catabolite repression of type 4 pilus-dependent gliding motility in the anaerobic pathogen Clostridium perfringens. J. Bacteriol. 190, 48-60. doi: 10.1128/JB.01407-07

Michel, G. P. F., and Voulhoux, R. (2009). "Chapter 4: Type II secretory system (T2SS) in Gramnegative bacteria: a molecular nanomachine for secretion of Sec and Tat-dependent extracellular proteins," in Bacterial Secreted Proteins: Secretory Mechanisms and Role in Pathogenesis, ed $\mathrm{K}$ Wooldridge (Norwich: Caister Academic Press), 67-92.

Minamino, T., Imada, K., and Namba, K. (2008). Mechanisms of type III protein export for bacterial flagellar assembly. Mol. Biosyst. 4, 1105-1115. doi: 10.1039/b808065h

Molina, M. A., Ramos, J. L., and Espinosa-Urgel, M. (2006). A two-partner secretion system is involved in seed and root colonization and iron uptake by Pseudomonas putida KT2440. Environ. Microbiol. 8, 639-647. doi: 10.1111/j.1462-2920.2005.00940.x

Morgan, E., Campbell, J. D., Rowe, S. C., Bispham, J., Stevens, M. P., Bowen, A. J., et al. (2004). Identification of host-specific colonization factors of Salmonella enterica serovar Typhimurium. Mol. Microbiol. 54, 994-1010. doi: 10.1111/j.1365-2958.2004.04323.x

Morra, M., and Cassinelli, C. (1996). Staphylococcus epidermidis adhesion to films deposited from hydroxyethylmethacrylate plasma. J. Biomed. Mater. Res. 31, 149-155. doi: $10.1002 /($ SICI) 1097-4636(1 99606)31:2<149::AID-JBM1>3.0.C $\mathrm{O} ; 2-\mathrm{N}$

Mosoni, P., and Gaillard-Martinie, B. (2001). Characterization of a 
spontaneous adhesion-defective mutant of Ruminococcus albus strain 20. Arch. Microbiol. 176, 52-61. doi: 10.1007/s002030100292 Nakane, D., Sato, K., Wada, H., McBride, M. J., and Nakayama, K. (2013a). Helical flow of surface protein required for bacterial gliding motility. Proc. Natl. Acad. Sci. U.S.A. 110, 11145-11150. doi: 10.1073/pnas. 1219753110

Nakane, D., Sato, K., Wada, H., McBride, M. J., and Nakayama, K. (2013b). Helical flow of surface protein required for bacterial locomotion. Biophys. J. 104, 639a-639a. doi: 10.1016/j.bpj.2012.11.3527

Nakao, R., Ramstedt, M., Wai, S. N., and Uhlin, B. E. (2012). Enhanced biofilm formation by Escherichia coli LPS mutants defective in hep biosynthesis. PLoS ONE 7:e51241. doi: 10.1371/journal.pone.0051241

Nelson, S. S., Glocka, P. P., Agarwal, S., Grimm, D. P., and Mcbride, M. J. (2007). Flavobacterium johnsoniae SprA is a cell surface protein involved in gliding motility. J. Bacteriol. 189, 7145-7150. doi: 10.1128/JB.00892-07

Newman, J. A., Rodrigues, C., and Lewis, R. J. (2013). Molecular basis of the activity of SinR protein, the master regulator of biofilm formation in Bacillus subtilis. J. Biol. Chem. 288, 10766-10778. doi: 10.1074/jbc.M113.455592

Niederweis, M. (2003). Mycobacterial porins-new channel proteins in unique outer membranes. Mol. Microbiol. 49, 1167-1177. doi: 10.1046/j.1365-2958.2003.03662.x

Niederweis, M., Danilchanka, O., Huff, J., Hoffmann, C., and Engelhardt, H. (2010). Mycobacterial outer membranes: in search of proteins. Trends Microbiol. 18, 109-116. doi: 10.1016/j.tim.2009.12.005

Nilsson, L. M., Thomas, W. E., Sokurenko, E. V., and Vogel, V. (2006). Elevated shear stress protects Escherichia coli cells adhering to surfaces via catch bonds from detachment by soluble inhibitors. Appl. Environ. Microbiol. 72, 3005-3010. doi: 10.1128/AEM.72.4.3005-3010.2006

Nuccio, S. P., and Baumler, A. J. (2007). Evolution of the chaperone/usher assembly pathway: fimbrial classification goes Greek. Microbiol. Mol. Biol. Rev. 71, 551-575. doi: 10.1128/MMBR.00014-07

Nummelin, H., Merckel, M. C., Leo, J. C., Lankinen, H., Skurnik, M., and Goldman, A. (2004). The Yersinia adhesin YadA collagen-binding domain structure is a novel left-handed parallel beta-roll. EMBO J. 23, 701-711. doi: 10.1038/sj.emboj.7600100

Nunn, D. (1999). Bacterial Type II protein export and pilus biogenesis: more than just homologies? Trends Cell Biol. 9, 402-408. doi: 10.1016/S0962-8924(99)01634-7

Oberhettinger, P., Schutz, M., Leo, J. C., Heinz, N., Berger, J., Autenrieth, I. B., et al. (2012). Intimin and invasin export their $\mathrm{C}$-terminus to the bacterial cell surface using an inverse mechanism compared to classical autotransport. PLoS ONE 7:e47069. doi: 10.1371/journal.pone.0047069

O'connell Motherway, M., Zomer, A., Leahy, S. C., Reunanen, J., Bottacini, F., Claesson, M. J., et al. (2011). Functional genome analysis of Bifidobacterium breve UCC2003 reveals type IVb tight adherence (Tad) pili as an essential and conserved host-colonization factor. Proc. Natl. Acad. Sci. U.S.A. 108, 11217-11222. doi: 10.1073/pnas.1105380108

Odenbreit, S., Till, M., Hofreuter, D., Faller, G., and Haas, R. (1999). Genetic and functional characterization of the alp $A B$ gene locus essential for the adhesion of Helicobacter pylori to human gastric tissue. Mol. Microbiol. 31, 1537-1548. doi: 10.1046/j.1365-2958.1999.01300.x

Ojha, A., Anand, M., Bhatt, A., Kremer, L., Jacobs, W. R., and Hatfull, G. F. (2005). GroEL1: a dedicated chaperone involved in mycolic acid biosynthesis during biofilm formation in mycobacteria. Cell 123, 861-873. doi: 10.1016/j.cell.2005. 09.012

O'neil, H. S., and Marquis, H. (2006). Listeria monocytogenes flagella are used for motility, not as adhesins, to increase host cell invasion. Infect. Immun. 74, 6675-6681. doi: 10.1128/IAI.00886-06

Ostrowski, A., Mehert, A., Prescott, A., Kiley, T. B., and Stanley-Wall, N. R. (2011). YuaB functions synergistically with the exopolysaccharide and TasA amyloid fibers to allow biofilm formation by Bacillus subtilis. J. Bacteriol. 193, 4821-4831. doi: 10.1128/JB.00223-11

Ottow, J. C. (1975). Ecology, physiology, and genetics of fimbriae and pili. Annu. Rev. Microbiol. 29, 79-108. doi: 10.1146/annurev.mi. 29.100175.000455

Pallen, M. J., Beatson, S. A., and Bailey, C. M. (2005). Bioinformatics, genomics and evolution of nonflagellar Type-III secretion systems: a Darwinian perspective. FEMS Microbiol. Rev. 29, 201-229. doi: 10.1016/j.femsre.2005.01.001
Palumbo, R. N., and Wang, C. (2006). Bacterial invasin: structure, function, and implication for targeted oral gene delivery. Curr. Drug Deliv. 3, 47-53. doi: 10.2174/156720106775197475

Parham, N. J., Pollard, S. J., Chaudhuri, R. R., Beatson, S. A., Desvaux, M., Russell, M. A., et al. (2005). Prevalence of pathogenicity island IICFT073 genes among extraintestinal clinical isolates of Escherichia coli. J. Clin. Microbiol. 43, 2425-2434. doi 10.1128/JCM.43.5.2425-2434.2005

Payot, S., Guedon, E., Desvaux, M., Gelhaye, E., and Petitdemange, E. (1999). Effect of dilution rate, cellobiose and ammonium availabilities on Clostridium cellulolyticum sporulation. Appl. Microbiol. Biotechnol. 52, 670-674. doi: 10.1007/s002530051577

Peabody, C. R., Chung, Y. J., Yen, M. R., Vidal-Ingigliardi, D., Pugsley, A. P., and Saier, M. H. Jr. (2003). Type II protein secretion and its relationship to bacterial Type IV pili and archaeal flagella. Microbiology 149, 3051-3072. doi: 10.1099/mic.0. 26364-0

Pearson, M. M., Lafontaine, E. R., Wagner, N. J., St Geme, J. W. 3rd., and Hansen, E. J. (2002). A hag mutant of Moraxella catarrhalis strain $\mathrm{O} 35 \mathrm{E}$ is deficient in hemagglutination, autoagglutination, and immunoglobulin D-binding activities. Infect. Immun. 70, 4523-4533. doi: 10.1128/IAI.70.8.4523-4533.2002

Pegden, R. S., Larson, M. A., Grant, R. J., and Morrison, M. (1998). Adherence of the Gram-positive bacterium Ruminococcus albus to cellulose and identification of a novel form of cellulose-binding protein which belongs to the Pil family of proteins. J. Bacteriol. 180, 5921-5927.

Pelicic, V. (2008). Type4 pili: e pluribus unum? Mol. Microbiol. 68, 827-837. doi: 10.1111/j.1365-2958.2008.06197.x

Planet, P. J., Kachlany, S. C., Desalle, R., and Figurski, D. H. (2001). Phylogeny of genes for secretion NTPases: identification of the widespread tadA subfamily and development of a diagnostic key for gene classification. Proc. Natl. Acad. Sci. U.S.A. 98, 2503-2508. doi: $10.1073 /$ pnas. 051436598

Poole, S. T., McVeigh, A. L., Anantha, R. P., Lee, L. H., Akay, Y. M., Pontzer, E. A., et al. (2007). Donor strand complementation governs intersubunit interaction of fimbriae of the alternate chaperone pathway.
Mol. Microbiol. 63, 1372-1384. doi: 10.1111/j.1365-2958.2007.05612.x

Pratt, L. A., and Kolter, R. (1998). Genetic analysis of Escherichia coli biofilm formation: roles of flagella, motility, chemotaxis and Type 1 pili. Mol. Microbiol. 30, 285-293. doi: 10.1046/j.1365-2958. 1998.01061.x

Pugsley, A. P., and Francetic, O. (1998). Protein secretion in Escherichia coli K-12: dead or alive? Cell Mol. Life Sci. 54, 347-352. doi: 10.1007/s000180050162

Puttamreddy, S., Cornick, N. A., and Minion, F. C. (2010). Genome-wide transposon mutagenesis reveals a role for pO157 genes in biofilm development in Escherichia coli O157:H7 EDL933. Infect. Immun. 78, 2377-2384. doi: 10.1128/IAI. 00156-10

Rabinovich, L., Sigal, N., Borovok, I., Nir-Paz, R., and Herskovits, A. A. (2012). Prophage excision activates Listeria competence genes that promote phagosomal escape and virulence. Cell 150, 792-802. doi: 10.1016/j.cell.2012.06.036

Raghunathan, D., Wells, T. J., Morris, F. C., Shaw, R. K., Bobat, S., Peters, S. E., et al. (2011). SadA, a trimeric autotransporter from Salmonella enterica serovar Typhimurium, can promote biofilm formation and provides limited protection against infection. Infect. Immun. 79, 4342-4352. doi: 10.1128/IAI. 05592-11

Rakotoarivonina, H., Jubelin, G., Hébraud, M., Gaillard-Martinie, B., Forano, E., and Mosoni, P. (2002). Adhesion to cellulose of the Gram-positive bacterium Ruminococcus albus involves Type 4 pili. Microbiology 148, 1871-1880.

Rakotoarivonina, H., Larson, M. A. Morrison, M., Girardeau, J. P., Gaillard-Martinie, B., Forano, E., et al. (2005). The Ruminococcus albus pilA1-pilA2 locus: expression and putative role of two adjacent pil genes in pilus formation and bacterial adhesion to cellulose. Microbiology 151, 1291-1299. doi: 10.1099/mic.0.27735-0

Ramphal, R., Arora, S. K., and Ritchings, B. W. (1996). Recognition of mucin by the adhesin-flagellar system of Pseudomonas aeruginosa. Am. J. Respir. Crit. Care Med. 154, S170-S174. doi: 10.1164/ajrccm/ 154.4_Pt_2.S170

Renier, S., Chambon, C., Viala, D., Chagnot, C., Hebraud, M., and Desvaux, M. (2013). Exoproteomic analysis of the SecA2-dependent secretion in Listeria monocytogenes 
EGD-e. J. Proteomics 80C, 183-195. doi: 10.1016/j.jprot.2012.11.027

Renier, S., Hebraud, M., and Desvaux, M. (2011). Molecular biology of surface colonization by Listeria monocytogenes: an additional facet of an opportunistic Gram-positive foodborne pathogen. Environ. Microbiol. 13, 835-850. doi: 10.1111/j.1462-2920.2010.02378.x

Renier, S., Micheau, P., Talon, R., Hebraud, M., and Desvaux, M. (2012). Subcellular localization of extracytoplasmic proteins in monoderm bacteria: rational secretomics-based strategy for genomic and proteomic analyses. PLoS ONE 7:e42982. doi: 10.1371/journal.pone.0042982

Riess, T., Andersson, S. G., Lupas, A., Schaller, M., Schafer, A., Kyme, P., et al. (2004). Bartonella adhesin a mediates a proangiogenic host cell response. J. Exp. Med. 200, 1267-1278. doi: $10.1084 /$ jem.20040500

Rigel, N. W., and Braunstein, M. (2008). A new twist on an old pathway-accessory Sec systems. Mol. Microbiol. 69, 291-302. doi: 10.1111/j.1365-2958.2008.06294.x

Rincon, M. T., Ding, S. Y., McCrae, S. I., Martin, J. C., Aurilia, V., Lamed, R., et al. (2003). Novel organization and divergent dockerin specificities in the cellulosome system of Ruminococcus flavefaciens. J. Bacteriol. 185, 703-713. doi: 10.1128/JB.185.3.703-713.2003

Roder, H. L., Hansen, L. H., Sorensen, S. J., and Burmolle, M. (2013). The impact of the conjugative IncP-1 plasmid pKJK5 on multispecies biofilm formation is dependent on the plasmid host. FEMS Microbiol. Lett. 344, 186-192. doi: 10.1111/1574-6968.12175

Rojas, C. M., Ham, J. H., Deng, W. L., Doyle, J. J., and Collmer, A. (2002). HecA, a member of a class of adhesins produced by diverse pathogenic bacteria, contributes to the attachment, aggregation, epidermal cell killing, and virulence phenotypes of Erwinia chrysanthemi EC16 on Nicotiana clevelandii seedlings. Proc. Natl. Acad. Sci. U.S.A. 99, 13142-13147. doi: 10.1073/pnas.202358699

Romero, D., Aguilar, C., Losick, R., and Kolter, R. (2010). Amyloid fibers provide structural integrity to Bacillus subtilis biofilms. Proc. Natl. Acad. Sci. U.S.A. 107, 2230-2234. doi: 10.1073/pnas.0910560107

Romero, D., Vlamakis, H., Losick, R., and Kolter, R. (2011). An accessory protein required for anchoring and assembly of amyloid fibres in
B. subtilis biofilms. Mol. Microbiol. 80, 1155-1168. doi: 10.1111/j.13652958.2011.07653.x

Rose, J. E., Meyer, D. H., and FivesTaylor, P. M. (2003). Aae, an autotransporter involved in adhesion of Actinobacillus actinomycetemcomitans to epithelial cells. Infect. Immun. 71, 2384-2393. doi: 10.1128/IAI.71.5.2384-2393.2003

Rossiter, A. E., Browning, D. F., Leyton, D. L., Johnson, M. D., Godfrey, R. E., Wardius, C. A., et al. (2011a). Transcription of the plasmid-encoded toxin gene from enteroaggregative Escherichia coli is regulated by a novel co-activation mechanism involving CRP and Fis. Mol. Microbiol. 81, 179-191. doi: 10.1111/j.1365-2958.2011.07685.x

Rossiter, A. E., Leyton, D. L., TveenJensen, K., Browning, D. F., Sevastsyanovich, Y., Knowles, T. J., et al. (2011b). The essential bbarrel assembly machinery complex components BamD and BamA are required for autotransporter biogenesis. J. Bacteriol. 193, 4250-4253. doi: 10.1128/JB.00192-11

Roussel-Jazede, V., Jongerius, I., Bos, M. P., Tommassen, J., and Van Ulsen, P. (2010). NalPmediated proteolytic release of lactoferrin-binding protein B from the meningococcal cell surface. Infect. Immun. 78, 3083-3089. doi: 10.1128/IAI.01193-09

Roux, A., Beloin, C., and Ghigo, J. M. (2005). Combined inactivation and expression strategy to study gene function under physiological conditions: application to identification of new Escherichia coli adhesins. J. Bacteriol. 187, 1001-1013. doi: 10.1128/JB.187.3.1001-1013.2005

Roy, K., Hilliard, G. M., Hamilton, D. J., Luo, J., Ostmann, M. M., and Fleckenstein, J. M. (2009). Enterotoxigenic Escherichia coli EtpA mediates adhesion between flagella and host cells. Nature 457, 594-558. doi: 10.1038/nature07568

Ruiz-Perez, F., Henderson, I. R., and Nataro, J. P. (2010). Interaction of FkpA, a peptidylprolyl cis/trans isomerase with EspP autotransporter protein. Gut Microbes 1, 339-344. doi: 10.4161/gmic.1.5.13436

Ryder, C., Byrd, M., and Wozniak, D. J. (2007). Role of polysaccharides in Pseudomonas aeruginosa biofilm development. Curr. Opin. Microbiol. 10, 644-648. doi: 10.1016/j.mib.2007.09.010

Salacha, R., Kovacic, F., BrochierArmanet, C., Wilhelm, S., Tommassen, J., Filloux, A., et al. (2010). The Pseudomonas aeruginosa patatin-like protein $\mathrm{PlpD}$ is the archetype of a novel Type V secretion system. Environ. Microbiol. 12, 1498-1512.

Salmond, G. P., and Reeves, P. J. (1993). Membrane traffic wardens and protein secretion in Gramnegative bacteria. Trends Biochem. Sci. 18, 7-12. doi: 10.1016/09680004(93)90080-7

Sandkvist, M. (2001). Biology of Type II secretion. Mol. Microbiol. 40, 271-283. doi 10.1046/j.1365-2958.2001.02403.x

Sarvas, M., Harwood, C. R., Bron, S., and Van Dijl, J. M. (2004). Post-translocational folding of secretory proteins in Gram-positive bacteria. Biochim. Biophys. Acta Mol. Cell. Res. 1694, 311-327. doi 10.1016/j.bbamcr.2004.04.009

Sato, K., Naito, M., Yukitake, H. Hirakawa, H., Shoji, M., McBride M. J., et al. (2010). A protein secretion system linked to bacteroidete gliding motility and pathogenesis. Proc. Natl. Acad. Sci. U.S.A. 107, 276-281. doi: 10.1073/pnas.0912010107

Sato, K., Yukitake, H., Narita, Y., Shoji, M., Naito, M., and Nakayama, K. (2013). Identification of Porphyromonas gingivalis proteins secreted by the Por secretion system. FEMS Microbiol. Lett. 338, 68-76. doi: 10.1111/1574-6968.12028

Sauer, F. G., Remaut, H., Hultgren, S. J., and Waksman, G. (2004). Fiber assembly by the chaperoneusher pathway. Biochim. Biophys Acta Mol. Cell. Res. 1694, 259-267. doi: 10.1016/j.bbamcr.2004.02.010

Saunders, N. J., Jeffries, A. C., Peden, J. F., Hood, D. W., Tettelin, H., Rappuoli, R., et al. (2000). Repeatassociated phase variable genes in the complete genome sequence of Neisseria meningitidis strain MC58. Mol. Microbiol. 37, 207-215. doi: 10.1046/j.1365-2958.2000.02000.x

Sava, I. G., Heikens, E., Kropec, A. Theilacker, C., Willems, R., and Huebner, J. (2010). Enterococcal surface protein contributes to persistence in the host but is not a target of opsonic and protective antibodies in Enterococcus faecium infection. J. Med. Microbiol. 59, 1001-1004. doi: 10.1099/jmm.0.020578-0

Scarselli, M., Serruto, D., Montanari, P., Capecchi, B., Adu-Bobie, J., Veggi, D., et al. (2006). Neisseria meningitidis NhhA is a multifunctional trimeric autotransporter adhesin. Mol. Microbiol. 61, 631-644. doi: 10.1111/j.1365-2958.2006.05261.x

Schmitt, C., Turner, D., Boesl, M., Abele, M., Frosch, M., and Kurzai, O. (2007). A functional two-partner secretion system contributes to adhesion of Neisseria meningitidis to epithelial cells. J. Bacteriol. 189, 7968-7976. doi: 10.1128/JB.00851-07

Schneewind, O., and Missiakas, D. M. (2012). Protein secretion and surface display in Gram-positive bacteria. Philos. Trans. R. Soc. Lond. B Biol. Sci. 367, 1123-1139. doi 10.1098/rstb.2011.0210

Serruto, D., Adu-Bobie, J., Scarselli, M., Veggi, D., Pizza, M., Rappuoli, R., et al. (2003). Neisseria meningitidis App, a new adhesin with autocatalytic serine protease activity. Mol. Microbiol. 48, 323-334. doi: $\quad 10.1046 / j .1365-2958.2003$. 03420.x

Serruto, D., Spadafina, T., Ciucchi, L., Lewis, L. A., Ram, S., Tontini, M., et al. (2010). Neisseria meningitidis GNA2132, a heparin-binding protein that induces protective immunity in humans. Proc. Natl. Acad. Sci. U.S.A. 107, 3770-3775. doi 10.1073/pnas.0915162107

Sexton, J. A., and Vogel, J. P. (2002). Type IVb secretion by intracellular pathogens. Traffic 3, 178-185. doi: 10.1034/j.1600-0854.2002.030303.x

Shatalkin, A. I. (2004). Highest level of division in classification of organisms. 3. Monodermata and Didermata. Zh. Obshch. Biol. 65 , 195-210.

Shaw, R. K., Berger, C. N., Feys, B., Knutton, S., Pallen, M. J., and Frankel, G. (2008). Enterohemorrhagic Escherichia coli exploits EspA filaments for attachment to salad leaves. Appl. Environ. Microbiol. 74, 2908-2914. doi: 10.1128/AEM.02704-07

Shaw, R. K., Berger, C. N., Pallen, M. J., Sjoling, A., and Frankel, G. (2011). Flagella mediate attachment of enterotoxigenic Escherichia coli to fresh salad leaves. Environ. Microbiol. Rep. 3, 112-117. doi: 10.1111/j.1758-2229.2010.00195.x

Sherlock, O., Schembri, M. A., Reisner, A., and Klemm, P. (2004). Novel roles for the AIDA adhesin from diarrheagenic Escherichia coli: cell aggregation and biofilm formation. J. Bacteriol. 186, 8058-8065. doi: 10.1128/JB.186.23.8058-8065.2004

Sherlock, O., Vejborg, R. M., and Klemm, P. (2005). The TibA adhesin/invasin from enterotoxigenic Escherichia coli is self recognizing and induces bacterial aggregation and biofilm formation. Infect. Immun. 73, 1954-1963. doi: 10.1128/IAI.73.4.1954-1963.2005

Shimoji, Y., Ogawa, Y., Osaki, M., Kabeya, H., Maruyama, S., Mikami, T., et al. (2003). 
Adhesive surface proteins of Erysipelothrix rhusiopathiae bind to polystyrene, fibronectin, and type I and IV collagens. J. Bacteriol. 185, 2739-2748. doi: 10.1128/JB.185.9.2739-2748.2003

Shirtliff, M. E., Mader, J. T., and Camper, A. K. (2002). Molecular interactions in biofilms. Chem. Biol. 9, 859-871. doi: 10.1016/S10745521(02)00198-9

Shoham, Y., Lamed, R., and Bayer, E. A. (1999). The cellulosome concept as an efficient microbial strategy for the degradation of insoluble polysaccharides. Trends Microbiol. 7, 275-281. doi: 10.1016/S0966842X(99)01533-4

Shoji, M., Sato, K., Yukitake, H., Kondo, Y., Narita, Y., Kadowaki, T., et al. (2011). Por secretion systemdependent secretion and glycosylation of Porphyromonas gingivalis hemin-binding protein 35. PLoS ONE 6:e21372. doi: 10.1371/journal.pone.0021372

Shoseyov, O., Shani, Z., and Levy, I. (2006). Carbohydrate binding modules: biochemical properties and novel applications. Microbiol. Mol. Biol. Rev. 70, 283-295. doi: 10.1128/MMBR.00028-05

Shrivastava, A., Johnston, J. J., Van Baaren, J. M., and McBride, M. J. (2013). Flavobacterium johnsoniae GldK, GldL, GldM, and SprA are required for secretion of the cell surface gliding motility Adhesins SprB and RemA. J. Bacteriol. 195, 3201-32012. doi: 10.1128/JB.00333-13

Shrivastava, A., Rhodes, R. G., Pochiraju, S., Nakane, D., and McBride, M. J. (2012). Flavobacterium johnsoniae RemA is a mobile cell surface lectin involved in gliding. J. Bacteriol. 194, 3678-3688. doi: 10.1128/JB.00588-12

Silverman, J. M., Brunet, Y. R., Cascales, E., and Mougous, J. D. (2012). Structure and regulation of the Type VI secretion system. Ann. Rev. Microbiol. 66, 453-472. doi 10.1146/annurevmicro-121809-151619

Skerker, J. M., and Shapiro, L. (2000). Identification and cell cycle control of a novel pilus system in Caulobacter crescentus. EMBO J. 19, 3223-3234. doi: 10.1093/emboj/19.13.3223

Skorko-Glonek, J., and SobieckaSzkatula, A. (2008). The extracytoplasmic protein quality control in bacterium Escherichia coli: the role of proteases and the folding factors. Postepy Biochem. 54, 317-326.
Slakeski, N., Seers, C. A., Ng, K., Moore, C., Cleal, S. M., Veith, P. D., et al. (2011). C-terminal domain residues important for secretion and attachment of RgpB in Porphyromonas gingivalis. J. Bacteriol. 193, 132-142. doi: 10.1128/JB.00773-10

Song, H., Sandie, R., Wang, Y., Andrade-Navarro, M. A. and Niederweis, M. (2008). Identification of outer membrane proteins of Mycobacterium tuberculosis. Tuberculosis (Edinb.) 88, 526-544. doi 10.1016/j.tube.2008.02.004

Soto, G. E., and Hultgren, S. J. (1999). Bacterial adhesins: common themes and variations in architecture and assembly. J. Bacteriol. 181, 1059-1071.

St Geme, J. W. 3rd., and Cutter, D. (2000). The Haemophilus influenzae Hia adhesin is an autotransporter protein that remains uncleaved at the $\mathrm{C}$ terminus and fully cell associated. J. Bacteriol. 182, 6005-6013. doi: 10.1128/JB.182.21.6005-6013.2000

St Geme, J. W. 3rd., Falkow, S., and Barenkamp, S. J. (1993). Highmolecular-weight proteins of nontypable Haemophilus influenzae mediate attachment to human epithelial cells. Proc. Natl. Acad. Sci. U.S.A. 90, 2875-2879. doi: 10.1073/pnas.90.7.2875

St Geme, J. W. 3rd., and Yeo, H. J. (2009). A prototype twopartner secretion pathway: the Haemophilus influenzae HMW1 and HMW2 adhesin systems. Trends Microbiol. 17, 355-360. doi: 10.1016/j.tim.2009.06.002

Stauder, M., Huq, A., Pezzati, E., Grim, C. J., Ramoino, P., Pane, L., et al. (2012). Role of GbpA protein, an important virulencerelated colonization factor, for Vibrio cholerae's survival in the aquatic environment. Environ. Microbiol. Rep. 4, 439-445. doi: 10.1111/j.1758-2229.2012.00356.x

Stoop, E. J., Bitter, W., and Van Der Sar, A. M. (2012). Tubercle bacilli rely on a type VII army for pathogenicity. Trends Microbiol. 20, 477-484. doi: 10.1016/j.tim.2012.07.001

Stover, A. G., and Driks, A. (1999). Control of synthesis and secretion of the Bacillus subtilis protein YqxM. J. Bacteriol. 181, 7065-7069.

Strom, M. S., and Lory, S. (1993). Structure-function and biogenesis of the Type 4 pili. Annu. Rev. Microbiol. 47, 565-596. doi: 10.1146/annurev.mi.47.100193. 003025

Suez, J., Porwollik, S., Dagan, A., Marzel, A., Schorr, Y. I., Desai, P.
T., et al. (2013). Virulence gene profiling and pathogenicity characterization of non-typhoidal Salmonella accounted for invasive disease in humans. PLoS ONE 8:e58449. doi 10.1371/journal.pone.0058449

Sutcliffe, I. C. (2010). A phylum level perspective on bacterial cell envelope architecture. Trends Microbiol. 18, 464-470. doi 10.1016/j.tim.2010.06.005

Swierczynski, A., and Ton-That, H. (2006). Type 3 pilus of Corynebacteria: pilus length is determined by the level of its major pilin subunit. J. Bacteriol. 188, 6318-6325. doi: 10.1128/JB.00606-06

Tampakaki, A. P., Fadouloglou, V. E., Gazi, A. D., Panopoulos, N. J., and Kokkinidis, M. (2004). Conserved features of Type III secretion. Cell Microbiol. 6, 805-816. doi 10.1111/j.1462-5822.2004.00432.x

Tampakaki, A. P., Skandalis, N., Gazi, A. D., Bastaki, M. N., Sarris, P. F., Charova, S. N., et al. (2010). Playing the "Harp": evolution of our understanding of hrp/hrc genes. Annu. Rev. Phytopathol. 48 347-370. doi: 10.1146/annurevphyto-073009-114407

Tang, J., Chen, J., Li, H., Zeng, P., and $\mathrm{Li}, \mathrm{J}$. (2013). Characterization of adhesin genes, staphylococcal nuclease, hemolysis, and biofilm formation among Staphylococcus aureus strains isolated from different sources. Foodborne Pathog. Dis. 10, 757-763. doi: 10.1089/fpd.2012. 1474

Tang, X., Xiao, Y., and Zhou, J. M. (2006). Regulation of the Type III secretion system in phytopathogenic bacteria. Mol. Plant Microbe Interact. 19, 1159-1166. doi: 10.1094/MPMI-19-1159

Telford, J. L., Barocchi, M. A., Margarit, I., Rappuoli, R., and Grandi, G. (2006). Pili in Gram-positive pathogens. Nat. Rev. Microbiol. 4 509-519. doi: 10.1038/nrmicro1443

Tendolkar, P. M., Baghdayan, A. S., Gilmore, M. S., and Shankar N. (2004). Enterococcal surface protein, Esp, enhances biofilm formation by Enterococcus faecalis. Infect. Immun. 72, 6032-6039. doi: 10.1128/IAI.72.10.6032-6039.2004

Terrasse, R., Tacnet-Delorme, P., Moriscot, C., Perard, J., Schoehn, G., Vernet, T., et al. (2012). Human and pneumococcal cell surface glyceraldehyde-3-phosphate dehydrogenase (GAPDH) proteins are both ligands of human Clq protein. J. Biol. Chem. 287, 42620-42633. doi: $10.1074 / \mathrm{jbc}$. M112.423731
Thanassi, D. G., Bliska, J. B., and Christie, P. J. (2012). Surface organelles assembled by secretion systems of Gram-negative bacteria: diversity in structure and function. FEMS Microbiol. Rev. 36, 1046-1082. doi: 10.1111/j.1574-6976.2012.00342.x

Timpe, J. M., Holm, M. M., Vanlerberg, S. L., Basrur, V., and Lafontaine, E. R. (2003). Identification of a Moraxella catarrhalis outer membrane protein exhibiting both adhesin and lipolytic activities. Infect. Immun. 71, 4341-4350. doi: 10.1128/IAI.71.8.4341-4350.2003

Tjalsma, H. (2007). Feature-based reappraisal of the Bacillus subtilis exoproteome. Proteomics 7, 73-81. doi: 10.1002/pmic. 200600520

Tjalsma, H., Bolhuis, A., Jongbloed, J. D., Bron, S., and Van Dijl, J. M. (2000). Signal peptidedependent protein transport in Bacillus subtilis: a genome-based survey of the secretome. Microbiol. Mol. Biol. Rev. 64, 515-547. doi: 10.1128/MMBR.64.3.515-547.2000

Todhanakasem, T., and Young, G. M. (2008). Loss of flagellumbased motility by Listeria monocytogenes results in formation of hyperbiofilms. J. Bacteriol. 190, 6030-6034. doi: 10.1128/JB.00155-08

Tomich, M., Planet, P. J., and Figurski, D. H. (2007). The tad locus: postcards from the widespread colonization island. Nat. Rev. Microbiol. 5, 363-375. doi: 10.1038/nrmicrol636

Ton-That, H., Marraffini, L. A., and Schneewind, O. (2004). Protein sorting to the cell wall envelope of Gram-positive bacteria. Biochim. Biophys. Acta Mol. Cell. Res. 1694, 269-278. doi: 10.1016/j.bbamcr.2004.04.014

Ton-That, H., and Schneewind, O. (2003). Assembly of pili on the surface of Corynebacterium diphtheriae. Mol. Microbiol. 50, 1429-1438. doi: 10.1046/j.1365-2958.2003.03782.x

Ton-That, H., and Schneewind, O. (2004). Assembly of pili in Gram-positive bacteria. Trends Microbiol. 12, 228-234. doi: 10.1016/j.tim.2004.03.004

Tormo, M. A., Knecht, E., Gotz, F. Lasa, I., and Penades, J. R. (2005). Bap-dependent biofilm formation by pathogenic species of Staphylococcus: evidence of horizontal gene transfer? Microbiology 151, 2465-2475. doi: 10.1099/mic. $0.27865-0$

Tormo, M. A., Ubeda, C., Marti, M., Maiques, E., Cucarella, C., Valle, J., et al. (2007). Phase-variable expression of the biofilm-associated 
protein (Bap) in Staphylococcus aureus. Microbiology 153, 1702-1710. doi: 10.1099/mic.0. 2006/005744-0

Totsika, M., Wells, T. J., Beloin, C., Valle, J., Allsopp, L. P., King, N. P., et al. (2012). Molecular characterization of the EhaG and UpaG trimeric autotransporter proteins from pathogenic Escherichia coli. Appl. Environ. Microbiol. 78, 2179-2189. doi: 10.1128/AEM.06680-11

Tran, V. B., Fleiszig, S. M., Evans, D. J., and Radke, C. J. (2011). Dynamics of flagellum- and pilus-mediated association of Pseudomonas aeruginosa with contact lens surfaces. Appl. Environ. Microbiol. 77, 3644-3652. doi: 10.1128/AEM.02656-10

Tresse, O., Lebret, V., Benezech, T., and Faille, C. (2006). Comparative evaluation of adhesion, surface properties, and surface protein composition of Listeria monocytogenes strains after cultivation at constant $\mathrm{pH}$ of 5 and 7. J. Appl. Microbiol. 101, 53-62. doi: 10.1111/j.13652672.2006.02968.x

Troge, A., Scheppach, W., Schroeder, B. O., Rund, S. A., Heuner, K., Wehkamp, J., et al. (2012). More than a marine propeller-the flagellum of the probiotic Escherichia coli strain Nissle 1917 is the major adhesin mediating binding to human mucus. Int. J. Med. Microbiol. 302, 304-314. doi: 10.1016/j.ijmm.2012.09.004

Tsai, J. C., Yen, M. R., Castillo, R., Leyton, D. L., Henderson, I. R., and Saier, M. H. Jr. (2010). The bacterial intimins and invasins: a large and novel family of secreted proteins. PLOS ONE 5:e14403. doi: 10.1371/journal.pone.0014403

Tunio, S. A., Oldfield, N. J., Ala’aldeen, D. A., Wooldridge, K. G., and Turner, D. P. (2010). The role of glyceraldehyde 3-phosphate dehydrogenase (GapA-1) in Neisseria meningitidis adherence to human cells. BMC Microbiol. 10:280. doi: 10.1186/1471-2180-10-280

Uchiyama, T., Kawano, H., and Kusuhara, Y. (2006). The major outer membrane protein $\mathrm{rOmpB}$ of spotted fever group rickettsiae functions in the rickettsial adherence to and invasion of Vero cells. Microbes Infect. 8, 801-809. doi: 10.1016/j.micinf.2005.10.003

Valle, J., Latasa, C., Gil, C., ToledoArana, A., Solano, C., Penades, J. R., et al. (2012). Bap, a biofilm matrix protein of Staphylococcus aureus prevents cellular internalization through binding to
GP96 host receptor. PLoS Pathog. 8:e1002843. doi: 10.1371/journal. ppat. 1002843

Valle, J., Mabbett, A. N., Ulett, G. C., Toledo-Arana, A., Wecker, K., Totsika, M., et al. (2008). UpaG, a new member of the trimeric autotransporter family of adhesins in uropathogenic Escherichia coli. J. Bacteriol. 190, 4147-4161. doi: 10.1128/JB.00122-08

Van Der Woude, A. D., Mahendran, K. R., Ummels, R., Piersma, S. R., Pham, T. V., Jimenez, C. R., et al. (2013). Differential detergent extraction of Mycobacterium marinum cell envelope proteins identifies an extensively modified threonine-rich outer membrane protein with channel activity. J. Bacteriol. 195, 2050-2059. doi: 10.1128/JB.02236-12

Van Der Woude, M. W., and Henderson, I. R. (2008). Regulation and function of Ag43 (flu). Annu. Rev. Microbiol. 62, 153-169. doi: 10.1146/annurev.micro.62.081307. 162938

Van Dijl, J. M., Bolhuis, A., Tjalsma, H., Jongbloed, J. D., De Jong, A., and Bron, S. (2001). "Protein transport pathways in Bacillus subtilis: a genome-based road map," in Bacillus Subtilis and Its Closest Relatives: from Genes to Cells, eds A. L. Sonenshein, J. A. Hoch, and R. Losick. (Washington, DC: ASM press), 337-355.

Van Ulsen, P., Adler, B., Fassler, P., Gilbert, M., Van Schilfgaarde, M., Van Der Ley, P., et al. (2006). A novel phase-variable autotransporter serine protease, AusI, of Neisseria meningitidis. Microbes Infect. 8, 2088-2097. doi: 10.1016/j.micinf.2006.03.007

Van Ulsen, P., Van Alphen, L., Ten Hove, J., Fransen, F., Van Der Ley, P., and Tommassen, J. (2003). A Neisserial autotransporter NalP modulating the processing of other autotransporters. Mol. Microbiol. 50, 1017-1030. doi: 10.1046/j.13652958.2003.03773.x

Varga, J. J., Nguyen, V., O'brien, D. K., Rodgers, K., Walker, R. A., and Melville, S. B. (2006). Type 4 pili-dependent gliding motility in the Gram-positive pathogen Clostridium perfringens and other Clostridia. Mol. Microbiol. 62, 680-694.

Varga, J. J., Therit, B., and Melville, S. B. (2008). Type 4 pili and the CcpA protein are needed for maximal biofilm formation by the Gram-positive anaerobic pathogen Clostridium perfringens.
Infect. Immun. 76, 4944-4951. doi: 10.1128/IAI.00692-08

Vatanyoopaisarn, S., Nazli, A., Dodd, C. E., Rees, C. E., and Waites, W. M. (2000). Effect of flagella on initial attachment of Listeria monocytogenes to stainless steel. Appl. Environ. Microbiol. 66, 860-863. doi: 10.1128/AEM.66.2.860-863.2000

Vengadesan, K., and Narayana, S. V. (2011). Structural biology of Gram-positive bacterial adhesins. Protein Sci 20, 759-772. doi: 10.1002/pro.613

Verstraeten, N., Braeken, K., Debkumari, B., Fauvart, M. Fransaer, J., Vermant, J., et al. (2008). Living on a surface: swarming and biofilm formation. Trends Microbiol. 16, 496-506. doi: 10.1016/j.tim.2008.07.004

Vlamakis, H., Aguilar, C., Losick, R., and Kolter, R. (2008). Control of cell fate by the formation of an architecturally complex bacterial community. Genes Dev. 22, 945-953. doi: 10.1101/gad.1645008

Vlamakis, H., Chai, Y., Beauregard, P., Losick, R., and Kolter, R. (2013). Sticking together: building a biofilm the Bacillus subtilis way. Nat. Rev. Microbiol. 11, 157-168. doi: 10.1038/nrmicro2960

Voigt, B., Hieu, C. X., Hempel, K., Becher, D., Schluter, R. Teeling, H., et al. (2012). Cell surface proteome of the marine planctomycete Rhodopirellula baltica. Proteomics 12, 1781-1791. doi: 10.1002/pmic. 201100512

Voth, D. E., Broederdorf, L. J., and Graham, J. G. (2012). Bacterial Type IV secretion systems: versatile virulence machines. Future Microbiol. 7 , 241-257. doi: 10.2217/fmb.11.150

Voulhoux, R., Ball, G., Ize, B., Vasil, M. L., Lazdunski, A., Wu, L. F., et al. (2001). Involvement of the twin-arginine translocation system in protein secretion via the Type II pathway. EMBO J. 20, 6735-6741. doi: $10.1093 / \mathrm{emboj} / 20.23 .6735$

Vu, B., Chen, M., Crawford, R. J., and Ivanova, E. P. (2009). Bacterial extracellular polysaccharides involved in biofilm formation. Molecules 14, 2535-2554. doi: 10.3390/molecules 14072535

Wagner, C., Polke, M., Gerlach, R. G., Linke, D., Stierhof, Y. D., Schwarz, H., et al. (2011). Functional dissection of SiiE, a giant nonfimbrial adhesin of Salmonella enterica. Cell Microbiol. 13, 1286-1301. doi: 10.1111/j.14625822.2011.01621.x

Waksman, G., and Fronzes, R. (2010). Molecular architecture of bacterial Type IV secretion systems. Trends
Biochem. Sci. 35, 691-698. doi: 10.1016/j.tibs.2010.06.002

Waksman, G., and Hultgren, S. J. (2009). Structural biology of the chaperone-usher pathway of pilus biogenesis. Nat. Rev. Microbiol. 7, 765-774. doi: 10.1038/nrmicro2220

Wallden, K., Rivera-Calzada, A., and Waksman, G. (2010). Type IV secretion systems: versatility and diversity in function. Cell Microbiol. 12, 1203-1212. doi: 10.1111/j.14625822.2010.01499.x

Wehrl, W., Brinkmann, V., Jungblut, P. R., Meyer, T. F., and Szczepek, A. J. (2004). From the inside outprocessing of the Chlamydial autotransporter $\mathrm{PmpD}$ and its role in bacterial adhesion and activation of human host cells. Mol. Microbiol. 51, 319-334. doi: 10.1046/j.13652958.2003.03838.x

Wells, T. J., McNeilly, T. N., Totsika, M., Mahajan, A., Gally, D. L., and Schembri, M. A. (2009). The Escherichia coli O157:H7 EhaB autotransporter protein binds to laminin and collagen I and induces a serum IgA response in O157:H7 challenged cattle. Environ. Microbiol. 11, 1803-1814. doi: 10.1111/j.14622920.2009.01905.x

Wells, T. J., Sherlock, O., Rivas, L., Mahajan, A., Beatson, S. A., Torpdahl, M., et al. (2008). EhaA is a novel autotransporter protein of enterohemorrhagic Escherichia coli $\mathrm{O} 157: \mathrm{H} 7$ that contributes to adhesion and biofilm formation. Environ. Microbiol. 10, 589-604. doi: 10.1111/j.1462-2920.2007.01479.x

Wong, E., Vaaje-Kolstad, G., Ghosh, A., Hurtado-Guerrero, R., Konarev, P. V., Ibrahim, A. F., et al. (2012). The Vibrio cholerae colonization factor GbpA possesses a modular structure that governs binding to different host surfaces. PLoS Pathog. 8:e1002373. doi: 10.1371/journal.ppat.1002373

Wong, K. K., McClelland, M., Stillwell, L. C., Sisk, E. C., Thurston, S. J., and Saffer, J. D. (1998). Identification and sequence analysis of a 27 kilobase chromosomal fragment containing a Salmonella pathogenicity island located at 92 minutes on the chromosome map of Salmonella enterica serovar typhimurium LT2. Infect. Immun. 66, 3365-3371.

Wurpel, D. J., Beatson, S. A., Totsika, M., Petty, N. K., and Schembri, M. A. (2013). Chaperone-usher fimbriae of Escherichia coli. PLoS ONE 8:e52835. doi: 10.1371/journal.pone. 0052835

Xu, Q., Barak, Y., Kenig, R., Shoham, Y., Bayer, E. A., and Lamed, R. (2004). A novel Acetivibrio cellulolyticus 
anchoring scaffoldin that bears divergent cohesins. J. Bacteriol. 186, 5782-5789. doi: 10.1128/JB.186.17. 5782-5789.2004

Xu, Q., Gao, W., Ding, S. Y., Kenig, R., Shoham, Y., Bayer, E. A., et al. (2003). The cellulosome system of Acetivibrio cellulolyticus includes a novel type of adaptor protein and a cell surface anchoring protein. J. Bacteriol. 185, 4548-4557. doi: 10.1128/JB.185.15.4548-4557.2003

Yakovenko, O., Sharma, S., Forero, M., Tchesnokova, V., Aprikian, P., Kidd, B., et al. (2008). FimH forms catch bonds that are enhanced by mechanical force due to allosteric regulation. J. Biol. Chem. 283, 11596-11605. doi: 10.1074/jbc.M707815200

Yang, H. S., and Hoober, J. K. (1998). Molecular cloning of a lightinducible gene (lipA) encoding a novel pilin from Arthrobacter photogonimos. FEMS Microbiol. Lett. 163, 85-89. doi: 10.1111/j.15746968.1998.tb13030.x

Yang, H. S., and Hoober, J. K. (1999). Regulation of lipA gene expression by cell surface proteins in Arthrobacter photogonimos. Curr. Microbiol. 38, 92-95. doi: 10.1007/s002849900409

Zambrano, M. M., and Kolter, R. (2005). Mycobacterial biofilms: a greasy way to hold it together. Cell 123, 762-764. doi: 10.1016/j.cell.2005.11.011

Zavialov, A., Zav'yalova, G., Korpela, T., and Zav'yalov, V. (2007). FGL chaperone-assembled fimbrial polyadhesins: anti-immune armament of Gram-negative bacterial pathogens. FEMS Microbiol. Rev. 31, 478-514. doi: 10.1111/j.1574-6976.2007.00075.x

Zav'yalov, V., Zavialov, A., Zav'yalova, G., and Korpela, T. (2010). Adhesive organelles of Gramnegative pathogens assembled with the classical chaperone/usher machinery: structure and function from a clinical standpoint. FEMS Microbiol. Rev. 34, 317-378. doi: 10.1111/j.1574-6976. 2009.00201.x

Zechner, E. L., Lang, S., and Schildbach, J. F. (2012). Assembly and mechanisms of bacterial Type IV secretion machines. Philos. Trans. R. Soc.
B Biol. Sci. 367, 1073-1087. doi: 10.1098/rstb.2011.0207

Zhang, W., Huhe, Pan, Y., Toyofuku,

M., Nomura, N., Nakajima,

T., and Uchiyama, H. (2013).

Dechlorination of chloral hydrate is

influenced by the biofilm adhesin

protein LapA in Pseudomonas

putida LF54. Appl. Environ.

Microbiol. 79, 4166-4169. doi: 10.1128/AEM.00804-13

Zhao, K., Tseng, B. S., Beckerman, B., Jin, F., Gibiansky, M. L., Harrison, J. J., et al. (2013). Psl trails guide exploration and microcolony formation in Pseudomonas aeruginosa biofilms. Nature 497, 388-391. doi: 10.1038/nature 12155

Zhou, J. M., and Chai, J. (2008). Plant pathogenic bacterial Type III effectors subdue host responses. Curr. Opin. Microbiol. 11, 179-185. doi: 10.1016/j.mib.2008. 02.004

Conflict of Interest Statement: The authors declare that the research was conducted in the absence of any commercial or financial relationships that could be construed as a potential conflict of interest.

Received: 18 July 2013; accepted: 22 September 2013; published online: 14 October 2013.

Citation: Chagnot C, Zorgani MA, Astruc $T$ and Desvaux $M$ (2013) Proteinaceous determinants of surface colonization in bacteria: bacterial adhesion and biofilm formation from a protein secretion perspective. Front. Microbiol. 4:303. doi: 10.3389/fmicb. 2013.00303

This article was submitted to Microbial Physiology and Metabolism, a section of the journal Frontiers in Microbiology. Copyright (c) 2013 Chagnot, Zorgani, Astruc and Desvaux. This is an openaccess article distributed under the terms of the Creative Commons Attribution License (CC BY). The use, distribution or reproduction in other forums is permitted, provided the original author(s) or licensor are credited and that the original publication in this journal is cited, in accordance with accepted academic practice. No use, distribution or reproduction is permitted which does not comply with these terms. 